\title{
AN INERTIA MODEL FOR THE ADOPTION OF NEW FARMING PRACTICES
}

\author{
by \\ Simon Seraphim Anastasiadis
}

A thesis

submitted to the Victoria University of Wellington in partial fulfilment of the requirements for the degree of

Master of Science

in Operations Research.

Victoria University of Wellington

2013 



\begin{abstract}
Nutrient emissions from agricultural land are now widely recognized as one of the key contributors to poor water quality in local lakes, rivers and streams. Nutrient trading for non-point sources, including farm land, has been suggested as a regulatory tool to improve and protect water quality. However, farmers' attitudes suggest that they are resistant to making the changes required under such a scheme where this requires them to adopt unfamiliar technologies and farm management practices.

This study develops a model of farmers' resistance to change and how this affects their adoption of new mitigation technologies under nutrient trading regulation. We specify resistance as a bound on the adoption of new technologies and allow this bound to relax as farmers' resistance to change weakens.
\end{abstract}

Key words: agriculture, inertia, mitigation, nutrient trading, technology adoption. 


\section{Acknowledgments}

I would like to thank Stefanka Chukova for the guidance and oversight she has provided throughout the development of this thesis. Her supervision has had a significant impact on both my thesis, and my development as a young researcher.

I am grateful to Motu Economic and Public Policy Research, which has been my place of employment throughout the writing of my thesis. Motu has provided me with a rich context in which to work. In particular I recognize Suzi Kerr, my manager, and the other senior fellows for sharing their experience and insights.

Much of the inspiration for this thesis arose from conversations with New Zealand farmers as part of a 'Water Games' project for the Ministry of Primary Industries (MPI). I would like to thank Jim Sinner and Andrew Fenemor for their leadership of that project.

Thank you to my parents: Jo and Angelos Anastasiadis, and my community: Ink, for their support and encouragement throughout this process. 


\section{Contents}

1 Introduction 1

1.1 The adoption of new agricultural practices .......... 2

1.2 Nutrient trading schemes .................... 5

2 The Inertia Model 9

2.1 The general model f . . . . . . . . . . . . . . . . 10

2.2 The general farmer level model . . . . . . . . . . . . . . . 15

2.3 Choice of decision variables . . . . . . . . . . . . . 17

2.4 Farm profit function $\ldots \ldots \ldots \ldots \ldots$

2.5 The inertia function . . . . . . . . . . . . . . . 23

2.6 Two example classifications . . . . . . . . . . . . . 25

2.7 Expected behavior $\ldots \ldots \ldots \ldots \ldots \ldots$

3 Two Farmer Case: Analytic Model Performance 29

3.1 Prices and allowance holdings . . . . . . . . . . . . . . 31

3.2 Transitions between stages . . . . . . . . . . . . . . . . 33

3.3 Profitability $\ldots \ldots \ldots \ldots \ldots \ldots \ldots \ldots \ldots \ldots \ldots \ldots$

3.4 Mitigation decisions for two farmers . . . . . . . . . . . . . 37

4 Many Farmer Case: General Model Performance 49

4.1 Parameterizing the model . . . . . . . . . . . . . . . . . 49

4.2 Demonstrated model performance . . . . . . . . . . . . . . 53 
4.3 Farmer performance .................... 58

5 Random Inertia $\quad 63$

5.1 Modeling random inertia . . . . . . . . . . . . . . 64

5.2 Model performances with random inertia . . . . . . . . . . . 65

$\begin{array}{lll}6 & \text { Estimation and Validation } & 71\end{array}$

6.1 Parameter estimation for farm profit functions . . . . . . . . . 71

6.2 Parameter estimation for farmers' inertia functions . . . . . . . . . . . 74

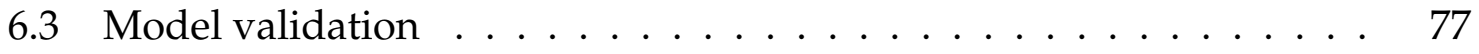

$\begin{array}{lll}7 & \text { Discussion and Conclusions } & 81\end{array}$

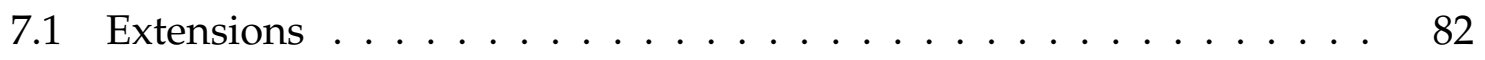

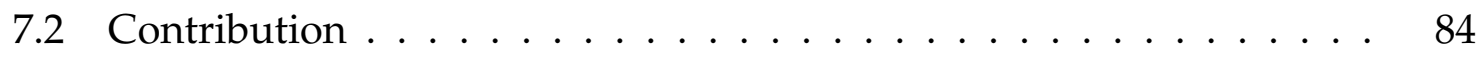

A Key Terminology $\quad 93$

B Non-trading behavior $\quad 95$

C Solving a System of First Order Linear Difference Equations 97

D Kernel Density Smoothing $\quad 99$ 


\section{Chapter 1}

\section{Introduction}

Nutrient emissions from non-point sources, such as agricultural land, are increasingly recognized as one of the key contributors to poor water quality. Declining water quality is a serious problem in many developed countries, including New Zealand, and in an increasing number of developing countries (Sutton et al. 2011, Parliamentary Commissioner for the Environment 2006). Mathematical modeling of different approaches to improving water quality can help inform the decisions of both policy makers and local stakeholders. However, some assumptions in the existing models that are necessary to make modeling tractable reduce the credibility of the associated results. The development of a more flexible model that better reflects reality is the focus of this research.

The static economic model for agent behavior under nutrient trading regulation (such as used by Anastasiadis et al. 2011, in their NManager model) makes several simplifying assumptions. These assumptions include: agents are willing to change, agents respond optimally to a nitrogen price, and agents' decisions are independent of their past decisions and the decisions of other agents. ${ }^{1}$

However, in the context of farmers, evidence suggests these assumptions are not a good representation of reality. Farmers have expressed a reluctance to change where it involves the adoption of unfamiliar farm management practices or technologies (Fenemor et al. 2012); they tend to manage their business with a ten (or more) year time horizon; and may have incentives to delay the adoption of new practices or technologies in order to capitalize on learning opportunities (Sin 2012). Furthermore, there is a well known psychological phenomenon where people and organizations continue a familiar practice, even though a better one is available, un-

\footnotetext{
${ }^{1}$ We thank our audience at the New Zealand Agricultural and Resource Economics conference (2011) for challenging these assumptions. Part of the motivation for this study is in response to this feedback.
} 
til the cost of continuing with their current practice exceeds the cost of change (Ram 1987).

Designing a model to reflect the reality identified above is a challenging task. It involves quantifying something that is difficult to identify and measure: farmers' willingness and motivation to change. Farmers' willingness and motivation to change will depend on time, their past behavior, and the past behavior of others farmers. We define the term inertia to describe the nature of a system or agent (farmers) that slows the speed at which they change. While this term appears to have a similar meaning across a broad range of literature, modeling of agents' inertia does not appear to be widely established in practice.

It is important to study not only adoption but also resistance to adoption (Ram 1987). In this study, we take a novel approach by specifying a model that explicitly includes farmers' inertia. The aim is to develop a model that can reflect a range of complex behaviors observed in reality, without requiring unnecessarily complex mathematical structures. Our ideal model will be not only robust but also intuitive, so users and decision makers can understand its key aspects with ease. While this is important for any model, it is essential in our case as we are taking a less conventional approach.

The study is set out as follows: In the remainder of this chapter we review some of the literature relevant to agricultural technology adoption, and briefly describe the workings of a nutrient trading scheme. In chapter 2 we specify our inertia model, first in the general form and then with specific functional forms. The performance of the model is demonstrated in chapters 3 and 4 . These two chapters consider analytical results in the two farmer case, and numerical results in the many farmer case, respectively. How these results vary when inertia contains a stochastic component is demonstrated in chapter 5. Parameter estimation and model validation is discussed in chapter 6 , and chapter 7 concludes this study.

\subsection{The adoption of new agricultural practices}

Research into the factors that affect the adoption of new agricultural practices and technologies has highlighted the importance of farmers' social and professional networks. Foster \& Rosenzweig (1995) use a modified version of the target-input model and find that imperfect knowledge is a key barrier to the adoption of new seed varieties for Indian households, and that households initially learn from their neighbors' experiences. Drawing on the same data, Munshi (2004) contrast wheat and rice farmers to demonstrate that social learning is less prevalent where the performance of the new technology (new seed varieties) is sensitive to unobservable char- 
acteristics. Bandiera \& Rasul (2006) consider how Mozambique farmers' adoption decisions are influenced by the decisions of their networks. They find an inverted U-shaped adoption curve: up to some point farmers become more likely to adopt a new seed variety as the number of adopters in their network increases, but beyond this point farmers become less likely to adopt as the number of adopters in their network increases (see figure 1 of Bandiera \& Rasul 2006). Bandiera \& Rasul (2006) suggests that this decline in the likelihood of adoption may be due to strategic behavior by farmers delaying adoption in order to capitalize on learning opportunities. Conley \& Udry (2010) draw similar conclusions to Foster \& Rosenzweig (1995) but with respect to the growing of pineapples in Ghana. They surveyed individual farmers to discover who they know and talk to about farming, this enabled them to identify each farmer's social network. They find that learning from other farmers via networks is significant, even after controlling for spatial and serial correlation.

Farmers' networks provide them with a wealth of information. However, the literature suggests that it is not just the receipt of information that is important. Duflo et al. (2004) find that while information has a significant effect on the adoption of fertilizer in rural Kenya, access to commitment strategies to finance the purchase of fertilizer has a greater effect. Pannell et al. (2006) and Bewsell \& Brown (2009) investigate adoption by Australian and New Zealand farmers respectively. They conclude that adoption is more likely where farmers can acquire first-hand, personalized information from trialling new technologies on their own farms. Hanna et al. (2012) demonstrate a model where farmers fail to learn, not because they do not have information, but because they fail to notice important features of the information they already possess.

Meta-analyses of the drivers of adoption have been conducted for the United States. Skinner \& Staiger (2005) compare adoption rates of hybrid corn, tractors, and $\beta$-blockers (for the treatment of heart attacks) across states. They find that high levels of human and social capital (i.e. education and involvement in local networks) are strongly associated with early adoption, while low financial costs of adoption have a much weaker effect. A more recent meta-analysis by Baumgart-Getz et al. (2012) highlights the importance of farmers' connections to local networks, the quality of their information, and their access to finance. Farmers' risk aversion does not appear to have a significant effect on their technology adoption.

A less emphasized driver of farmers' adoption decisions is farmers' attitudes to farming and to change. Dury et al. (2010) interviewed farmers in France and identify the following as farmer objectives: maximizing profit or income, establishing and maintaining a secure source of income, and reducing or simplifying their workload. Connor et al. (2008) and Ward et al. (2008) give classifications of Australian 
farmers according to their attitudes towards how they manage their farm. The five key elements of farmers' attitudes they identify are: business focus, innovativeness, willingness to learn, responsiveness to social influence, and environmental concern.

\begin{tabular}{|ll|c|c|c|c|c|}
\hline Description & & $\begin{array}{c}\text { Business } \\
\text { focus }\end{array}$ & Innovative & $\begin{array}{c}\text { Willing } \\
\text { to learn }\end{array}$ & $\begin{array}{c}\text { Socially } \\
\text { responsive }\end{array}$ & $\begin{array}{c}\text { Envir. } \\
\text { concern }\end{array}$ \\
\hline Business oriented & $52 \%$ & + & & & - & \\
\hline Innovative & $22 \%$ & + & + & & & ++ \\
\hline Traditionalists & $13 \%$ & & - & - & - & -- \\
\hline
\end{tabular}

Table 1. Classification of farmers by Connor et al. (2008)

\begin{tabular}{|ll|c|c|c|c|c|}
\hline Description & & $\begin{array}{c}\text { Business } \\
\text { focus }\end{array}$ & Innovative & $\begin{array}{c}\text { Willing } \\
\text { to learn }\end{array}$ & $\begin{array}{c}\text { Socially } \\
\text { responsive }\end{array}$ & $\begin{array}{c}\text { Envir. } \\
\text { concern }\end{array}$ \\
\hline Socially influenced & $52 \%$ & - & & & ++ & - \\
\hline Innovative & $25 \%$ & + & + & - & & - \\
\hline Lifestyle & $10 \%$ & -- & & - & - & + \\
\hline Capital Constrained & $13 \%$ & & & ++ & & ++ \\
\hline
\end{tabular}

Table 2. Classification of farmers by Ward et al. (2008)

Tables 1 and 2 give the characteristics of farmers as classified by Connor et al. (2008) and Ward et al. (2008). Cells containing $+(++)$ indicate (very) strong presence of an attribute, and cells containing - (- -) indicate (very) weak presence of an attribute. Blank cells indicate that the characteristic is not indicative of the corresponding class of farmers. The remaining 13 percent of farmers from Connor et al. (2008) are not described. In addition to the characteristics identified in table 2, the farmers described by Ward et al. (2008) as capital constrained face significant capital constraints.

Sin (2012) provides a framework for thinking about farmers' decisions to adopt new environmentally friendly technologies. Sin notes that delaying adoption may be an optimal individual decision as it allows farmers to learn from earlier adopters, take advantage of alternative technologies that might arise, and avoid irreversible costs of adopting and locking-in inferior technologies. Where farmers' individual adoption decisions are not socially optimal, Sin (2012) identify the roles for regulatory intervention to encourage adoption. Results from Marshall (2008) suggest that local government involvement has a stronger positive effect on the adoption of conservation practices than regional government involvement.

A common approach when modeling individual agents' adoption decisions is to treat adoption as an irreversible binary decision: in some period agents make 
a step change from the old technology to the new technology. The key question under this framework is when will agents adopt the new technology? Griliches (1957) describes the proportion of the target population who have adopted a new technology using an S-shaped function of the time since the technology became available. Griliches fits these S-curves with logistic functions and characterizes them according to three aspects: (i) origin, when the population begin to adopt; (ii) slope, the speed of adoption; and (iii) ceiling, the total proportion who adopt. A review of the approaches used more recently to study adoption and their data requirements has been conducted by Besley \& Case (1993).

Following the approach by Griliches (1957), Berger (2001) develops an agentbased simulation model where agents learn about a new technology from observing nearby agents who have already adopted it. As agents learn about the technology they become more likely to adopt it. Ellison \& Fudenberg (1993) also develop an agent-based model, but allow agents to revise their choice of two technologies in response to further learning. However, not all agents may revise their technology choice each period, a property they call inertia. Ellison \& Fudenberg (1993) appear to be the first to use the term inertia with respect to modeling agents' decisions to adopt new technology.

Our work in this study is consistent with the approach taken by Dong \& Saha (1998) who develop a double-limit hurdle model that separates the decision "whether to adopt?" from the decision "how much to adopt?" Instead of considering the adoption of specific mitigation practices and technologies, we treat adoption as a continuous decision. Rather than deciding when to adopt, in each period farmers decide whether, and how much more, to adopt new technologies.

\subsection{Nutrient trading schemes}

We will frequently discuss the development of our inertia model in the context of a trading scheme for nutrient emissions. In this section we provide a brief overview of nutrient trading schemes and their application to farms (or, more generally, diffuse emitters of nutrients). A list of key terms is given in appendix A.

The key nutrients emitted by agricultural activities in New Zealand are nitrogen and phosphorus. Increased levels of these nutrients in local water bodies leads to reduced water clarity and increased algal growth. The resulting concentrations of algae lead to eutrophication of water ways, are harmful to fish, and in sufficient quantities can be poisonous to humans and livestock (Carpenter et al. 1998, Parliamentary Commissioner for the Environment 2006). 
Nitrogen and phosphorus tend to enter the farming system via the application of fertilizers and the importing of feed for livestock. Some of these nutrients leave the farm as produce: milk, meat, fiber and crops. Of the nutrients that do not leave the farm as produce, a proportion remain in the soil and plants but the rest is lost from the farm as nutrient emissions into local water ways (such as rivers, streams, and lakes) or into groundwater (underground bodies of water).

In New Zealand, farms' nutrient losses can be estimated using the OVERSEER software tool developed by AgResearch (2009). This gives farms' long run average nutrient losses as a function of farm management practices, including: farm type, output produced, stocking rate, fertilizer use, imported feed, area for effluent irrigation, and the use of mitigation technologies (nitrogen inhibitors, wintering and stand-off pads); and farm location, including: slope, rainfall, soil type and drainage.

Where a local water body (lake, bay, river or stream) is suffering from environmental degradation due to high nutrient levels, regulation may be introduced on those farms that contribute emissions to the water body. The catchment is the land area within which nutrient emissions lead to increased levels of nutrients in the local water body. So all farms within the catchment will be subject to regulation.

One design of regulation for managing nutrient emissions is a nutrient emissions trading scheme. Under an emissions trading scheme the regulator provides a fixed supply of annual allowances. Each allowance entitles the bearer to emit a single unit of nutrients. At the start of each regulatory period, farmers receive or purchase an initial allocation of allowances. During the period, farmers are free to buy and sell allowances. At the end of the regulatory period, farmers must surrender sufficient allowances to cover the nutrient emissions from their property for that period. Farmers with insufficient allowances to cover their intended emissions must either purchase unused allowances from farmers with excess allowances, reduce their emissions, or risk non-compliance. By controlling the supply of allowances a regulator can manage the total amount of nutrient emissions.

A trading scheme is theoretically desirable, as it encourages mitigation to occur where it is most cost effective. ${ }^{2}$ Profit-maximizing farmers will mitigate as long as the cost of mitigation is less than the value of the allowances they would otherwise have to hold. This implies that the price of allowances will be such that all allowances are used and each farmer is indifferent between further mitigation

\footnotetext{
${ }^{2}$ Cost effective mitigation is theoretically possible with any design of regulation. However, in order for more prescriptive regulation to be cost effective the regulator needs a significant amount of information from farmers. As farmers are seldom willing to share financially sensitive information and may have incentives to provide incorrect information, we anticipate that prescriptive regulation is seldom as cost effective as trading regulation.
} 
and purchasing additional allowances. It follows that under a trading scheme the least costly mitigation activities will take place first. ${ }^{3}$

For a more general introduction to the literature on environmental trading schemes we recommend Tietenberg (2006). Barnes \& Breslow (2001) provide a good introduction to the application of emissions trading for air quality, and Kerr et al. (2012) provide a good introduction to the application of nutrient trading for water quality. Horan \& Shortle (2011) discuss how the reality of nutrient trading frequently differs from the theoretical ideal.

${ }^{3} \mathrm{~A}$ trading scheme may also encourage more efficient technology adoption decisions as suggested by Kerr \& Newell (2003) in the context of the U.S. petroleum industry's phase-down of lead in gasoline. 


\section{Chapter 2}

\section{The Inertia Model}

Next we consider a farmer faced with regulatory pressure to reduce nutrient emissions. The farmer can either adopt new mitigation technologies and practices designed to lower the cost of reducing emissions, or can attempt to reduce emissions given their current technologies and practices. The adoption of new technologies is potentially threatening to the farmer or the farm business as it will involve risk and learning new or unfamiliar activities. In contrast, managing with current technologies is likely to be less threatening to the farmer and, while costly in the long run, will be more comfortable in the short run. In this chapter we develop our model of when and how much farmers will adopt new technologies in response to nutrient regulation.

With regard to specific technologies or practices, we anticipate abatement activities in the short run might include fencing waterways, reducing fertilizer applications, introducing nitrogen inhibitors, and decreasing stocking rates. Abatement activities in the long run are likely to have capital costs and might include introducing feeding or winter pads, more advanced effluent management, the installation of a herd home, and if necessary changes in farm type or location.

Although the optimal response to nutrient regulation must involve the adoption of appropriate technologies and practices in the long run, farmers are likely to be resistant to making certain changes in the short run. We will describe this resistance as inertia. Farmers' inertia will decline with time, as they seek more profitable ways of managing their farms, and as farmers observe their neighbors making changes on their own farms.

The passing of time gives farmers greater opportunity to learn and prepare for change. Over time social and regulatory pressure will increase, and better technologies will become available. In addition, farmers' existing technologies will de- 
preciate increasing the likelihood that farmers will replace them with new, and superior, technologies.

Farming is a business and, while profit does not drive all farming activity, many farmers have significant mortgages to repay (see for example Ministry of Agriculture and Forestry 2011, in the context of New Zeland farms). It follows that under nutrient regulation farmers have incentives to improve the efficiency of their farm's management by adopting technologies that improve the cost effectiveness of their current activities.

Farmers within the same catchment are often part of the same networks (social or professional) and therefore have opportunities to learn from each other. The prevalence of network effects on farmers' adoption decisions has been well established in the literature (see for example Foster \& Rosenzweig 1995, Conley \& Udry 2010). Furthermore, farmers may have incentives to strategically delay adoption in order to capitalize on learning from their peers (Bandiera \& Rasul 2006).

The relative impacts of time, financial pressure and network effects on technology adoption decisions will differ between farmers. Building a model enables us to observe and analyze the importance of different drivers of technology adoption, and how progressive technology adoption affects the cost of nutrient regulation.

\subsection{The general model}

Consider a catchment containing several farms. Each farm is managed by a farmer who chooses the level of inputs (animals, fertilizer, labor, capital) to put on their farm and how much to adopt new mitigation technologies. Farms have two outputs: their production good (e.g., meat, milk, or fiber) that results in profit that is collected by the farmer, and nutrient emissions (e.g., nitrogen or phosphorus) that are a byproduct that results in environmental degradation. In general, more intensive farms (i.e., farms with higher levels of inputs) generate both more profits and more nutrient emissions.

The wider community is concerned about the environmental degradation caused by farms' nutrient emissions. However, this concern is not sufficient to motivate farmers to reduce emissions where these reductions are costly. As a result, the community has asked the local government body to intervene in the catchment as a regulator. The aim for regulatory intervention is to lower nutrient emissions in the catchment to acceptable levels.

Farmers can theoretically achieve any level of nutrient emissions, without adopting new technologies, by reducing their use of existing inputs. However, if 
a farm is profit maximizing with respect to their current emissions, lowering emissions via reducing inputs is very costly to the farm business as it has a large impact on profit. ${ }^{1}$ New mitigation technologies (and the associated practices) are designed to lower the cost to the farmer of reducing nutrient emissions by making reductions more cost effective. A farmer who adopts some new technology will be able to meet any nutrient target at lower cost (with more profit) than a farmer who adopts no technology. It follows that, where farmers are required to reduce nutrient emissions, they have incentives to adopt new technology.

While farmers have incentives to adopt new technologies, they may be slow to adopt due to their inertia. We consider a discrete time model of $I$ farmers over $T$ consecutive time periods, $t=1, \ldots, T$. Each period, farmers' inertia will determine what new technologies (and the associated practices) they are willing to adopt. As farmers' inertia changes over time they will become more willing to adopt new technologies.

The optimal decision in this context could be determined by a benevolent social planner. The social planner's aim is to maximize the combined profit of all farmers, given that nutrient emissions from farming $\left(n_{i t}\right)$ must not exceed specified levels $\left(\bar{N}_{t}\right)$, and that farmers face limits on their adoption of new technologies each period. To accomplish this, the social planner chooses the use of technology $\left(m_{i t}\right)$ and inputs $\left(\theta_{i t}\right)$ for all farmers $i,(i=1, \ldots, I)$ and time periods $t,(t=1, \ldots, T)$.

In order to find the optimal combined profit for these $I$ farmers over $T$ time periods, under the described constraints, the following constrained optimization problem can be formulated:

$$
\begin{aligned}
& \max _{\forall i, t: \theta_{i t}, m_{i t}} \sum_{t=1}^{T} \sum_{i=1}^{I} \frac{1}{(1+r)^{t}} \pi_{i}\left(x_{i t}, \theta_{i t}, m_{i t}\right) \\
& \text { s.t.: } \quad \forall t: \sum_{i=1}^{I} n_{i}\left(x_{i t}, \theta_{i t}, m_{i t}\right) \leq \bar{N}_{t}, \\
& \forall i, t: \Delta m_{i t} \leq \Delta \bar{m}_{i t}\left(t, m_{i, t-1},\left\{m_{j \neq i, t-1}\right\}\right) \\
& \forall i, t: \theta_{i t}, m_{i t} \geq 0,
\end{aligned}
$$

where

$\theta_{i t}$ - is the decision variable that gives the use of all other inputs on farm $i$ in period $t$

\footnotetext{
${ }^{1}$ We will assume that farms are profit maximizing with respect to their current emissions. However in practice, farms may not be profit maximizing with respect to their current emissions and may be able to carry out mitigation at very low (or negative) cost by changing their inputs: for example, a farmer who is applying more nitrogen fertilizer than than his pasture can make effective use of might improve profitability and reduce nitrogen loss by decreasing his fertilizer application.
} 
$m_{i t}$ - is the decision variable that gives the use of technology on farm $i$ in pe$\operatorname{riod} t$

$x_{i t}$ - gives various exogenous factors (such as prices, land quality, soil type, and climate)

$\pi_{i}(\cdot)$ - is the profit function of farmer $i$, and includes the revenue from production, the cost of new technologies and the cost of all other inputs

$n_{i}(\cdot)$ - gives the nutrient emissions $\left(n_{i t}\right)$ of farm $i$ as a function of farm inputs

$\bar{N}_{t}$ - is the maximum acceptable level of nutrient emissions for the catchment (the cap) in period $t$

$\Delta m_{i t}$ - is the new technology adopted by farmer $i$ in period $t: \Delta m_{i t}=m_{i t}-m_{i, t-1}$ $\Delta \bar{m}_{i t}(\cdot)$ - gives the maximum amount of new technology farmer $i$ is willing to adopt in period $t$

$r$ - is the discount rate, so the social planner accounts for the value of money between periods ${ }^{2}$ and maximizes the net present value of all future profits

We refer to (2.2) as the environmental constraint. The nutrient cap $\left(\bar{N}_{t}\right)$ is set outside the model by the regulator in response to advice from ecological and hydrological scientists.

We refer to (2.3) as farmers' inertia constraint. $\Delta m_{i t}=m_{i t}-m_{i, t-1}$ is the new technology adopted by farmer $i$ in period $t$, and $\Delta \bar{m}_{i t}(\cdot)$ gives the maximum amount of new technology farmer $i$ is willing to adopt in period $t$. Farmers' adoption of new technology is bounded by their willingness to adopt: $\Delta m_{i t} \leq \Delta \bar{m}_{i t}$.

Definition. A farmer's inertia, $\bar{m}_{i t}$, is the maximum amount of technology that farmer $i$ is willing to adopt by the end of period $t: \bar{m}_{i t}=m_{i, t-1}+\Delta \bar{m}_{i t}$. Given this definition farmers' inertia constraint, (2.3) in the above optimization problem, is equivalent to $\forall i, t$ : $m_{i t} \leq \bar{m}_{i t}$.

Definition. A farmer's inertia is binding if $m_{i t}=\bar{m}_{i t}$.

Definition. A farmer's inertia weakens $a s \bar{m}_{i t}$ increases over time and farmers are willing to adopt more technology.

In reality, as the inputs on a farm increase both the profit and nutrient emissions of the farm also increase. However, beyond some point, profit ceases to increase with inputs though nutrient emissions continue to increase. To reflect this reality, we require that nutrient emissions are increasing with inputs,

$$
\frac{\partial n_{i}}{\partial \theta_{i t}} \geq 0 ;
$$

\footnotetext{
${ }^{2}$ The social planner prefers $\$ 1$ today over $\$ 1$ next year, and is indifferent between $\$ 1$ today and $\$(1+r)$ next year.
} 
profit is initially increasing with inputs (up to some level $\theta_{i}^{u}$ ),

$$
\theta_{i t} \in\left[0, \theta_{i}^{u}\right] \rightarrow \frac{\partial \pi_{i}}{\partial \theta_{i t}} \geq 0
$$

and profit exhibits decreasing marginal returns with respect to inputs,

$$
\frac{\partial^{2} \pi_{i}}{\partial \theta_{i t}^{2}}<0
$$

These requirements ensure nutrient emissions are increasing with farm inputs, and that there exists a finite, non-negative profit maximizing level of inputs (so given the exogenous inputs, $x_{i t}$, profit maximizing farmers will seek to use the optimal level of inputs, $\theta_{i t}^{*}$, in order to earn the maximum possible profit, $\left.\pi_{i}^{*}(\cdot)\right)$.

It follows that farmers can decrease their nutrient emissions $\left(n_{i t}\right)$ by reducing their inputs $\left(\theta_{i t}\right)$. However, lowering inputs results in reduced farm profits (unless farmers' current inputs exceed the profit maximizing level of inputs, $\theta_{i t}^{*}$ ). The adoption of new technologies improves the cost effectiveness of input reductions. So that the same reduction in nutrient emissions can be achieved with a smaller reduction in profit. We require that the change in profit with respect to inputs $\left(\partial \pi_{i} / \partial \theta_{i t}\right)$ is initially decreasing with the adoption of technology (up to some level $m_{i t}^{u}\left(\theta_{i t}\right)$ ).

$$
m_{i t} \in\left[0, m_{i t}^{u}\left(\theta_{i t}\right)\right] \rightarrow \frac{\partial^{2} \pi_{i}}{\partial m_{i t} \partial \theta_{i t}}<0 .
$$

This ensures that there is a financial benefit to farmers from adopting technology (up to some point). This benefit may differ depending on a farm's nutrient emissions. In addition, it implies that there exists a finite, non-negative optimal level of technology adoption.

The key contribution of our model is the inclusion of farmers' inertia in the social planner's decision problem as given by (2.3). This extends the static economic model for profit maximization given an environmental constraint (see for example Tietenberg 2006). If farmers' have no inertia (2.3) will always be non-binding, and our model reduces to the static economic model (such at that given by Tietenberg 2006, chapter 2) as follows:

$$
\begin{aligned}
& \max _{\forall i, t: \theta_{i t}, m_{i t}} \sum_{t=1}^{T} \sum_{i=1}^{I} \frac{1}{(1+r)^{t}} \pi_{i}\left(x_{i t}, \theta_{i t}, m_{i t}\right) \\
& \text { s.t.: } \quad \forall t: \sum_{i=1}^{I} n_{i}\left(x_{i t}, \theta_{i t}, m_{i t}\right) \leq \bar{N}_{t} \\
& \forall i, t: \theta_{i t}, m_{i t} \geq 0 .
\end{aligned}
$$

Note that farm profits, in period $t$, are additive in (2.1) and (2.4). This implies that profits from different farms are equivalent and the social planner has no 
preference as to which farms generate the profits. While (2.1) could be adapted for circumstances where the social planner has preferences regarding the distribution of farm profits (perhaps caused by differences in farm types, interactions between farms, or wider social impacts), we maintain the additive structure as it is important for the construction of our solution algorithm in the next section.

One approach to finding a solution for the social planner's decision problem, is to specify it as a dynamic program and solve using backwards recursion. It is well known that a dynamic program, with value function $V_{t}$, can be expressed as follows (Bellman 1957):

$$
\begin{aligned}
V_{t}\left(\left\{m_{i, t-1}\right\}\right)=\max _{\forall i: \theta_{i t}, m_{i t}} & \left(\sum_{i=1}^{I} \pi_{i}\left(x_{i t}, \theta_{i t}, m_{i t}\right)+\frac{1}{1+r} V_{t+1}\left(\left\{m_{i t}\right\}\right)\right) \\
\text { s.t. } & \sum_{i=1}^{I} n_{i}\left(x_{i t}, \theta_{i t}, m_{i t}\right) \leq \bar{N}_{t}, \\
& \forall i: \Delta m_{i t} \leq \Delta \bar{m}_{i t}\left(t, m_{i, t-1},\left\{m_{j \neq i, t-1}\right\}\right) \\
& \forall i: \theta_{i t}, m_{i t} \geq 0 .
\end{aligned}
$$

Note that the state for the problem at time $t$ is defined by the set of all farmers' technology decisions in period $t-1\left(\left\{m_{i, t-1}\right\}\right)$. As a result, this problem rapidly becomes computationally intractable as the number of farmers increases.

To make the decision problem tractable we solve it under the following additional assumption: The social planner is short-sighted and optimizes within each time period sequentially rather than over all time periods. The social planner's decision problem can then be expressed as a series of constrained optimization problems. The social planner's optimization problem for time period $t$ can be formulated as follows:

$$
\begin{aligned}
\max _{\forall i: \theta_{i t}, m_{i t}} & \sum_{i=1}^{I} \pi_{i}\left(x_{i t}, \theta_{i t}, m_{i t}\right) \\
\text { s.t. } & \sum_{i=1}^{I} n_{i}\left(x_{i t}, \theta_{i t}, m_{i t}\right) \leq \bar{N}_{t}, \\
& \forall i: \Delta m_{i t} \leq \Delta \bar{m}_{i t}\left(t, m_{i, t-1},\left\{m_{j \neq i, t-1}\right\}\right), \\
& \forall i: \theta_{i t}, m_{i t} \geq 0,
\end{aligned}
$$

where (2.6) follows from (2.1) according to the short-sightedness assumption; and (2.7) and (2.8) are the parts of (2.2) and (2.3) respectively that relate to time period $t$. Note that we need not include the discounting factor $\left((1+r)^{-t}\right)$ in (2.6) as it reduces to a multiplicative constant in this formulation.

Given the decision problem for period $t$, it is then straightforward to solve 
the social planner's decision problem over all time periods using forward recursion (see the algorithm in the following section). As any solution to the revised model, given by (2.6) to (2.8), will also be a solution to the original model, given by (2.1) to (2.3), solutions to the revised model will provide a lower bound on the objective function of the original model.

\subsection{The general farmer level model}

In practice, it is difficult for a social planner to obtain farm specific information (i.e., to observe $x_{i t}, \pi_{i}(\cdot)$ or $\left.n_{i t}(\cdot)\right)$. This hinders their ability to solve the decision problem (2.6) - (2.8).

An alternative to solving the social planner's decision problem is to establish a regulatory environment such that the result of farmers' individual farm management decisions will be identical to the result that would be obtained by the social planner. The standard regulatory approach to accomplish this is a trading scheme.

Under a nutrient trading scheme the regulator provides a supply of allowances equal to $\bar{N}_{t}$, with each allowance entitling the owner to emit one unit of nutrients. Farmers can trade allowances between themselves, but must surrender sufficient allowances to cover their emissions at the end of each period. The equilibrium price of allowances $\left(p_{t}\right)$ is determined by the profit that can be earned from using them. Given this price, farmers' individual decisions will be identical to the equivalent decisions made by the social planner. This can be demonstrated via the KarushKuhn-Tucker conditions (see Tietenberg 2006).

Following the Karush-Kuhn-Tucker conditions, the constrained optimization problem (2.6) - (2.8) implies the following optimization problem for each farmer $i$ in period $t$ when nutrient trading regulation is introduced:

$$
\begin{array}{cl}
\max _{\theta_{i t}, m_{i t}} & \pi_{i}\left(x_{i t}, \theta_{i t}, m_{i t}\right)-p_{t} n_{i}\left(x_{i t}, \theta_{i t}, m_{i t}\right) \\
\text { s.t. } & \Delta m_{i t} \leq \Delta \bar{m}_{i t}\left(t, m_{i, t-1},\left\{m_{j \neq i, t-1}\right\}\right), \\
& \theta_{i t}, m_{i t} \geq 0,
\end{array}
$$

where the price of nutrient allowances faced by all farmers, $p_{t} \geq 0$, is determined within the model to be the smallest price such that, given farmers' input and technology decisions, their nutrient emissions satisfy the environmental constraint:

$$
\sum_{i=1}^{I} n_{i}\left(x_{i t}, \theta_{i t}, m_{i t}\right) \leq \bar{N}_{t}
$$

It is straightforward to show that (2.9) follows from (2.6) and (2.7) according to the 
Karush-Kuhn-Tucker conditions, (2.10) follows from (2.8), and (2.11) follows from (2.7) when constructing a single farmer's decision problem.

It follows that we can solve the model using a disaggregated or agent based approach where individual farmers are the decision makers. As farmers' inertia in each period depends on decisions in the previous period, the following solution algorithm solves the model using forwards recursion.

1. Each farmer observes the decisions of all other farmers $\left(m_{j \neq i, t-1}\right)$, and the resulting nutrient price $\left(p_{t-1}\right)$, from the previous period.

2. Each farmer calculates the maximum amount of new technology that they are willing to adopt this period $\left(\Delta \bar{m}_{i t}\right)$.

3. Each farmer constructs their demand schedule for nutrient allowances (expressing their intended $n_{i t}$ for any given $p_{t}$ ) by considering the nutrient emissions that would result from the optimal decisions on their property $\left(\theta_{i t}\right.$ and $m_{i t}$ ) for any given allowance price.

4. All farmers receive an initial allocation of allowances. Farmers will search for and engage in mutually beneficial bilateral trades (as determined by their demand schedules). ${ }^{3}$ Once all mutually beneficial trades have been exhausted, the equilibrium price of allowances $p_{t}$ will be such that no farmer is willing to sell an allowance for less than this price and no farmer is willing to buy an allowance for more than this price.

5. All farmers exit the nutrient trading market with allowance holdings as determined by their demand schedules and the market price.

6. Each farmer chooses the technology and other inputs $\left(m_{i t}\right.$ and $\left.\theta_{i t}\right)$ for their property that maximize their profit given their allowance holdings.

By the Coase Theorem, if we assume zero transaction (trading) costs, the final allocation of allowances is independent of the initial allocation of allowances (Coase 1960). Hence all we are concerned with is: What is the price? And given the price, how many allowances will each farmer hold? It follows that we need not specify an initial allocation of allowances, or model the trading between farmers, and can instead focus on the final allocation of allowances. For computational purposes it will be equivalent to modify step four in the above algorithm as follows:

4. Farmers' submit their demand schedules (constructed in step three) to a cen-

\footnotetext{
${ }^{3} \mathrm{~A}$ mutually beneficial trade occurs where two farmers meet and can find a price such that at this price one farmer wishes to hold more allowances than they currently have and the other farmer wishes to hold less allowances than they currently have. If such a price can be found then the first farmer buys allowances from the second farmer at this price until, the trade is no longer mutually beneficial.
} 
tral agency that determines the price of allowances $\left(p_{t}\right)$ such that total demand for allowances equals the cap (the supply of allowances).

In the remainder of this chapter we will propose and justify specific functional forms for the farm profit $\left(\pi_{i}\right)$ and farmer inertia functions $\left(\Delta \bar{m}_{i t}\right)$. These are the functional forms we will assume for the remainder of the study.

\subsection{Choice of decision variables}

So far in our model, we have used $\theta_{i t}$ to represent all inputs other than technology. However, in reality there are many farm inputs (including stock, fertilizer, imported feed, fencing materials, and labor) and the combination of these inputs, not just the quantity, is important. Furthermore the same quantity of nutrient emissions could be achieved using many different combinations of inputs. Incorporating in our model the process by which inputs are converted to profits and emissions is unnecessary and detracts from our focus on farmers' inertia.

For any given farm-level nutrient target (and given technology) a skilled farmer could determine the profit maximizing combination of inputs that will meet this nutrient target. This implies that we do not need to consider the set of all possible combinations of inputs but can focus on the subset that would be used by a skilled farmer to maximize profit. Note that by construction there exists a bijection between this subset and the set of all feasible $n_{i t}$. Hence rather than treating $\theta_{i t}$ as a decision variable (so nutrient emissions are determined implicitly) it will be equivalent to treat $n_{i t}$ as the decision variable (so farm inputs are determined implicitly). For our specific functional forms we will treat $m_{i t}$ and $n_{i t}$ as decision variables. To simplify the notation, we will suppress $x_{i t}$ and $\theta_{i t}$.

Recall from the previous section, that we require that there exists a finite, non-negative profit maximizing level of inputs, and that the adoption of technology improves the cost effectiveness of reductions in inputs. When we consider $n_{i t}$ as a decision variable, these requirements can be expressed as follows: profit is initially increasing with nutrient emissions (up to some level $n_{i}^{u}$ ),

$$
n_{i t} \in\left[0, n_{i}^{u}\right] \rightarrow \frac{\partial \pi_{i}}{\partial n_{i t}} \geq 0 ;
$$

marginal profit is decreasing with nutrient emissions,

$$
\frac{\partial^{2} \pi_{i}}{\partial n_{i t}^{2}}<0
$$

and the change in profit with respect to nutrient emissions is initially decreasing 
with the adoption of technology (up to some level $m_{i t}^{u}\left(n_{i t}\right)$ ),

$$
m_{i t} \in\left[0, m_{i t}^{u}\left(n_{i t}\right)\right] \rightarrow \frac{\partial^{2} \pi_{i}}{\partial m_{i t} \partial n_{i t}}<0 .
$$

The first two requirements ensure that higher profit from a farm results in increased emissions, and that there exists a finite, non-negative profit maximizing level of emissions. The third requirement ensures that farmers have a financial incentive to adopt technology, and that there exists a finite, non-negative optimal level of technology adoption.

\subsection{Farm profit function}

We will express farms' profits as a function of their nutrient emissions $\left(n_{i t}\right)$ and their technology $\left(m_{i t}\right) .{ }^{4}$ We propose the following functional form for farms' profit function.

$$
\pi_{i}\left(m_{i t}, n_{i t}\right)=a_{i} n_{i t}^{2}+b_{i} n_{i t}+c_{i}+d_{i}\left(e_{i}-n_{i t}-m_{i t}\right)^{2}-q_{i} m_{i t}
$$

where

- $a_{i}, b_{i}, c_{i}$ and $d_{i}$ are coefficients $\left(a_{i}<0, d_{i}<0\right.$ and $\left.b_{i}>0\right)$,

- $e_{i}$ is the farm's baseline emissions (emissions at time $t=0$ before regulation is introduced) ${ }^{5}$

- $q_{i} \geq 0$ is the cost of technology to farmer $i$ (including interest and depreciation).

This form extends that used by Anastasiadis et al. (2011), and can intuitively be decomposed into three parts: The first three terms give profit from production as a quadratic function of nutrient emissions; the fourth term provides a measure of the difference between farmers' current nutrient mitigation $\left(e_{i}-n_{i t}\right)$ and their technology $\left(m_{i t}\right)$; the fifth term accounts for the cost of technology.

We choose a quadratic form for the profit from production for its simplicity and because it results in linear (or piece-wise linear) demand functions, as we will see in figure 2 , below. With quadratic polynomials it is straightforward to determine coefficient values that ensure any sign restrictions will be satisfied. If profits from production is determined by a more complex function, a quadratic form provides a second order approximation.

Recall from the start of chapter 2 that farmers' optimal responses to nutrient regulation must involve the adoption of appropriate technologies and practices.

\footnotetext{
${ }^{4}$ In order to measure $m_{i t}$ and $n_{i t}$ using the same units, we may quantify a farm's technology as the amount of nutrients that the technology can help to cost effectively mitigate.

${ }^{5}$ In this study $e$ always refers to a farm's baseline emissions, it never refers to the natural exponent.
} 
The profit function (2.12) assumes that the appropriate technology is such that all, or almost all, nutrient mitigation is supported by technology adoption $\left(m_{i t} \approx e_{i}-n_{i t}\right){ }^{6}$ It follows that farms that adopt technology that is consistent with their nutrient reductions should earn more profit. This is done in (2.12) by penalizing farmers who adopt too little technology $\left(m_{i t}<e_{i}-n_{i t}\right)$ or too much technology $\left(m_{i t}>e_{i}-n_{i t}\right){ }^{7}$ We require a measure of difference between $e_{i}-n_{i t}$ and $m_{i t}$. Two standard ways of quantifying the difference between two measures are to consider the absolute difference $\left(\left|e_{i}-m_{i t}-n_{i t}\right|\right)$ or the squared difference $\left(\left(e_{i}-n_{i t}-m_{i t}\right)^{2}\right)$. We choose the squared difference $\left(\left(e_{i}-n_{i t}-m_{i t}\right)^{2}\right)$ for its mathematical elegance. Using the squared difference ensures that the expression for farm profit (2.12) when $m_{i t}$ is fixed intersects at a tangent the expression for farm profit (2.12) when $m_{i t}$ is optimized. This can be seen in figure 1 where the black lines approach the gray line at a tangent. This guarantees that the profit function given by (2.12) has continuous first-order derivatives. It also means that farm profit when inertia is non-binding can be constructed as an envelope function of all the farm profit curves when inertia is binding.

We recognize that over time new technologies are developed and existing technologies become cheaper to produce and hence the cost of technology $q_{i}$ is unlikely to be time independent. However for the purpose of this model we will assume that the cost of technology $q_{i}$ only differs between farms as the inclusion of time dependent technology costs would imply the potential for additional short-run dynamics (such as farmers delaying adoption because technology will be cheaper in future periods) which are beyond the scope of this study. ${ }^{8}$

Figure 1 gives an example of the functional form for $\pi_{i}\left(m_{i t}, n_{i t}\right)$. We use the form in (2.12) with the parameters values: $a_{i}=-0.33, b_{i}=40, c_{i}=150, d_{i}=-2$, $e_{i}=50, q_{i}=2$ and $m_{i, t-1}=0$. The gray line gives farms' profit if they have no resistance to change. The long- and short-dashed black lines demonstrate farms' profit functions given bounds on their adoption of technologies $\left(\bar{m}_{i t}\right.$ equals 30 and 10 respectively).

\footnotetext{
${ }^{6}$ This assumption has been made for modeling purposes. In reality, we might expect that farmers could carry out some mitigation without adopting technology. The functional form for farms' profit function could be extended to account for this.

${ }^{7}$ The penalty for adopting too much technology arises not because this makes mitigation more costly, but because the resources used to finance the purchase of the excess technology could have been applied elsewhere.

${ }^{8} \mathrm{We}$ also note that as agricultural science and farming practice are improving $a_{i}, b_{i}, c_{i}$ and $d_{i}$ may also be time dependent. However time dependence in these parameters does not contribute to our model and will be be left for future research.
} 


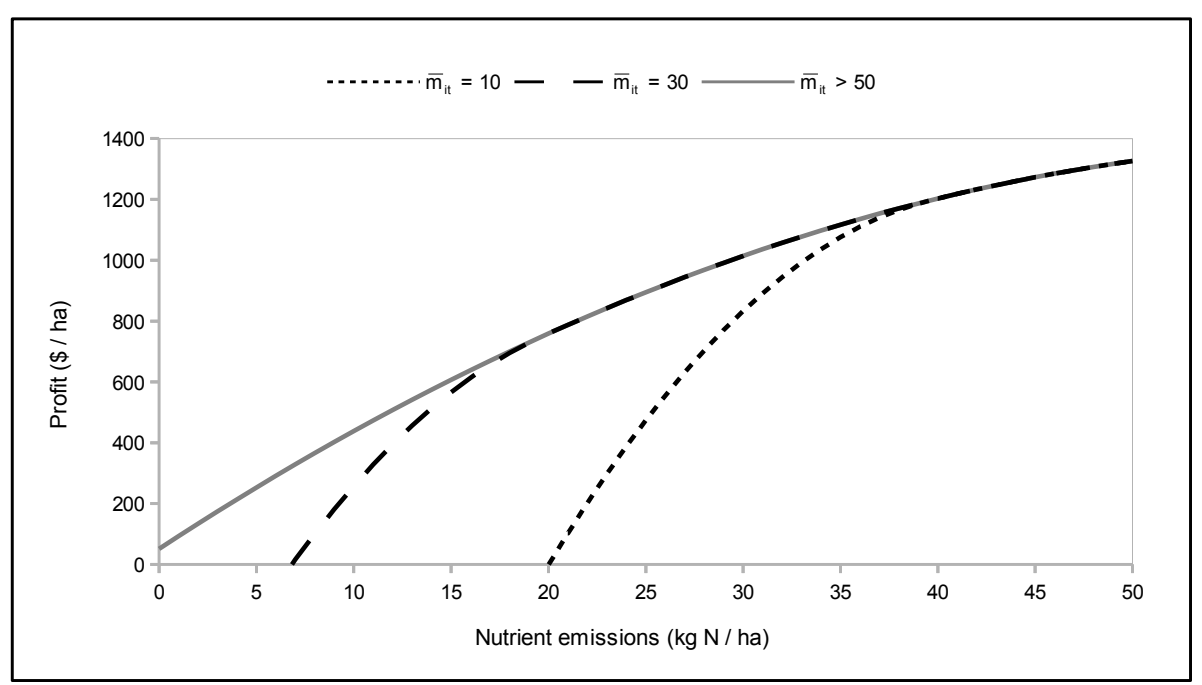

Figure 1. Farm's profit per hectare for levels of inertia

From figure 1 it is clear that farm profit decreases as nutrient emissions decreases. Furthermore, for any level of nutrient emissions, farm profit is non-decreasing as farmers' inertia weakens ( $\bar{m}_{i t}$ increases). As farmers' inertia weakens, farmers are willing to adopt more technology and this improves the cost effectiveness of some reductions in nutrients.

Given the functional form of the farm profit functions we can determine a farmer's optimal decision as a function of the price of allowances and their inertia. First, we consider farmers' decisions under two alternatives: a farmer's inertia is binding and a farmer's inertia is non-binding. Second, we consider how to identify whether a farmer's inertia will be binding or not.

Suppose a farmer's inertia is non-binding. This implies $m_{i t}<\bar{m}_{i t}$ (for example, this must occur if $\bar{m}_{i t}>e_{i}$ ). Then given the price of allowances, $p_{t}$, a farmer will choose the technology and nutrient emissions that maximize their objective function given by (2.9). Let $f_{i t}\left(m_{i t}, n_{i t}\right)$ denote the function farmers are trying to maximize, i.e.,

$$
f_{i t}\left(m_{i t}, n_{i t}\right)=\pi_{i}\left(m_{i t}, n_{i t}\right)-p_{t} n_{i t}
$$

A farmer's optimal technology can be determined by setting $\frac{\partial f_{i t}}{\partial m_{i t}}=0$.From (2.12), this implies $-2 d_{i}\left(e_{i}-n_{i t}-m_{i t}\right)-q_{i}=0$. Therefore,

$$
m_{i t}^{*}=e_{i}-n_{i t}+\frac{q_{i}}{2 d_{i}}
$$

And a farmer's optimal nutrient emissions can be determined by setting $\frac{\partial f_{i t}}{\partial n_{i t}}=0$, which implies $2 a_{i} n_{i t}+b_{i}+q_{i}-p_{t}=0$. Therefore,

$$
n_{i t}^{*}=\frac{p_{t}-b_{i}-q_{i}}{2 a_{i}}
$$


Equations (2.13) and (2.14) give a farmer's optimal choice of technology and nutrient emissions when their inertia is non-binding. When a farmer's inertia is non-binding, their choice of nutrient emissions (and hence their choice of technology) depends only on the price of nutrient allowances, see (2.14). We note that a farmer's optimal technology choice can be decomposed into two parts: the total amount of mitigation they have carried out $\left(e_{i}-n_{i t}\right)$ and the ratio of costs to benefits from technology adoption $\left(q_{i} / 2 d_{i}\right)$.

Suppose a farmer's inertia is binding. This implies $m_{i t}=\bar{m}_{i t}$ (for example, this must occur if $\bar{m}_{i t}=0$ ). Then given the price of allowances, $p_{t}$, a farmer will choose only the nutrient emissions that maximize their objective function given by (2.9). Note that as the farmer's inertia is binding, by definition $m_{i t}=\bar{m}_{i t}$ so a farmer does not choose their technology.

A farmer's optimal nutrient emissions can be determined by setting $\frac{\partial f_{i t}}{\partial n_{i t}}=0$. From (2.12), this implies $2 a_{i} n_{i t}+b_{i}-2 d_{i}\left(e_{i}-n_{i t}-\bar{m}_{i t}\right)-p_{t}=0$. Therefore:

$$
n_{i t}^{*}=\frac{p_{t}-b_{i}+2 d_{i}\left(e_{i}-\bar{m}_{i t}\right)}{2 a_{i}+2 d_{i}} .
$$

Equation (2.15) gives a farmer's optimal choice of nutrient emissions when their inertia is binding. When a farmer's inertia is binding, their choice of nutrient emissions depends on both the price of nutrient allowances and their inertia.

Whether a farmer's inertia is binding or non-binding depends on the price of nutrient allowances. Consider a farmer with inertia $\bar{m}_{i t}=15$ : If the price of allowances is low the farmer can buy many allowances and have high nutrient emissions. Given these emissions, suppose it is optimal for the farmer to use only a few units of technology, say 5 units. As their inertia is 15 , the farmer is willing to use 5 units hence their inertia will be non-binding $\left(m_{i t}=5\right)$. Alternatively, if the price of allowances is high the farmer will buy few allowances and have low nutrient emissions. Given these emissions, suppose it is optimal for the farmer to use more units of technology, say 20 units. However, as their inertia is 15 the farmer is not willing to use 20 units of technology and will use only 15 instead, hence their inertia will be binding $\left(m_{i t}=15\right)$.

For a given allowance price, we can determine $\check{m}_{i t}$, the inertia value at which a farmer's inertia is only just binding. This occurs where $\bar{m}_{i t}$ is equal to $m_{i t}$ given by (2.13) and $n_{i t}$ is given by (2.15). Substituting one equation into the other gives:

$$
\check{m}_{i t}=e_{i}-\frac{p_{t}-b_{i}-q_{i}}{2 a_{i}}+\frac{q_{i}}{2 d_{i}} .
$$

So for a given allowance price, farmers with $\bar{m}_{i t}$ lower than $\check{m}_{i t}$ will have a binding inertia constraint and farmers with $\bar{m}_{i t}$ higher than $\check{m}_{i t}$ will have a non-binding inertia constraint. 
From (2.13) and (2.16) we can observe that there are two key reasons why farmers may not adopt technology. First, farmers' inertia $\left(\bar{m}_{i t}\right)$ in period $t$ may be binding, according to (2.16). So while the farmer may adopt more technology in a future period, they are unwilling to adopt any more technology in the current period. Second, the benefits of adopting new technologies may not exceed the cost. The third term in (2.13) gives the ratio between the cost of technology $\left(q_{i}\right)$ and the improvements in the cost effectiveness of nutrient reductions $\left(-d_{i}\right)$ that come from adopting technology. Where the costs of adoption are large, or the benefits small, farmers will adopt less technology.

Given a farmer's inertia we can determine the price at which their inertia will be binding according to (2.16). This enables us to construct a farmer's demand for allowances as a function of price. When the price of allowances is less than the price implied by (2.16), the farmer's inertia is non-binding and their demand for allowances is given by (2.14). When the price of allowances is more than the price implied by (2.16), the farmer's inertia is binding and their demand for allowances is given by (2.15). Figure 2 gives an example of farmers' demand functions that correspond to the example profit functions given in Figure 1.

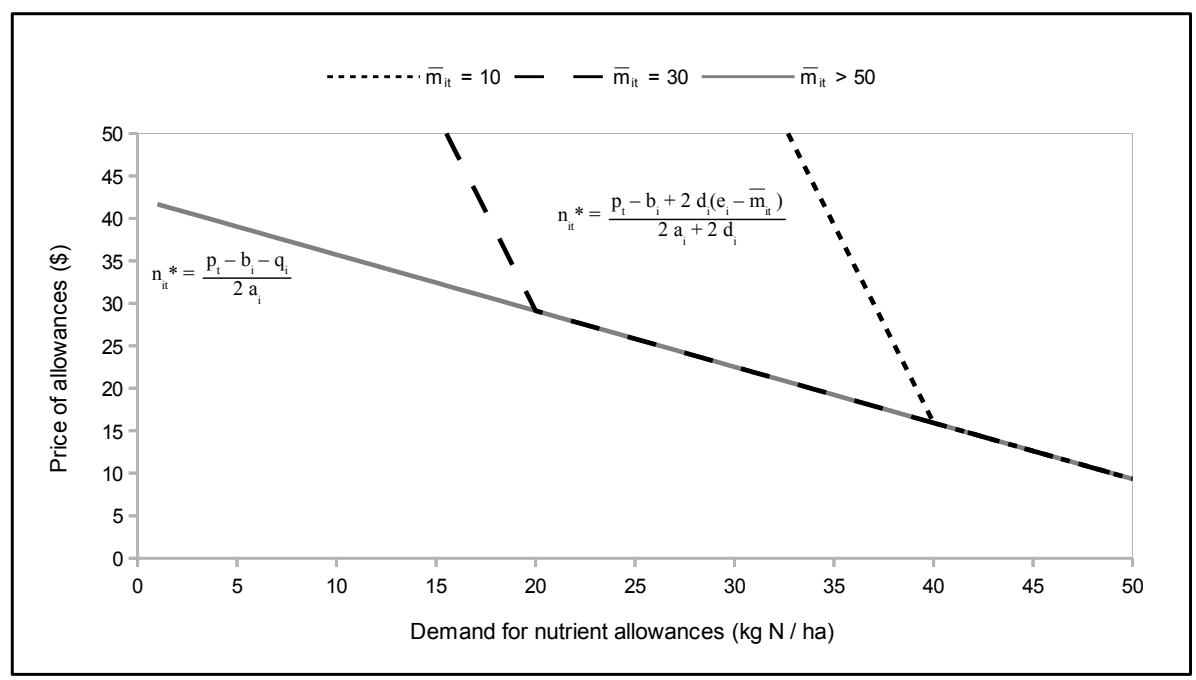

Figure 2. The demand for allowances for different levels of inertia

It is clear from figure 2 that farmers' demand for allowances is decreasing as the price of allowances rises. Furthermore, we observe that farmers' demand for allowances is higher, at any given price, when their inertia is binding. This is to be expected as, from figure 1, the loss of profit from reducing emissions is much higher when a farmer's inertia is binding than when it is non-binding. Proposition 1 establishes this formally.

Proposition 1. Farmers will hold more allowances when their inertia is binding $\left(m_{i t}=\bar{m}_{i t}\right)$ than when their inertia is non-binding $\left(m_{i t}<\bar{m}_{i t}\right)$ for the same allowances price. 
Proof. For ease of notation we will omit subscripts. Then

$$
\begin{aligned}
\frac{p-b-q}{2 a} & \leq \frac{p-b+2 d(e-\bar{m})}{2 a+2 d} \\
\bar{m} & \leq e-\frac{p-b-q}{2 a}+\frac{q}{2 d} \\
\bar{m} & \leq m^{*},
\end{aligned}
$$

where $m^{*}$ is given by (2.13). This must be true for any binding $\bar{m}$.

\subsection{The inertia function}

The form of the inertia function $\Delta \bar{m}_{i t}(\cdot)$ is independent of the functional form chosen for farms' profit functions. In designing an inertia function thought needs to be given to the range of behavior it must be able to exhibit. How long will farmers maintain their current practices before changing? When farmers are willing to change, how rapidly will they change? Do farmers make many small changes period-to-period or larger less frequent changes? How prevalent are cascade effects (where one farmer's technology adoption triggers adoption by other farmers, which in turn triggers adoption by yet more farmers)?

It may be helpful when specifying the functional form for farmers' inertia function to separate inertia into two components: 1) the decision to change, and 2) the maximum amount a willing farmer will change this period.

We propose the following functional form for farmers' inertia function. We use a linear form for simplicity in the absence of strong preferences for any other shape.

$$
\Delta \bar{m}_{i t}\left(\tau_{i}, m_{i, t-1}, p_{t-1},\left\{m_{j \in I_{i}, t-1}\right\}\right)=\left\{\begin{array}{ccc}
0 & \text { if } & g_{i t} \leq \delta_{i} \\
g_{i t}-\delta_{i} & \text { if } & g_{i t}>\delta_{i}
\end{array}\right.
$$

with $g_{i t}$ a measure of the motivation of (or pressure on) farmer $i$ to adopt new technologies, expressed as follows:

$$
g_{i t}=\alpha_{i} e_{i} \tau_{i}+\beta_{i}\left(m_{i, t-1}^{*}-m_{i, t-\tau_{i}}\right)+\gamma_{i}\left(\max _{j}\left\{m_{j \in I_{i}, t-1}\right\}-m_{i, t-\tau_{i}}\right),
$$

where

- $\alpha_{i}, \beta_{i}$ and $\gamma_{i}$ are coefficients $\left(\alpha_{i}, \beta_{i}, \gamma_{i} \in[0,1]\right)$,

- $\delta_{i}$ is a farmer specific threshold,

- $\tau_{i}$ is the time since the farmer last adopted new technologies,

- $m_{i, t-1}^{*}$ is the technology that would have been optimal last period (as determined by equations (2.13) and (2.14)),

- $I_{i}$ is the subset of all farmers $(i=1, \ldots, I)$ that farmer $i$ might learn from, including themselves $\left(i \in I_{i}\right)$, 
- $\max _{j}\left\{m_{j \in I_{i}, t-1}\right\}$ is the most technology adopted by any farmer that farmer $i$ might learn from.

In our functional form, a farmer's inertia depends on three factors: the time since they last adopted new technologies $\left(\tau_{i}\right)$; the difference between their technology and the technology that would have been optimal last period $\left(m_{i, t-1}^{*}-m_{i, t-\tau_{i}}\right)$; and the difference between their technology and the most technology used by any comparable farmer $\left(\max _{j}\left\{m_{j \in I_{i}, t-1}\right\}-m_{i, t-\tau_{i}}\right)$.

We use $\alpha_{i}$ to capture how often farmer $i$ replaces or updates their existing farm technologies and reviews the associated management practices $\left(\alpha_{i} \in[0,1]\right)$. Farmers with low $\alpha$ values will be more likely to have long delays between changes in technology, perhaps because they are capital constrained. We interpret $\alpha_{i}=1$ as indicating that a farmer considers updating all their existing farm technologies every year, and $\alpha_{i}=0$ as indicating that a farmer never considers updating their existing farm technologies.

We use $\beta_{i}$ to capture the business focus of the farm $\left(\beta_{i} \in[0,1]\right)$. Farmers with high $\beta$ values will be more likely to adopt additional technology when their current technologies are not optimal. This may be because they are more comfortable innovating. We interpret $\beta_{i}=1$ as indicating that a farmer is always motivated to adopt technology in order to earn more profit, and $\beta_{i}=0$ as indicating that a farmer is never motivated to adopt technology in order to earn more profit.

We use $\gamma_{i}$ to capture a farmer's willingness and ability to learn from other farmers $\left(\gamma_{i} \in[0,1]\right)$. Farmers with high $\gamma$ values will be more likely to adopt technology when other farmers have already done so. This may be because they are receptive to being social influenced or because they are resistant to implementing new technologies on their own farm until they have observed these being implemented on other farms. We interpret $\gamma_{i}=1$ as indicating that a farmer is continually seeking to learn from their networks, and $\gamma_{i}=0$ as indicating that a farmer never seeks to learn from their networks.

From (2.18) we can see that the minimum value of $g_{i t}$ is zero. While the maximum value of $g_{i t}$ is theoretically $\tau_{i} e_{i}+m_{i, t-1}^{*}+\max _{j}\left\{m_{j \in I_{i}, t-1}\right\},{ }^{9}$ in practice we may treat any value of $g_{i t}$ greater than $e_{i}+\delta_{i}$ as equal to $e_{i}+\delta_{i}$. This is because $g_{i t} \geq e_{i}+\delta_{i}$ implies that a farmer is willing to adopt technology that would cost effectively mitigate the nutrient emissions from their entire farm.

Recall that $e_{i}$ gives the emissions of farm $i$ prior to regulation. We are inter-

\footnotetext{
${ }^{9}$ The minimum value of $g_{i t}$ occurs when $\alpha_{i}=0, \beta_{i}\left(m_{i, t-1}^{*}-m_{i, t-\tau_{i}}\right)=0$ and $\gamma_{i}\left(\max _{j}\left\{m_{j \in I_{i}, t-1}\right\}-\right.$ $\left.m_{i, t-\tau_{i}}\right)=0$. The maximum value of $g_{i t}$ occurs when $\alpha_{i}, \beta_{i}, \gamma_{i}=1$, and $m_{i, t-\tau_{i}}=0$.
} 
ested in $g_{i t} / e_{i}$ : the ratio of a farmer's motivation to adopt technology against their farm's baseline nutrient emissions. We can interpret this as the proportion of the farm's baseline emissions that farmer $i$ is considering mitigating using new technology in period $t$. We treat $g_{i t} / e_{i} \geq 1$ as $g_{i t} / e_{i}=1$ : the farmer is considering adopting new technology in order to mitigate all their emissions cost effectively.

In (2.17), we use $\delta_{i}$ to capture overall resistance to change $\left(\delta_{i} \geq 0\right)$. As $\delta_{i}$ acts as a threshold for $g_{i t}$, we would expect it to take similar values to $g_{i t}$. Hence we anticipate that in practice $\delta_{i}$ will be less than or equal to $e_{i}$. Farmers with high $\delta$ values will be less likely to adopt new technologies, this may be because they have low environmental concern or prefer traditional methods of farming. We can interpret $\delta_{i} / e_{i}$ as the proportion of a farm's initial emissions which the farmer is especially resistant to changing.

It should be noted that the $\alpha_{i}$ and $\delta_{i}$ parameters do not affect farmers' inertia independently of each other. They can be used together to model 1) continuous or 2) periodic technology adoption.

1. Continuous technology adoption can occur if $\alpha_{i} e_{i}>\delta_{i}$ : so when $\tau=1, g_{i t}$ will be greater than $\delta_{i}$ and the farmer will adopt new technology.

For example: Suppose farmer $i$ will always be willing to adopt $k_{1}$ units of technology every period $\left(k_{1} \geq 0\right)$. This can be reflected in the model by choosing $\alpha_{i} e_{i}-\delta_{i}=k_{1} \cdot{ }^{10}$

2. Periodic technology adoption can occur if $\alpha_{i} e_{i}<\delta_{i}$ : so when $\tau=1, g_{i t}$ is not greater than $\delta_{i}$ and the farmer will not adopt new technology, but for some $\tau>1, g_{i t}$ will be greater than $\delta_{i}$ and the farmer will adopt new technology.

For example: Suppose farmer $i$ is willing to adopt $k_{2}$ units of technology every $k_{3}$ periods $\left(k_{2} \geq 0\right.$ and $\left.k_{3} \in \mathbb{N}\right)$. This can be reflected in the model by choosing $\delta_{i}$ large, and $k_{3} \alpha_{i} e_{i}=\delta_{i}+k_{2}$.

\subsection{Two example classifications}

The inertia function given in the previous section can reflect the farmer attitudes towards farming and change as classified by Connor et al. (2008) and Ward et al. (2008). From tables 1 and 2, we associate business focus and innovation with farmers' $\beta$ values, willingness to learn and social responsiveness with farmers' $\gamma$ values, and environmental concern with farmers' $\delta$ values. The farmers who are capital constrained will have both very low $\alpha$ values and also lower $\beta$ values, as their capital

\footnotetext{
${ }^{10}$ As there are infinitely many combinations of $\alpha_{i}$ and $\delta_{i}$ that satisfy $\alpha_{i} e_{i}-\delta_{i}=k_{1}$ we prefer the combination where $\delta_{i}=0$ and $\alpha_{i} e_{i}=k_{1}$.
} 
constraints reduce their ability to replace existing technology and to innovate. This suggests parameter values as follows:

\begin{tabular}{|ll|l|c|c|c|}
\hline Description & & $\alpha$ value & $\beta$ value & $\gamma$ value & $\delta$ value \\
\hline Business oriented & $52 \%$ & & + & - & \\
\hline Innovative & $22 \%$ & & ++ & & -- \\
\hline Traditionalists & $13 \%$ & & - & -- & ++ \\
\hline
\end{tabular}

Table 3. Inertia coefficients for farmers classified by Connor et al. (2008)

\begin{tabular}{|ll|c|c|c|c|}
\hline Description & & $\alpha$ value & $\beta$ value & $\gamma$ value & $\delta$ value \\
\hline Socially influenced & $52 \%$ & & - & ++ & + \\
\hline Innovative & $25 \%$ & & + & - & + \\
\hline Lifestyle & $10 \%$ & & -- & -- & - \\
\hline Capital Constrained & $13 \%$ & -- & - & ++ & -- \\
\hline
\end{tabular}

Table 4. Inertia coefficients for farmers classified by Ward et al. (2008)

Tables 3 and 4 indicate relative parameter values for farmers' inertia function. Cells containing $+(++)$ indicate (very) high parameter values, and cells containing - (- -) indicate (very) low parameter values. Blank cells indicate that the parameter takes moderate values.

\subsection{Expected behavior}

Consider a catchment containing farmers who differ only in the coefficients of their inertia functions $(\alpha, \beta$ and $\gamma)$. Suppose there were to be a step decrease in the total permitted level of nutrient emissions. This could be driven by the introduction of a nutrient trading scheme or a decrease in the supply of emission allowances within an established scheme. Equilibrium, with respect to this permitted level of emissions, is reached when all farmers have finished adopting new technologies and no further adoption will take place. We anticipate that the values of the $\alpha, \beta$ and $\gamma$ parameters can be set such that the inertia model captures the following response by farmers:

1. Initial inertia is high. There is minimal adoption of new technologies, most farms respond by trying to manage within their current technology and practices.

2. The price of allowances will rise and be much higher than its long run value. 
3. Some farmers' inertia will weaken, motivating them to introduce new technologies. These farmers will be the ones most motivated by profit (having high $\beta_{i}\left(m_{i, t-1}{ }^{*}-m_{i, t-1}\right)$ values $)$.

4. The price of allowances will decrease as those farmers who adopted technology now demand fewer allowances at each price.

5. Some farmers will learn from those farmers who have already adopted new technology, motivating them to also adopt new technologies. These farmers will be the ones motivated by their social and professional networks (having high $\gamma_{i}\left(\max _{j}\left\{m_{j \in I_{i}, t-1}\right\}-m_{i, t-1}\right)$ values). This will further lower the price of allowances.

6. Stages three to five will repeat as farmers acquire the technology they will use in equilibrium.

7. Some farmers may have adopted more technology that is optimal in equilibrium. These farmers will decrease the use of their excess technologies (and may increase emissions) as the price of allowances declines.

8. As farmers approach their equilibrium decisions they will adopt new technologies less frequently and in smaller amounts (driven by the $\alpha_{i} \tau_{i}$ component of $\left.g_{i t}\right)$. 


\section{Chapter 3}

\section{Two Farmer Case: Analytic Model Performance}

We consider the performance of the inertia model when there are only two farmers. This enables us to isolate and identify the effects of different parameters and interactions within the model. Recall that $m_{i t}$ is the technology used by farmer $i$ in period $t$, and that $\bar{m}_{i t}$ is the maximum technology farmer $i$ is willing to use in period $t$.

When considering scenarios with only two farmers we may define three stages depending on farmers' inertias:

1. Both farmers' inertias are binding $\left(\bar{m}_{1 t}=m_{1 t}\right.$ and $\left.\bar{m}_{2 t}=m_{2 t}\right)$, so farmers cannot yet adopt the amount of technology that would be ideal in equilibrium.

2. One farmer's inertia is non-binding, and the other farmer's inertia is binding $\left(\bar{m}_{1 t}>m_{1 t}\right.$ and $\left.\bar{m}_{2 t}=m_{2 t}\right)$. So the first farmer is willing to adopt at least the amount of technology that will be optimal in equilibrium (we calculate the minimum $\bar{m}_{i t}$ for this farmer in section 3.2), while the second farmer cannot yet adopt the amount of technology that would be ideal in equilibrium.

3. Both farmers' inertias are non-binding $\left(\bar{m}_{1 t}>m_{1 t}\right.$ and $\left.\bar{m}_{2 t}>m_{2 t}\right)$, so both farmers are willing to adopt the amount of technology that is ideal in equilibrium.

These stages partition the time since the introduction of nutrient regulation. We will always label our farmers so that $\bar{m}_{1 t} \geq \bar{m}_{2 t}$ and $m_{1 t} \geq m_{2 t}$.

During stage one, both farmers' technology adoption is limited by their inertia. As each farmer's inertia weakens they will both adopt more technology. Eventually, one farmer's inertia will weaken sufficiently that it becomes non-binding. At this point stage one ends and stage two begins (unless both farmers' inertias become non-binding in the same period, in this case stage three begins). 
During stage two, only one farmer's technology adoption is limited by their inertia. As this farmer's inertia weakens they will adopt more technology. Eventually their inertia will weaken sufficiently that it becomes non-binding. At this point stage two ends and stage three begins. Through stage two, the other farmer uses the optimal level of technology $\left(m_{i t}=m_{i t}^{*}\right)$ as given by (2.13).

Stage three is the ideal long run equilibrium for both farmers. Neither farmer's inertia is binding and both farmers are willing to adopt the optimal level of technology. As a result their total combined profits are maximized. The outcomes under stage three are identical to the outcomes under the static economic model (given by equations (2.4) - (2.5)). If both farmers have identical profit functions (as we consider in this chapter) then both farmers will hold half the nutrient allowances each.

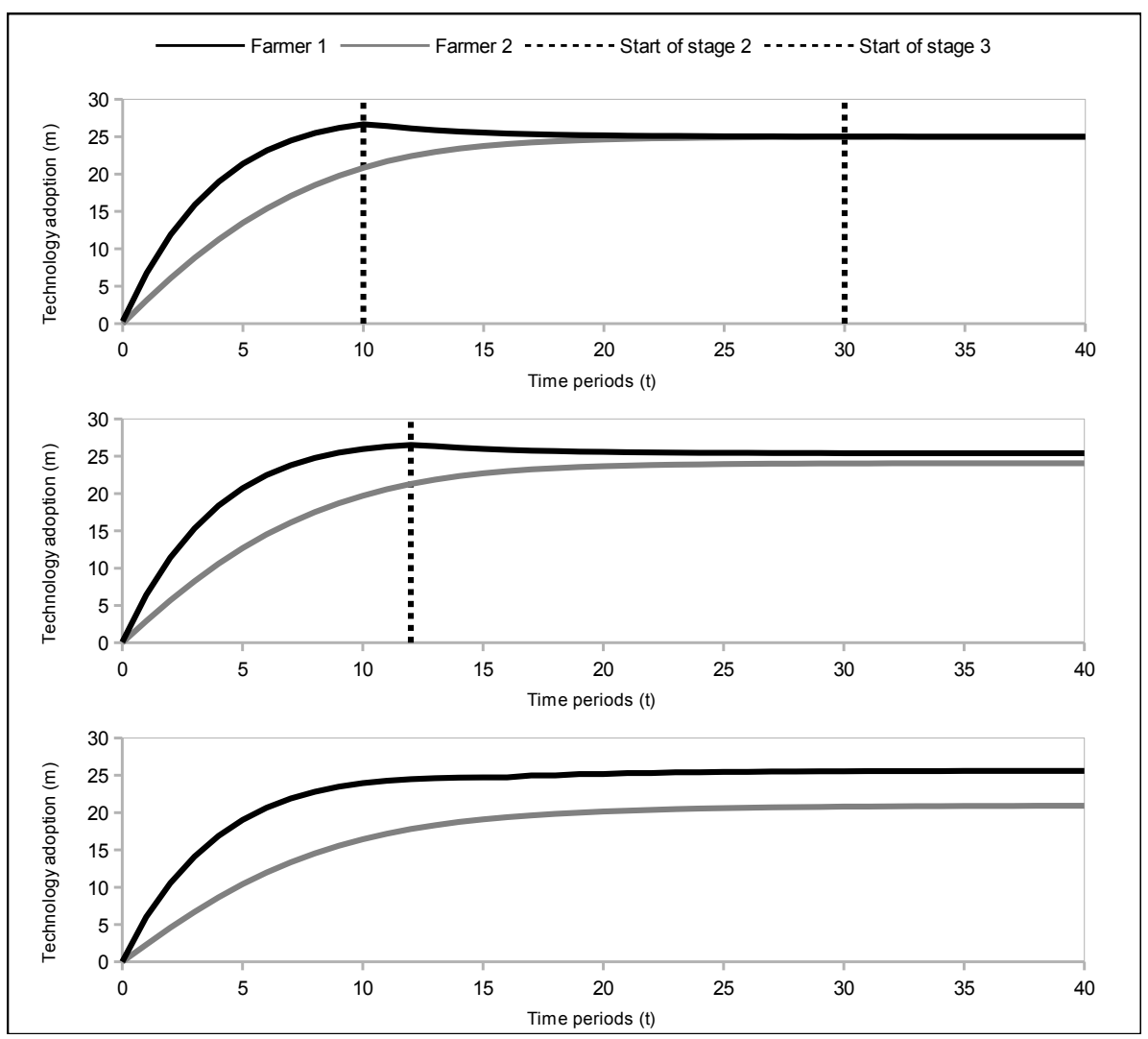

Figure 3. Farmers technology adoption over time

Note that, farmers' $\delta_{i}$ values can prevent stage one transitioning to stage two and stage two transitioning to stage three. Where this occurs a pair of farmers may never reach stage three, instead attaining an alternative equilibrium in stage two or one. Figure 3 gives an example of farmers reaching equilibrium in each of the stages. For each panel in figure 3 farmers have reached equilibrium by period $40 .^{1}$

\footnotetext{
${ }^{1}$ Figure 3 has been generated by solving a numerical version of the two farmer model when $\alpha_{1}=$ $0.006, \beta_{1}=0.1, \gamma_{1}=0.02, \alpha_{2}=0, \beta_{2}=0.05$, and $\gamma_{2}=0.1$. The $\delta_{i}$ values are $0,0.2$ and 0.8 for both farmers in the first, second and third panels respectively. The parameter values for both farms' profit
} 
Panel 1 of figure 3 illustrates the case where equilibrium is reached in stage three. This is the ideal outcome as both farmers adopt their optimal level of technology $\left(m_{i t}^{*}\right)$ in the long run. Equilibrium is reached in stage three when first one farmer's and then the other farmer's inertia becomes non-binding. This must occur where $\delta_{1}, \delta_{2}=0$ (as in our example) but may also occur when $\delta_{1}$ and $\delta_{2}$ take small values. So, while both farmers may have some resistance to change $\left(\delta_{i}\right)$ this is overcome by their motivation to change $\left(g_{i t}\right)$.

Panel 2 of figure 3 illustrates the case where equilibrium is reached in stage two. This occurs where the first farmers' inertia becomes non-binding but the second farmers' inertia will always be binding. So, while both farmers are willing to make changes on their farms, for the second farmer their motivation to change $\left(g_{2 t}\right)$ can not overcome their resistance to change $\left(\delta_{2}\right)$ in the long run. This means that, the second farmer's inertia is binding $\left(m_{2 t}=\bar{m}_{2 t}\right)$ and their inertia will not weaken $\left(\Delta \bar{m}_{2 t}=0\right)$.

Panel 3 of figure 3 illustrates the case where equilibrium is reached in stage one. This occurs where neither farmers' inertia ever becomes non-binding. So, while both farmers are willing to make some changes on their farms, their motivation to change $\left(g_{i t}\right)$ can not overcome their resistance to change $\left(\delta_{i}\right)$ in the long run.

\subsection{Prices and allowance holdings}

In this section we determine the market price of allowances and farmers' allowance holdings, for each stage, as functions of the nutrient cap $\left(\bar{N}_{t}\right)$ and farmers' inertia $\left(\bar{m}_{i t}\right)$. These results are important for considering different aspects of the model in sections 3.2 to 3.4. In order to focus on the effects of inertia, we will assume farmers have identical profit functions $\left(a, b, c, d\right.$ and $e$ values) and initial technology $\left(m_{t-1}\right)$, and only differ in their inertia $\left(\bar{m}_{i t}\right)$. While farms may have significantly different profit functions and initial technology in practice, these assumptions enable us to consider two representative farms. For ease of notation we suppress the $t$ subscripts.

Stage 1. Both farmers' inertias are binding $\left(\bar{m}_{1}=m_{1}\right.$ and $\left.\bar{m}_{2}=m_{2}\right)$.

The presence of a binding nutrient cap implies $\bar{N}=n_{1}+n_{2}$. As both farmers' inertias are binding their demand for allowances is given by (2.15). It follows that the price of allowances will be such that:

$$
\bar{N}=n_{1}+n_{2}=\frac{p-b+2 d\left(e-\bar{m}_{1}\right)}{2 a+2 d}+\frac{p-b+2 d\left(e-\bar{m}_{2}\right)}{2 a+2 d} .
$$

$\overline{\text { functions are } a_{i}=-0.3347, b_{i}=41.46, c_{i}}=92.22, d_{i}=-0.5, e_{i}=50$ and $q_{i}=0$. 
Rearranging with respect to $p$ gives:

$$
p=a \bar{N}+b+q-d\left(2 e-\bar{N}-\bar{m}_{1}-\bar{m}_{2}+\frac{q}{d}\right) .
$$

Substituting (3.1) into farmers' demand for allowances (2.15) gives the nutrient emissions and allowance holdings for farmers 1 and 2 as follows:

$$
\begin{aligned}
& n_{1}=\frac{\bar{N}}{2}-\frac{d}{2 a+2 d}\left(\bar{m}_{1}-\bar{m}_{2}\right), \\
& n_{2}=\frac{\bar{N}}{2}+\frac{d}{2 a+2 d}\left(\bar{m}_{1}-\bar{m}_{2}\right) .
\end{aligned}
$$

Stage 2. Only one farmer's inertia is binding $\left(\bar{m}_{1}>m_{1}\right.$ and $\left.\bar{m}_{2}=m_{2}\right)$.

The presence of a binding cap implies $\bar{N}=n_{1}+n_{2}$. Farmers demand for allowances is given by (2.14) and (2.15), when their inertia is non-binding and binding, respectively. It follows that the price of allowances will be such that:

$$
\bar{N}=n_{1}+n_{2}=\frac{p-b-q}{2 a}+\frac{p-b+2 d\left(e-\bar{m}_{2}\right)}{2 a+2 d} .
$$

Rearranging with respect to $p$ gives:

$$
p=a \bar{N}+b+q-\frac{a d}{2 a+d}\left(2 e-\bar{N}-2 \bar{m}_{2}+\frac{q}{d}\right) .
$$

Substituting (3.3) into farmers' demand for allowances (2.14) and (2.15) gives the nutrient emissions and allowance holdings for farmers 1 and 2 as follows:

$$
\begin{aligned}
& n_{1}=\frac{\bar{N}}{2}-\frac{d}{2 a+d}\left(e-\bar{m}_{2}-\bar{N} / 2+\frac{q}{2 d}\right), \\
& n_{2}=\frac{\bar{N}}{2}+\frac{d}{2 a+d}\left(e-\bar{m}_{2}-\bar{N} / 2+\frac{q}{2 d}\right) .
\end{aligned}
$$

Stage 3. Neither farmers' inertias are binding $\left(\bar{m}_{1}>m_{1}\right.$ and $\left.\bar{m}_{2}>m_{2}\right)$.

The presence of a binding nutrient cap implies $\bar{N}=n_{1}+n_{2}$. As both farmers' inertias are non-binding their demand for allowances is given by (2.14). It follows that the price of allowances will be such that:

$$
\bar{N}=n_{1}+n_{2}=\frac{p-b-q}{2 a}+\frac{p-b-q}{2 a} .
$$

Rearranging with respect to $p$ gives:

$$
p=a \bar{N}+b+q .
$$

Substituting (3.5) into farmers' demand for allowances (2.14) gives the nutrient emissions and allowance holdings for farmers 1 and 2 as follows:

$$
n_{1}=n_{2}=\frac{\bar{N}}{2}
$$


We observe that both the market price $(p)$ and farmers' nutrient emissions and allowance holdings $\left(n_{i}\right)$ can be expressed as their ideal long run (stage three) value plus some measure of distance from this ideal value. As farmers' inertia weakens these distances will decrease and the outcomes under the inertia model will approach the outcomes under the static economic model (given by equations (2.4) (2.5)).

\subsection{Transitions between stages}

We have identified three stages that occur in the two farmer model. In this section, we are concerned with transitions between these stages. We first show that the price of allowances decreases as we move from stage one through to stage three, and go on to identify when transitions between stages occur as functions of $\bar{m}_{1 t}$ and $\bar{m}_{2 t}$.

Proposition 2. The prices of nutrient allowances in stage two will never exceed the prices in stage one ( $\left.p^{\text {stage } 1} \geq p^{\text {stage } 2}\right)$, and the prices in stage three will never exceed the prices in stage two ( $\left.p^{\text {stage } 2} \geq p^{\text {stage } 3}\right)$.

Proof. It is clear from (3.1), (3.3) and (3.5) that the price of nutrient allowances is non-increasing during any given stage (for a fixed nutrient cap). We therefore only need to consider the price of allowances where stage one ends and stage two begin, and also where stage two ends and stage three begins. We will consider each pair of stages in turn.

Stage 1 and stage 2. The change in price when the first farmer's inertia becomes nonbinding.

$$
\begin{aligned}
p^{\text {stage } 1}-p^{\text {stage } 2} & =-d\left(2 e-\bar{N}-\bar{m}_{1}-\bar{m}_{2}+\frac{q}{d}\right)+\frac{a d}{2 a+d}\left(2 e-\bar{N}-2 \bar{m}_{2}+\frac{q}{d}\right) \\
& >-d\left(2 e-\bar{N}-2 \bar{m}_{2}+\frac{q}{d}\right)+\frac{a d}{2 a+d}\left(2 e-\bar{N}-2 \bar{m}_{2}+\frac{q}{d}\right) \\
& =d\left(2 e-\bar{N}-2 \bar{m}_{2}+\frac{q}{d}\right)\left(\frac{a}{2 a+d}-1\right),
\end{aligned}
$$

which must be non-negative as $a, d<0, \frac{a}{2 a+d}<1$ and $\bar{m}_{2} \leq e-\bar{N} / 2+q / 2 d$.

Stage 2 and stage 3 . The change in price when the second farmer's inertia becomes nonbinding.

$$
\begin{aligned}
p^{\text {stage } 2}-p^{\text {stage } 3} & =a \bar{N}+b-\frac{a d}{2 a+d}\left(2 e-\bar{N}-2 \bar{m}_{2}\right)+\frac{a+d}{2 a+d} q-a \bar{N}-b-q \\
& =-\frac{a d}{2 a+d}\left(2 e-\bar{N}-2 \bar{m}_{2}+\frac{q}{d}\right),
\end{aligned}
$$

which must be non-negative as $a, d<0$ and $\bar{m}_{2} \leq e-\bar{N} / 2+q / 2 d$. 
Hence, the price of allowances is non-increasing as we move from stage one to stage two, and as we move from stage two to stage three.

This supports our description of the expected behavior of the model in section 2.7. It also suggests that a higher price of allowances in the short run may be necessary to motivate farmers to adopt new technologies.

Transitions between stages in a two farmer system can be defined by farmers' inertia constraints (a transition can be identified by $\bar{m}_{i, t-1}=m_{i, t-1}$ and $\bar{m}_{i t}>m_{i t}$ for any farmer $i$ ). We next identify when these transitions will occur as functions of $\bar{m}_{1 t}$ and $\bar{m}_{2 t}$.

From proposition 2 we have shown that the price of nutrient allowances is non-increasing (for any given $\bar{m}_{i t}$ ) as we move from stage one through to stage three. It follows that transitions between stages occur at the $\bar{m}_{i t}$ such that the price difference between the two stages in question is zero. ${ }^{2}$

Hence, stage one transitions to stage two when $\bar{m}_{1 t}$ and $\bar{m}_{2 t}$ are such that $p^{\text {stage } 1}-p^{\text {stage } 2} \leq 0$. This occurs when:

$$
\bar{m}_{1 t} \geq \bar{m}_{2 t}+\frac{a+d}{2 a+d}\left(2 e-\bar{N}-2 \bar{m}_{2 t}+q / d\right) \text {. }
$$

We will denote the period in which stage one transitions to stage two, i.e., the first period in which (3.7) is true, as $t_{2}$. Farmers' technology adoption decisions in this period can be denoted $m_{i, t_{2}}$. It is straightforward to show that the technology used by the first farmer immediately after their inertia becomes non-binding $\left(m_{1, t_{2}}\right)$ is equal to the right hand-side of (3.7).

Furthermore, stage two transitions to stage three when $\bar{m}_{2 t}$ is such that $p^{\text {stage } 2}-$ $p^{\text {stage } 3} \leq 0$. This occurs when:

$$
\bar{m}_{2 t} \geq e-\frac{\bar{N}}{2}+\frac{q}{2 d} .
$$

This result is as expected as the right hand-side of the above equation is the ideal equilibrium technology adoption of farmer 2 (as given by (2.13) and (3.6)). We will denote the period in which stage two transitions to stage three as $t_{3}$.

\subsection{Profitability}

We expect that as farmers' inertias weaken and they adopt more technology, that they will require fewer nutrient allowances and will earn higher profits. In this sec-

\footnotetext{
${ }^{2}$ This defines the boundary at which transitions between stages occur. In practice a transition between stages must have occurred if the $\bar{m}_{i t}$ are such that the price difference between the two stages in question is zero or negative.
} 
tion we show that the functional forms we have chosen for our model are consistent with these expectations. Our proofs draw on the prices of allowances and farmers' allowances holdings specified in section 3.1. For ease of notation we suppress the $t$ subscripts. Where stage three is trivial we omit it from the following proofs.

Proposition 3. Given two farmers with identical profit functions, the farmer who is more willing to adopt technology will hold fewer nutrient allowances $\left(\bar{m}_{1} \geq \bar{m}_{2}\right.$ implies $\left.n_{1} \leq n_{2}\right)$.

Proof. We will consider each of the stages in turn.

Stage 1. Both farmers' inertias are binding $\left(\bar{m}_{1}=m_{1}\right.$ and $\left.\bar{m}_{2}=m_{2}\right)$.

$$
\begin{aligned}
n_{1}-n_{2} & =\left(\frac{\bar{N}}{2}-\frac{d}{2 a+2 d}\left(\bar{m}_{1}-\bar{m}_{2}\right)\right)-\left(\frac{\bar{N}}{2}+\frac{d}{2 a+2 d}\left(\bar{m}_{1}-\bar{m}_{2}\right)\right) \\
& =-\frac{2 d}{2 a+2 d}\left(\bar{m}_{1}-\bar{m}_{2}\right)
\end{aligned}
$$

which must be non-positive as $a, d<0$ and $\bar{m}_{1} \geq \bar{m}_{2}$. Therefore $n_{1} \leq n_{2}$.

Stage 2. Only one farmer's inertia is binding $\left(\bar{m}_{1}>m_{1}\right.$ and $\left.\bar{m}_{2}=m_{2}\right)$.

$$
\begin{aligned}
n_{1}-n_{2} & =\left(\frac{\bar{N}}{2}-\frac{d}{2 a+d}\left(e-\bar{m}_{2}-\frac{\bar{N}}{2}+\frac{q}{2 d}\right)\right)-\left(\frac{\bar{N}}{2}+\frac{d}{2 a+d}\left(e-\bar{m}_{2}-\frac{\bar{N}}{2}+\frac{q}{2 d}\right)\right) \\
& =-\frac{2 d}{2 a+d}\left(e-\bar{m}_{2}-\bar{N} / 2+\frac{q}{2 d}\right)
\end{aligned}
$$

which must be non-positive as $a, d<0$ and $\bar{m}_{2}<e-\bar{N} / 2+q / 2 d$.

Hence, for two farmers with identical profit functions $\bar{m}_{1} \geq \bar{m}_{2}$ implies $n_{1} \leq n_{2}$.

It follows from proposition 3 that farmers' demand for nutrient allowances declines as they adopt technology. This is consistent with the result from proposition 2 , the price of allowances declines as farmers adopt technology. So, we observe that as the demand for allowances declines, the price of allowances also declines (note that the supply of allowances is constant and equal to the nutrient cap).

Proposition 4. Given two farmers with identical profit functions, the farmer who is more willing to adopt technology will be more profitable $\left(\bar{m}_{1} \geq \bar{m}_{2}\right.$ implies $\left.f_{1} \geq f_{2}\right)$.

Proof. We will consider each of the stages in turn.

Stage 1. Both farmers' inertias are binding $\left(\bar{m}_{1}=m_{1}\right.$ and $\left.\bar{m}_{2}=m_{2}\right)$. 
As in section 2.4, we will use $f_{i t}\left(m_{i t}, n_{i t}\right)$ to denote the profit from farm $i$ net of the value of allowances: $f_{i t}\left(m_{i t}, n_{i t}\right)=\pi_{i}\left(m_{i t}, n_{i t}\right)-p_{t} n_{i t}$.

$$
\begin{aligned}
f_{1}-f_{2} & =(a+d)\left(n_{1}^{2}-n_{2}^{2}\right)+(b-p-2 d e)\left(n_{1}-n_{2}\right)+2 d\left(n_{1} \bar{m}_{1}-n_{2} \bar{m}_{2}\right) \\
& +d\left(\bar{m}_{1}^{2}-\bar{m}_{2}^{2}\right)-2 d e\left(\bar{m}_{1}-\bar{m}_{2}\right)-q\left(\bar{m}_{1}-\bar{m}_{2}\right) \\
& =\frac{-2 a d}{a+d}\left(\bar{m}_{1}-\bar{m}_{2}\right)\left(e-\frac{p-b-q}{2 a}-\frac{\bar{m}_{1}+\bar{m}_{2}}{2}+\frac{q}{2 d}\right)
\end{aligned}
$$

given $n_{1}$ and $n_{2}$ as defined in (3.2). $f_{1}-f_{2}$ must be non-negative as $a, d<0, \bar{m}_{1} \geq \bar{m}_{2}$, and the last term can be show to be positive from proposition 1 and (2.16).

Stage 2. Only one farmer's inertia is binding $\left(\bar{m}_{1}>m_{1}\right.$ and $\left.\bar{m}_{2}=m_{2}\right)$.

$$
\begin{gathered}
f_{1}-f_{2}=a\left(n_{1}{ }^{2}-n_{2}{ }^{2}\right)+(b-p)\left(n_{1}-n_{2}\right)-d\left(e-n_{2}-\bar{m}_{2}\right)^{2} \\
-q\left(e-n_{1}-\bar{m}_{2}+\frac{q}{2 d}\right)+\frac{q^{2}}{4 d} \\
=\frac{-4 a d(a+d)}{(2 a+d)^{2}}\left(e-\bar{N} / 2-\bar{m}_{2}+\frac{q}{2 d}\right)^{2},
\end{gathered}
$$

given $n_{1}$ and $n_{2}$ as defined in (3.4). This must be positive as all terms are positive.

Hence, for two farmers with identical profit functions $\bar{m}_{1} \geq \bar{m}_{2}$ implies $f_{1} \geq f_{2}$.

This result is consistent with our expectations, farmers who adopt more technology (and hence carry out more mitigation cost effectively) will be more profitable. In addition, this result implies that farmers always have a profit based incentive to adopt technology whenever their inertia is binding.

Proposition 5. Given two farmers with identical profit functions, if $\bar{m}_{j}$ is binding then $f_{i}$ $(i=1,2)$ is increasing in $\bar{m}_{j}$ for any $j=1,2$. So, increasing $\bar{m}_{j}$ will increase the profits of both farmers net of the value of allowances.

Proof. From proposition 4 we have effectively shown that $\frac{\partial f_{i}}{\partial \bar{m}_{j}}>0$ whenever $i=j$. We therefore only need to show that the relationship holds for $i \neq j$.

Stage 1. Both farmers' inertias are binding $\left(\bar{m}_{1}=m_{1}\right.$ and $\left.\bar{m}_{2}=m_{2}\right)$.

$$
\begin{aligned}
\frac{\partial f_{i}}{\partial \bar{m}_{j}} & =2 a n_{i} \frac{\partial n_{i}}{\partial \bar{m}_{j}}+b \frac{\partial n_{i}}{\partial \bar{m}_{j}}+2 d\left(e-n_{i}-\bar{m}_{i}\right)\left(-\frac{\partial n_{i}}{\partial \bar{m}_{j}}\right)-\frac{\partial p}{\partial \bar{m}_{j}} n_{i}-p \frac{\partial n_{i}}{\partial \bar{m}_{j}} \\
& =\frac{2 a d}{2 a+2 d} n_{i}+\frac{b d}{2 a+2 d}-\frac{2 d^{2}}{2 a+2 d}\left(e-n_{i}-\bar{m}_{i}\right)-d n_{i}-\frac{p d}{2 a+2 d} \\
& =\frac{d}{2 a+2 d}\left[(b-p)-2 d\left(e-\bar{m}_{i}\right)\right],
\end{aligned}
$$

where the third line follows from the second as $\frac{\partial n_{i}}{\partial \bar{m}_{j}}=\frac{d}{2 a+2 d}$ and $\frac{\partial p}{\partial \bar{m}_{j}}=d$. This implies $\frac{\partial f_{i}}{\partial \bar{m}_{j}}$ must be greater than zero as $a, d<0, b>p$, and $e>\bar{m}_{i}$. 
Stage 2. Only one farmer's inertia is binding $\left(\bar{m}_{1}>m_{1}\right.$ and $\left.\bar{m}_{2}=m_{2}\right)$.

In this stage we ignore $\bar{m}_{1}$ as it is non-binding and focus on $\bar{m}_{2}$.

$$
\begin{aligned}
\frac{\partial f_{1}}{\partial \bar{m}_{2}} & =2 a n_{1} \frac{\partial n_{1}}{\partial \bar{m}_{2}}+b \frac{\partial n_{1}}{\partial \bar{m}_{2}} q \frac{\partial n_{1}}{\partial \bar{m}_{2}}-\frac{\partial p}{\partial \bar{m}_{2}} n_{1}-p \frac{\partial n_{1}}{\partial \bar{m}_{2}} \\
& =\frac{2 a d}{2 a+d} n_{1}+\frac{b d}{2 a+d}+\frac{q d}{2 a+d}-\frac{2 a d}{2 a+d} n_{1}-\frac{p d}{2 a+d} \\
& =\frac{d}{2 a+d}(b+q-p),
\end{aligned}
$$

where the third lines follows from the second as $\frac{\partial n_{1}}{\partial \bar{m}_{2}}=\frac{d}{2 a+d}$ and $\frac{\partial p}{\partial \bar{m}_{2}}=\frac{2 a d}{2 a+d}$. This implies $\frac{\partial f_{1}}{\partial \bar{m}_{2}}$ must be greater than zero as $a, d<0$, and $b+q>p$.

Hence, we have shown in the two farmer case that if $\bar{m}_{j}$ is binding, profit for all farmers is increasing in $\bar{m}_{j}$.

These results are important as they suggest that there are synergy effects. More technology adopted by one farmer has a positive spill over effect to other farmers: As a farmer adopts more technology their profit increases even while their demand for allowances decreases. This lowers the price of allowances and frees up allowances for other farmers, increasing their profits as well. The presence of these synergy effects is a potential justification for a regulator to provide incentives for farmers to adopt additional technologies or practices. While a single farmer bears the cost of adopting technology, many farmers may benefit from the technology adoption.

\subsection{Mitigation decisions for two farmers}

In this section we derive analytic results for farmers' technology adoption over time in several special cases of the two farmer model. For our special cases, farmers only differ in their inertia coefficients, so both farmers have identical profit functions. To isolate the different determinants of farmers' technology adoption we require that only one of $\alpha_{i}, \beta_{i}$ and $\gamma_{i}$ may be non-zero for each farmer, and that $\delta_{i}=0$ for both farmers. ${ }^{3}$ The special cases are as follows:

- Special Case 1. Both farmers only adopt new technologies as they update their existing farm technologies. Hence $\alpha_{1}$ and $\alpha_{2}$ are non-zero.

\footnotetext{
${ }^{3}$ We do not consider all possible combinations of $\alpha_{i}, \beta_{i}$ and $\gamma_{i}$ in our special cases. We omit the special case when $\alpha_{1}$ and $\beta_{2}$ (or $\beta_{1}$ and $\alpha_{2}$ ) are non-zero, as the outcomes in this special case depend on the relative magnitudes of the farmers' $\alpha$ and $\beta$ values. We omit the special case when $\gamma_{1}$ and $\gamma_{2}$ are non-zero. In this special case neither farmer will adopt technology, because both farmers only adopt technology in response to observing adoption by the other farmer.
} 
- Special Case 2. Both farmers only adopt new technology when their existing technologies are not optimal, and both farmers always adopt the same technology. Hence $\beta_{1}$ and $\beta_{2}$ are non-zero and $\beta_{1}=\beta_{2}$.

- Special Case 3. Both farmers only adopt new technology when their existing technologies are not optimal, and one farmer tends to adopt more technology than the other farmer. Hence $\beta_{1}$ and $\beta_{2}$ are non-zero and $\beta_{1}>\beta_{2}$.

- Special Case 4. One farmer only adopts new technology as they update their existing farm technologies, while the other farmer only adopts new technology in response to observing adoption by the first farmer. Hence $\alpha_{1}$ and $\gamma_{2}$ are nonzero.

- Special Case 5. One farmer only adopts new technology when their existing technologies are not optimal, while the other farmer only adopts new technology in response to observing adoption by the first farmer. Hence $\beta_{1}$ and $\gamma_{2}$ are non-zero.

For all the special cases, we will consider the introduction of nutrient regulation, at $t=1$, with a constant cap $(\bar{N})$. In the absence of regulation at $t=0$, we will assume $p_{0}=0, \bar{m}_{i 0}=0$, and $n_{i 0}=e_{i}$ for all $i$.

Note that for all five special cases, the farmer who initially adopts the most technology (in periods 1 or 2) will never have less technology than the other farmer. Hence, without loss of generality we label our farmers 1 and 2 , such that $\bar{m}_{1 t} \geq \bar{m}_{2 t}$ and $m_{1 t} \geq m_{2 t}$ for all $t$.

Analytic solutions to these special cases require us to consider farmers' technology adoption under each of the three stages. As all five special cases have the same result for stage three, we give it here rather than repeating it with each solution below:

In stage three neither farmer's inertia is binding $\left(\bar{m}_{1 t}>m_{1 t}\right.$ and $\left.\bar{m}_{2 t}>m_{2 t}\right)$, so both farmers are willing to adopt the amount of technology that is optimal in equilibrium. Let period $t_{3}$ be the first period in which stage three occurs. It follows from (2.13) and (3.6) that $\forall t \geq t_{3}: m_{1 t}=m_{2 t}=e-\bar{N} / 2+q / 2 d$.

We next consider each of the special cases in turn. Following the analytic results of each special case, we provide figures to demonstrate farmers' technology adoption. Figures 4 to 8 are drawn from numerical solutions to the inertia model in the two-farmer case, and are consistent with the analytic solutions. ${ }^{4}$

\footnotetext{
${ }^{4}$ The numerical solutions for figures 4 to 8 use the same $a, b, c, d, e$ and $q$ values as are used for figure 3.
} 
Special Case 1. Both farmers only adopt new technologies as they update their existing farm technologies ( $\alpha_{1}$ and $\alpha_{2}$ are non-zero).

Assume $\tau_{i}=0$ for both farmers. As $\delta_{i}=0$, farmer $i$ will be willing to adopt $\alpha_{i} e$ additional technology each period. If we require $\alpha_{1}>\alpha_{2}$ then $\bar{m}_{1 t} \geq \bar{m}_{2 t}$ for all $t$. We will consider each stage in turn.

Stage 1. Both farmers' inertias are binding $\left(\bar{m}_{1}=m_{1}\right.$ and $\left.\bar{m}_{2}=m_{2}\right)$.

As both $\bar{m}_{1 t}$ and $\bar{m}_{2 t}$ are binding, it follows that $m_{1 t}=\bar{m}_{1 t}$ and $m_{2 t}=\bar{m}_{2 t}$.

$$
\begin{aligned}
m_{1 t} & =m_{1, t-1}+\alpha_{1} e \\
& =\alpha_{1} e t \\
m_{2 t} & =m_{2, t-1}+\alpha_{2} e \\
& =\alpha_{2} e t
\end{aligned}
$$

Stage 2. Only one farmer's inertia is binding $\left(\bar{m}_{1}>m_{1}\right.$ and $\left.\bar{m}_{2}=m_{2}\right)$.

As only $\bar{m}_{2 t}$ is binding and $\bar{m}_{1 t}$ is non-binding, it follows that $m_{2 t}=\bar{m}_{2 t}$ and $m_{1 t}=e-n_{1 t}+q / 2 d$.

$$
\begin{aligned}
m_{2 t} & =\alpha_{2} e t \\
m_{1 t} & =e-\bar{N} / 2+\frac{q}{2 d}+\frac{d}{2 a+d}\left(e-\frac{\bar{N}}{2}-m_{2 t}+\frac{q}{2 d}\right) \\
& =e-\bar{N} / 2+\frac{q}{2 d}+\frac{d}{2 a+d}\left(e-\frac{\bar{N}}{2}-\alpha_{2} e t+\frac{q}{2 d}\right)
\end{aligned}
$$

Figure 4 illustrates farmers' technology adoption $\left(m_{i t}\right)$ over time in special case 1 . This figure has been drawn with $\alpha_{1} e=2$ and $\alpha_{2} e=1$.

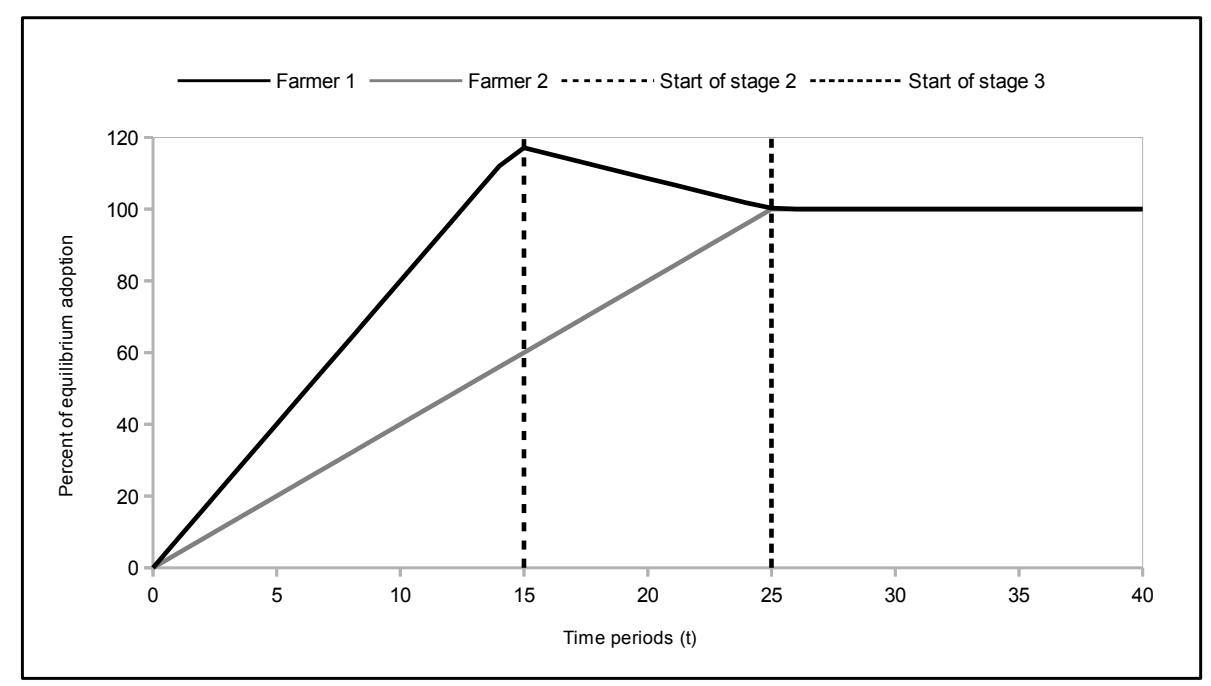

Figure 4. Farmers' technology adoption over time (special case 1) 
It is clear from special case 1 that the length of stage one decreases as both $\alpha_{1}$ and $\alpha_{2}$ increase, and that the length of stage two decreases as $\alpha_{2}$ increases. This is as expected: the faster farmers adopt new technology the sooner they will reach equilibrium.

It is important to note that the model allows for farmer 1 to adopt more technology in the short run (before equilibrium is reached) than is optimal in the long run. This behavior will be partly due to the assumption that decision makers are short-sighted. Where technology adoption is costly, forward looking decision makers may avoid adopting technology that they will not need in the long run. So technology use by farmer 1 from year 13 to year 20 is likely to be less than suggested by figure 4 . However, we may still expect farmer 1 to adopt more technology in the short run than is optimal in the long run: If farmer 2 is slow to adopt technology, then the benefits to farmer 1 from temporarily adopting additional technology may exceeds the costs.

Special Case 2. Both farmers only adopt new technology when their existing technologies are not optimal, and both farmers always adopt the same technology ( $\beta_{1}$ and $\beta_{2}$ are non-zero, and $\beta_{1}=\beta_{2}$ ).

As the $\beta$ terms are identical, $m_{1 t}=m_{2 t}$ and $\bar{m}_{1 t}=\bar{m}_{2 t}$ for all $t$. It follows that stage one will tend to stage three directly and stage two will not occur.

Stage 1. Both farmers' inertias are binding $\left(\bar{m}_{1}=m_{1}\right.$ and $\left.\bar{m}_{2}=m_{2}\right)$.

In this stage, as we have $m_{1 t}=\bar{m}_{1 t}=\bar{m}_{2 t}=m_{2 t}$ we suppress the $i$ subscripts.

$$
\begin{aligned}
m_{t} & =m_{t-1}+\beta\left(e-\frac{p_{t-1}-b}{2 a}+\frac{q}{2 d}-m_{t-1}\right) \\
& =\left(1-\beta-\frac{\beta d}{a}\right) m_{t-1}+\beta\left(1+\frac{d}{a}\right)\left(e-\bar{N} / 2+\frac{q}{2 d}\right) \\
& =\left(e-\bar{N} / 2+\frac{q}{2 d}\right)\left(1-\left(1-\beta-\frac{\beta d}{a}\right)^{t-1}\right)
\end{aligned}
$$

Figure 5 illustrates farmers' technology adoption $\left(m_{i t}\right)$ over time in special case 2 . This figure has been drawn with $\beta_{1}=\beta_{2}=0.1$. Due to the initial conditions and the one-period lag in the inertia function, farmers' technology adoption starts from zero in period one and is non-zero from period two onwards. 


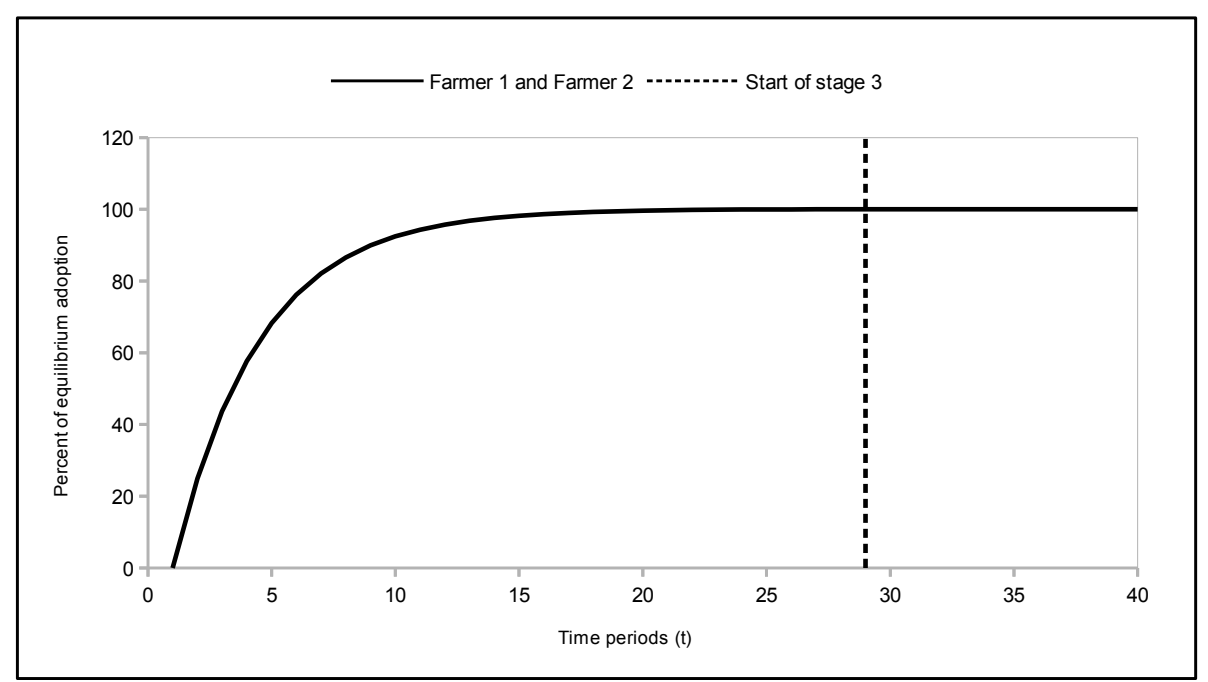

Figure 5. Farmers' technology adoption over time (special case 2)

It is clear from special case 2 that farmers' motivation to adopt technology when their existing technologies are not optimal declines exponentially with their adoption of new technology. This means that business oriented farmers' adopt the majority of their technology in the years immediately following the introduction of regulation, and the remainder of their technology much more slowly.

We note that farmers' adoption of technology is slow when $\beta(1+d / a)$ is close to 0 and faster as $\beta(1+d / a)$ approaches 1 . Parameter choices that result in $\beta(1+d / a)$ greater than 1 suggest that farmers are willing to adopt their equilibrium amount of technology as soon as they realize it is profitable (adjustment is instantaneous).

Special Case 3. Both farmers only adopt new technology when their existing technologies are not optimal, and one farmer tends to adopt more technology than the other farmer ( $\beta_{1}$ and $\beta_{2}$ are non-zero, and $\beta_{1}>\beta_{2}$ ).

If we require $\beta_{1}>\beta_{2}$ then $\bar{m}_{1 t} \geq \bar{m}_{2 t}$ for all $t$. We will consider each stage in turn.

Stage 1. Both farmers' inertias are binding $\left(\bar{m}_{1}=m_{1}\right.$ and $\left.\bar{m}_{2}=m_{2}\right)$.

As both $\bar{m}_{1 t}$ and $\bar{m}_{2 t}$ are binding, if follows that $m_{1 t}=\bar{m}_{1 t}$ and $m_{2 t}=\bar{m}_{2 t}$.

$$
\begin{aligned}
m_{1 t} & =m_{1, t-1}+\beta_{1}\left(e-\frac{p_{t-1}-b-q}{2 a}+\frac{q}{2 d}-m_{1, t-1}\right) \\
& =\left(1-\beta_{1}-\frac{\beta_{1} d}{2 a}\right) m_{1, t-1}-\frac{\beta_{1} d}{2 a} m_{2, t-1}+\beta_{1}\left(1+\frac{d}{a}\right)\left(e-\bar{N} / 2+\frac{q}{2 d}\right), \\
m_{2 t} & =m_{2, t-1}+\beta_{2}\left(e-\frac{p_{t-1}-b-q}{2 a}+\frac{q}{2 d}-m_{2, t-1}\right) \\
& =\left(1-\beta_{2}-\frac{\beta_{2} d}{2 a}\right) m_{2, t-1}-\frac{\beta_{2} d}{2 a} m_{1, t-1}+\beta_{2}\left(1+\frac{d}{a}\right)\left(e-\bar{N} / 2+\frac{q}{2 d}\right) .
\end{aligned}
$$

This relationship defines a system of first order linear difference equations. This system can be solved according to the methodology given in appendix $\mathrm{C}$. 
We can construct the following upper bound for technology adoption, if we ignore the $\frac{\beta_{1} d}{2 a} m_{2, t-1}$ and $\frac{\beta_{2} d}{2 a} m_{1, t-1}$ terms in the expressions for $m_{1 t}$ and $m_{2 t}$ respectively:

$$
m_{i t}=\left(e-\bar{N} / 2+\frac{q}{2 d}\right)\left(1-\left(1-\beta_{i}-\frac{\beta_{i} d}{2 a}\right)^{t-1}\right)
$$

where $\frac{\beta_{1} d}{2 a} m_{2, t-1}$ and $\frac{\beta_{2} d}{2 a} m_{1, t-1}$ are small, this upper bound will give a good approximation to the true value. We note that this upper bound is very similar to the solution in special case 2 . This is to be expected as adoption by farmer $i$ in both the upper bound and special case 2 is driven by the farmer's $\beta_{i}$ value.

Stage 2. Only one farmer's inertia is binding $\left(\bar{m}_{1}>m_{1}\right.$ and $\left.\bar{m}_{2}=m_{2}\right)$.

As $\bar{m}_{2 t}$ is binding and $\bar{m}_{1 t}$ is non-binding, if follows that $m_{2 t}=\bar{m}_{2 t}$ and $m_{1 t}=$ $e-n_{1 t}+q / 2 d$.

$$
\begin{aligned}
m_{2 t} & =m_{2, t-1}+\beta_{2}\left(e-\frac{p_{t-1}-b-q}{2 a}+\frac{q}{2 d}-m_{2, t-1}\right) \\
& =\left(1-\beta_{2}-\frac{\beta_{2} d}{2 a+d}\right) m_{2, t-1}+\beta_{2}\left(1+\frac{d}{2 a+d}\right)\left(e-\bar{N} / 2+\frac{q}{2 d}\right) \\
& =\left(e-\bar{N} / 2+\frac{q}{2 d}\right)\left(1-\left(1-\beta_{2}-\frac{\beta_{2} d}{2 a+d}\right)^{t-t_{2}}\right)+m_{2, t_{2}}\left(1-\beta_{2}-\frac{\beta_{2} d}{2 a+d}\right)^{t-t_{2}}, \\
m_{1 t} & =e-\bar{N} / 2+\frac{q}{2 d}+\frac{d}{2 a+d}\left(e-\bar{N} / 2+\frac{q}{2 d}-m_{2 t}\right) \\
& =\left(e-\bar{N} / 2+\frac{q}{2 d}\right)+\frac{d}{2 a+d}\left(e-\bar{N} / 2+\frac{q}{2 d}-m_{2, t_{2}}\right)\left(1-\beta_{2}-\frac{\beta_{2} d}{2 a+d}\right)^{t-t_{2}},
\end{aligned}
$$

where $m_{i, t_{2}}$ denotes technology adoption by farmer $i$ at the start of stage two.

Figure 6 illustrates farmers' technology adoption $\left(m_{i t}\right)$ over time in special case 3. This figure has been drawn with $\beta_{1}=0.25$ and $\beta_{2}=0.13$.

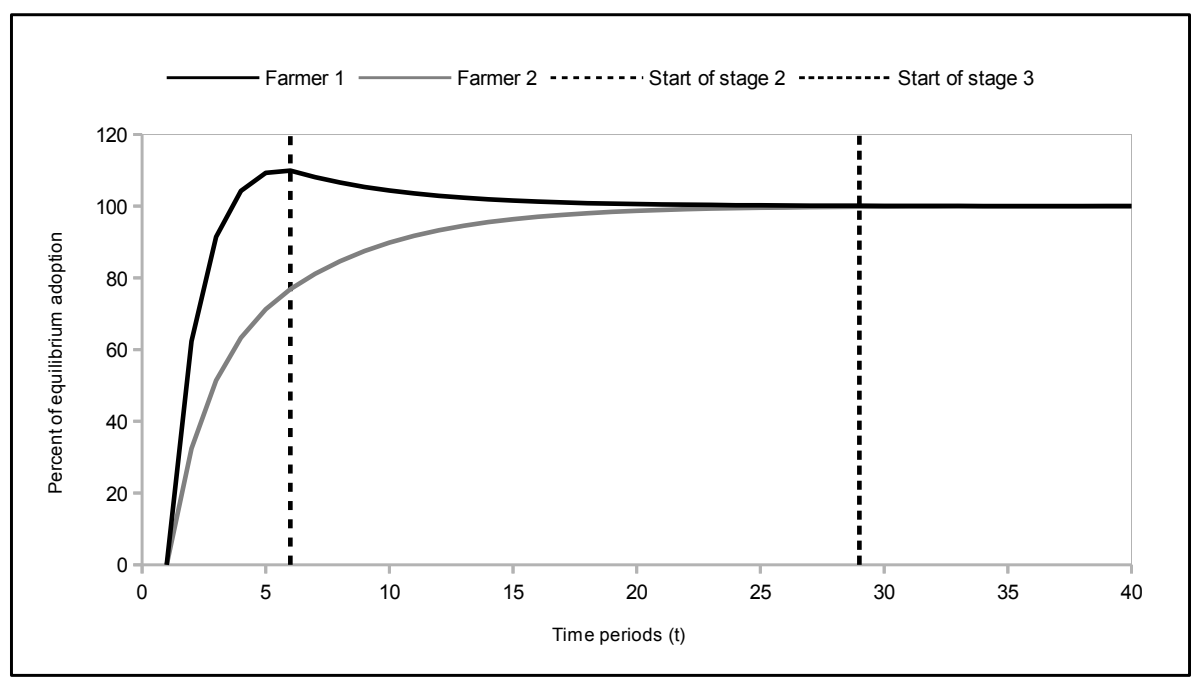

Figure 6. Farmers' technology adoption over time (special case 3) 
It is clear from special case 3 that, during stage two, both $m_{1 t}$ and $m_{2 t}$ converge exponentially from their values at the start of stage two $\left(m_{1, t_{2}}\right.$ and $\left.m_{2, t_{2}}\right)$ towards their long run values $(e-\bar{N} / 2+q / 2 d)$. We note that convergence is slower when $\beta\left(1-\frac{d}{2 a+d}\right)$ is close to 0 and is instant if $\beta\left(1-\frac{d}{2 a+d}\right)$ is greater than 1 . Although $m_{1 t}$ is decreasing during stage two, we observe that $m_{2 t}$ is increasing at a faster rate, so the total adoption of technology is increasing.

We also note that the length of stage two depends solely on on the technology adoption of the second farmer (in particular $\beta_{2}$ ). As $\beta_{2}$ increases the length of stage two will decrease and the difference between farmers' technology adoption paths will likewise decrease.

Special Case 4. One farmer only adopts new technology as they update their existing farm technologies, while the other farmer only adopts new technology in response to observing adoption by the first farmer ( $\alpha_{1}$ and $\gamma_{2}$ are non-zero).

Assume $\tau_{1}=0$. As $\delta_{1}=0$, farmer 1 will be willing to adopt $\alpha_{1} e$ additional technology each period. By construction, farmer 2 will only ever carry out additional mitigation in response to the mitigation currently being carried out by farmer 1 , hence $\bar{m}_{1 t} \geq \bar{m}_{2 t}$. We will consider each stage in turn.

Stage 1. Both farmers' inertias are binding $\left(\bar{m}_{1}=m_{1}\right.$ and $\left.\bar{m}_{2}=m_{2}\right)$.

As both $\bar{m}_{1 t}$ and $\bar{m}_{2 t}$ are binding, we have $m_{1 t}=\bar{m}_{1 t}$ and $m_{2 t}=\bar{m}_{2 t}$.

$$
\begin{aligned}
m_{1 t} & =m_{1, t-1}+\alpha_{1} e \\
& =\alpha_{1} e t \\
m_{2 t} & =m_{2, t-1}+\gamma_{2}\left(m_{1, t-1}-m_{2, t-1}\right) \\
& =\left(1-\gamma_{2}\right) m_{2, t-1}+\gamma_{2} \alpha_{1} e(t-1) \\
& =\alpha_{1} e(t-1)-\alpha_{1} e \frac{\left(1-\gamma_{2}\right)}{\gamma_{2}}\left(1-\left(1-\gamma_{2}\right)^{t-1}\right) .
\end{aligned}
$$

We observe that the result for $m_{2 t}$ can be decomposed into a one-period lag of $m_{1 t}$ and a decay factor. As $\gamma_{2}$ tends towards $1, m_{2 t}$ tends to $m_{1, t-1}$, and hence farmer 2 mimics farmer 1 with a one-period lag.

Stage 2. Only one farmer's inertia is binding $\left(\bar{m}_{1}>m_{1}\right.$ and $\left.\bar{m}_{2}=m_{2}\right)$. 
As $\bar{m}_{2 t}$ is binding and $\bar{m}_{1 t}$ is non-binding, it follows that $m_{2 t}=\bar{m}_{2 t}$ and $m_{1 t}=$ $e-n_{1 t}+q / 2 d$.

$$
\begin{aligned}
m_{2 t} & =m_{2, t-1}+\gamma_{2}\left(m_{1, t-1}-m_{2, t-1}\right) \\
& =\left(1-\gamma_{2}-\frac{\gamma_{2} d}{2 a+d}\right) m_{2, t-1}+\gamma_{2}\left(1+\frac{d}{2 a+d}\right)\left(e-\bar{N} / 2+\frac{q}{2 d}\right) \\
& =\left(e-\bar{N} / 2+\frac{q}{2 d}\right)\left(1-\left(1-\gamma_{2}-\frac{\gamma_{2} d}{2 a+d}\right)^{t-t_{2}}\right)+m_{2, t_{2}}\left(1-\gamma_{2}-\frac{\gamma_{2} d}{2 a+d}\right)^{t-t_{2}}, \\
m_{1 t} & =e-\bar{N} / 2+\frac{q}{2 d}+\frac{d}{2 a+d}\left(e-\bar{N} / 2+\frac{q}{2 d}-m_{2 t}\right) \\
& =\left(e-\bar{N} / 2+\frac{q}{2 d}\right)+\frac{d}{2 a+d}\left(e-\bar{N} / 2+\frac{q}{2 d}-m_{2, t_{2}}\right)\left(1-\gamma_{2}-\frac{\gamma_{2} d}{2 a+d}\right)^{t-t_{2}} .
\end{aligned}
$$

We observe identical behavior in stage two as we observed in stage two of special case 3 ( $\beta_{1}$ and $\beta_{2}$ non-zero, and $\left.\beta_{1}>\beta_{2}\right)$, but with $\beta_{2}$ terms replaced by $\gamma_{2}$ terms. This makes it clear that both $\beta_{i}$ and $\gamma_{i}$ cause $m_{1 t}$ and $m_{2 t}$ to converge exponentially from their values at the start of stage two $\left(m_{1, t_{2}}\right.$ and $\left.m_{2, t_{2}}\right)$ towards their long run values $(e-\bar{N} / 2+q / 2 d)$.

Figure 7 illustrates farmers' technology adoption $\left(m_{i t}\right)$ over time in special case 4 . This figure has been drawn with $\alpha_{1} e=2$ and $\gamma_{2}=0.2$.

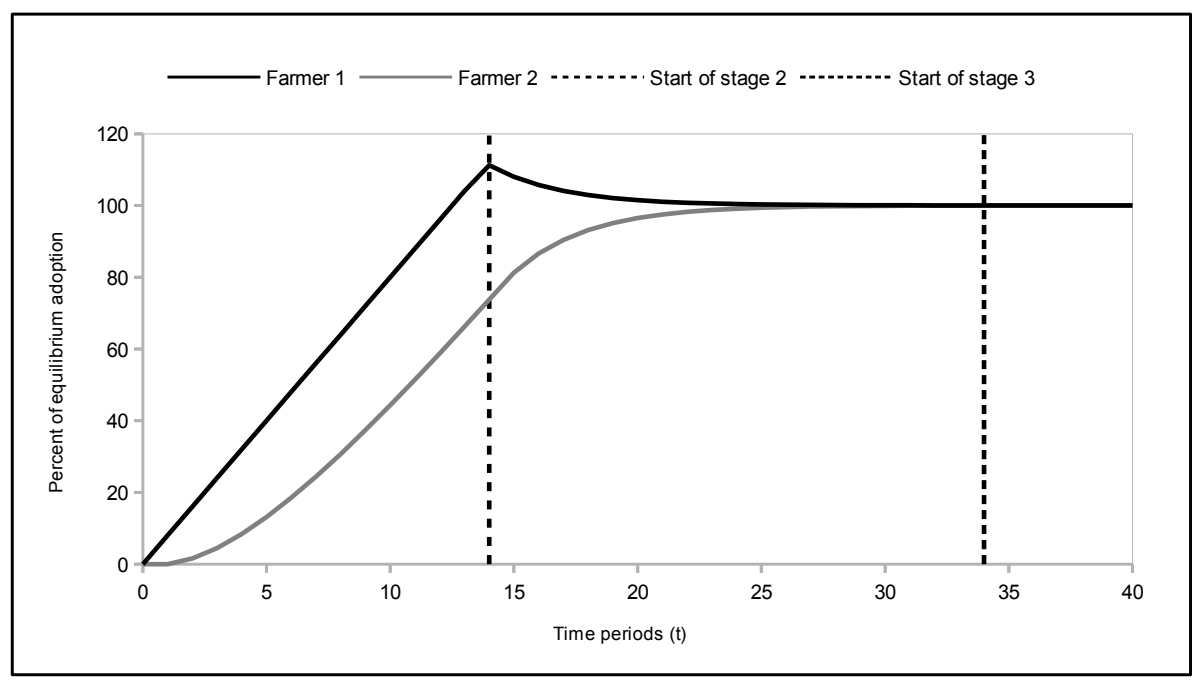

Figure 7. Farmers' technology adoption over time (special case 4)

It is clear from special case 4 that $\alpha_{1}$ is the key parameter that determines the length of stage one, while $\gamma_{2}$ is the key parameter that determines the length of stage two. Hence, as the first farmer revises more of their farm each year and the second farmer mimics the first more closely both farmers will reach equilibrium adoption sooner.

Special Case 5. One farmer only adopts new technology when their existing technologies are not optimal, while the other farmer only adopts new technology in response to observing 
adoption by the first farmer ( $\beta_{1}$ and $\gamma_{2}$ are non-zero).

By construction, farmer 2 will only adopt technology in response to the technology currently used by farmer 1 , hence $\bar{m}_{1 t} \geq \bar{m}_{2 t}$. We will consider each stage in turn.

Stage 1. Both farmers' inertias are binding $\left(\bar{m}_{1}=m_{1}\right.$ and $\left.\bar{m}_{2}=m_{2}\right)$.

As both $\bar{m}_{1 t}$ and $\bar{m}_{2 t}$ are binding, we have $m_{1 t}=\bar{m}_{1 t}$ and $m_{2 t}=\bar{m}_{2 t}$.

$$
\begin{aligned}
m_{1 t} & =m_{1, t-1}+\beta_{1}\left(e-\frac{p_{t-1}-b-q}{2 a}+\frac{q}{2 d}-m_{1, t-1}\right) \\
& =\left(1-\beta_{1}-\frac{\beta_{1} d}{2 a}\right) m_{1, t-1}-\frac{\beta_{1} d}{2 a} m_{2, t-1}+\beta_{1}\left(1+\frac{d}{a}\right)\left(e-\bar{N} / 2+\frac{q}{2 d}\right), \\
m_{2 t} & =m_{2, t-1}+\gamma_{2}\left(m_{1, t-1}-m_{2, t-1}\right) \\
& =\left(1-\gamma_{2}\right) m_{2, t-1}+\gamma_{2} m_{1, t-1} .
\end{aligned}
$$

This relationship defines a system of first order linear difference equations. This system can be solved according to the methodology given in appendix C.

We can construct upper bounds for technology adoption in this case if we ignore the $\frac{\beta_{1} d}{2 a} m_{2, t-1}$ term in the above equation for $m_{1 t}$ :

$$
\begin{aligned}
m_{1 t}=\left(e-\bar{N} / 2+\frac{q}{2 d}\right)\left(1-\left(1-\beta_{1}-\frac{\beta_{1} d}{2 a}\right)^{t-1}\right) \\
m_{2 t}=\left(e-\frac{\bar{N}}{2}+\frac{q}{2 d}\right)\left(1-\left(1-\gamma_{2}\right)^{t}\right) \\
\quad+\gamma_{2}\left(e-\frac{\bar{N}}{2}+\frac{q}{2 d}\right) \sum_{i=0}^{t-1}\left(1-\gamma_{2}\right)^{i}\left(1-\beta_{1}-\frac{\beta_{1} d}{2 a}\right)^{t-i}
\end{aligned}
$$

where $\frac{\beta_{1} d}{2 a}$ is small, these upper bounds will give a good approximation to the true value.

Stage 2. Only one farmer's inertia is binding $\left(\bar{m}_{1}>m_{1}\right.$ and $\left.\bar{m}_{2}=m_{2}\right)$.

As $\bar{m}_{2 t}$ is binding and $\bar{m}_{1 t}$ is non-binding, it follows that $m_{2 t}=\bar{m}_{2 t}$ and $m_{1 t}=$ $e-n_{1 t}+q / 2 d$.

$$
\begin{aligned}
m_{2 t} & =m_{2, t-1}+\gamma_{2}\left(m_{1, t-1}-m_{2, t-1}\right) \\
& =\left(1-\gamma_{2}-\frac{\gamma_{2} d}{2 a+d}\right) m_{2, t-1}+\gamma_{2}\left(1+\frac{d}{2 a+d}\right)\left(e-\bar{N} / 2+\frac{q}{2 d}\right) \\
& =\left(e-\bar{N} / 2+\frac{q}{2 d}\right)\left(1-\left(1-\gamma_{2}-\frac{\gamma_{2} d}{2 a+d}\right)^{t-1}\right)+m_{2, t_{2}}\left(1-\gamma_{2}-\frac{\gamma_{2} d}{2 a+d}\right)^{t-t_{2}}, \\
m_{1 t} & =e-\bar{N} / 2+\frac{q}{2 d}+\frac{d}{2 a+d}\left(e-\bar{N} / 2+\frac{q}{2 d}-m_{2 t}\right) \\
& =\left(e-\bar{N} / 2+\frac{q}{2 d}\right)+\frac{d}{2 a+d}\left(e-\bar{N} / 2+\frac{q}{2 d}-m_{2, t_{2}}\right)\left(1-\gamma_{2}-\frac{\gamma_{2} d}{2 a+d}\right)^{t-t_{2}} .
\end{aligned}
$$


These results are identical to those in stage two of special case 4 (where $\alpha_{1}$ and $\gamma_{2}$ are non-zero). This makes it clear that during stage two, both farmers' adoption decisions depend solely on the behavior of the farmer who's inertia is still binding.

Figure 8 illustrates farmers' technology adoption $\left(m_{i t}\right)$ over time in special case 5. This figure has been drawn with $\beta_{1}=0.20$ and $\gamma_{2}=0.15$.

It is clear from special case 5 that a farmer's motivation to adopt new technology because their existing technology is not optimal (as represented by $\beta$ ) has a strong short term effect that weakens over time. In contrast, a farmer's motivation to adopt new technology in response to observing adoption by other farmers (as represented by $\gamma$ ) has a weak effect in the short term, but a stronger effect in the medium term.

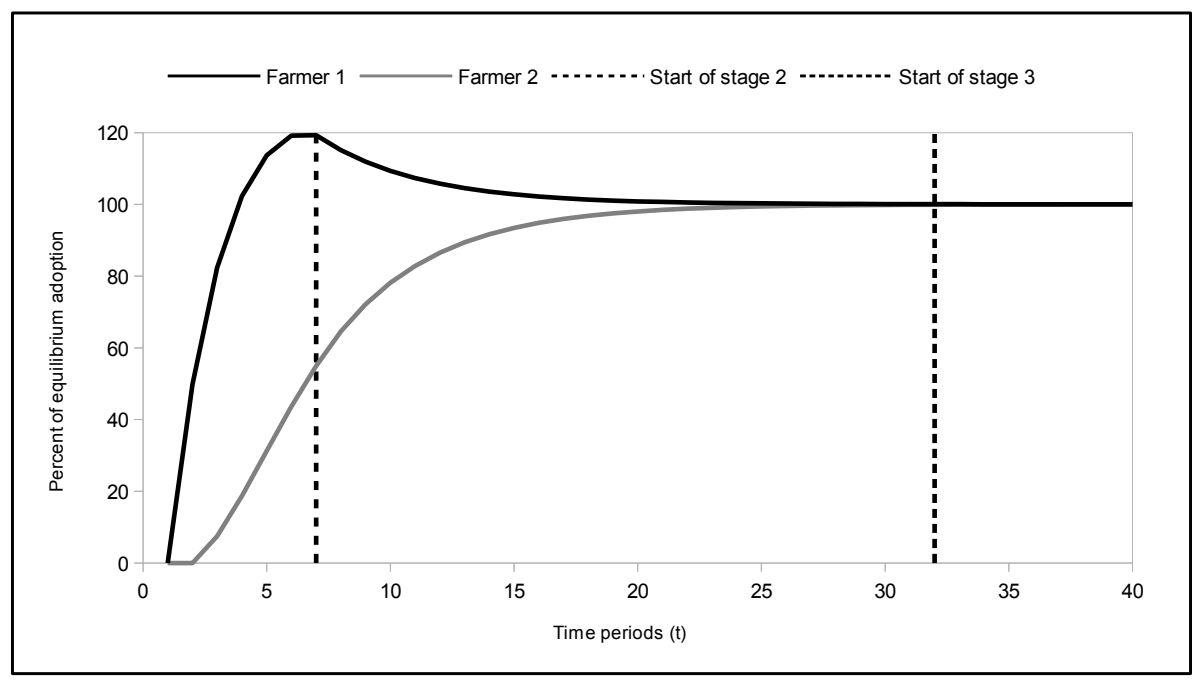

Figure 8. Farmers' technology adoption over time (special case 5)

This is consistent with our intuition: when farmers' existing technology is not optimal then farmers have significant scope and opportunity to use innovation and technology adoption as a means of increasing profits. As it may take several time periods for the benefits of technology adoption to be obvious, farmers who adopt technology only after observing its adoption on similar farms may be slow to adopt new technology before its benefits are well established, but will adopt technology rapidly once its benefits are known.

Looking at all the special cases we have considered in this section we make three observations of the model's performance.

1. Farmers' technology adoption is exponential with respect to the $\beta_{i}$ and $\gamma_{i}$ parameters and linear with respect to the $\alpha_{i}$ parameter. When $\alpha_{2}=0$ this means that during stage two both farmers' technology decisions can be expressed as a weighted average of their technology at the start of stage two $\left(m_{i, t_{2}}\right)$ and their 
equilibrium technology $\left(m_{i, t_{3}}=e-\bar{N} / 2+q / 2 d\right)$, where the weights are an exponential function of the number of time periods that have passed since the stage of stage two $\left(t-t_{2}\right)$.

2. We note that the $\alpha_{i}, \beta_{i}$ and $\gamma_{i}$ parameters of farmer one only appear in the analytic expressions for each farmers' adoption decisions in stage one. And that neither of farmers' $\alpha_{i}, \beta_{i}$ and $\gamma_{i}$ parameters appear in the analytic expression for farmers' decisions in stage three. This suggests that, for a fixed nutrient cap, once a farmer's inertia becomes non-binding it has no further effect on any farmers' adoption decisions. By extension, we would expect that in an $n$ farmer case (with $n+1$ stages) the technology adoption decisions of all farmers in stage $z$ would be a function of the inertia of the $n+1-z$ farmers who's inertia was still binding. This suggests that once a farmer's inertia becomes non-binding and they cease to adopt new technology, their ongoing decisions have minimal impact on those farmers who's inertia is still binding.

3. Figures 4 to 8 demonstrate that the first farmer(s) to adopt technology may adopt more technology than is optimal in the long run. As the adoption of technology is costly this imposes a cost on these farmers. However, all farmers experience higher profits as a result of one farmer adopting additional technology (proposition 5). The presence of this externality, that early adopters bear a cost while benefiting all farmers, may justify intervention by the regulator. Such intervention could take the form of subsidies for early adopters, the funding of farm trials and demonstrations, or the introduction of minimum standards to hasten the slow adopters.

While our model suggests some farmers will adopt more technology than is optimal in the equilibrium, we expect that the magnitude of this over-adoption will be much smaller in reality for two reasons. First, our solution algorithm assumes farmers are short-sighted and so will adopt technology if it is profitable in the current year regardless of whether it is likely to be profitable in future years. In reality, farmers are forward looking and are likely to avoid adopting technology unless it will benefit their farm over multiple years. Second, our model ignores the possibility that farmers will expect other farmers to contribute 'their fair share' of nutrient mitigation and technology adoption. In reality farmers may slow or cease to adopt technology once they perceive themselves to have carried out their 'share' of the work. While both these reasons will reduce farmers' motivation to over-adopt technology, we would expect over-adoption to occur in reality especially in situations where there are significant differences between the rates at which farmers adopt technology. 


\section{Chapter 4}

\section{Many Farmer Case: General Model Performance}

Analytic analysis of farmers' technology adoption decisions in the many farmer case is intractable. In order to observe the performance of the model with three or more farmers we construct a numerical model. This model is written and solved in Matlab (release 2012b) and follows the solution algorithm given in section 2.2 with an annual time step. We wrote our own solver for this study using a combination of quasi-Newton methods and line search algorithms. The code and key data files are available from the author upon request.

In this chapter, we first suggest parameter values for the farm profit functions and for farmers' inertia functions. These parameter values are then used to demonstrate the performance of the model. We discuss both the adoption of new technology and the cost of mitigating nutrient emissions in our results.

\subsection{Parameterizing the model}

According to the functional forms we have proposed for the farm profit and farmer inertia functions (chapter 2), the behavior of any given farmer is described by ten parameters: six of these determine the farm's profitability and the remaining four determine the farmer's inertia, equations (2.12) and (2.17) respectively (see table 5 for a brief overview).

As the emphasis of this study is farmers' adoption of technology we will not consider heterogeneity in farms' profit functions, but will allow for heterogeneity in farmers' inertia functions. Hence all farmers will have identical $a, b, c, d, e$ and $q$ values but may differ in their $\alpha_{i}, \beta_{i}, \gamma_{i}$ and $\delta_{i}$ values, $i=1, \ldots, I$. 


\begin{tabular}{|c|c|l|}
\hline Function & Parameter & Description \\
\hline \multirow{5}{*}{ profit } & $a$ & Farm production revenue (quadratic term) \\
& $b$ & Farm production revenue (linear term) \\
& $d$ & Farm production revenue (constant term) \\
& $e$ & Cost of using non-optimal technology \\
& $q$ & Cost of technology \\
\hline \multirow{5}{*}{ inertia } & $\alpha$ & How frequently farm technologies are updated \\
& $\gamma$ & Profit motivation of farmer \\
& $\delta$ & Farmer's willingness to learn from others \\
& $\delta$ & Farmer's overall resistance to change \\
\hline
\end{tabular}

Table 5. Overview of model parameters

For this demonstration of the model, we are unable to estimate the model parameters formally due to data limitations. The profit of farms with sub-optimal choices of technology are seldom reported, and we do not have records of farmers' past technology adoption. Instead of estimating the parameters, we will calibrate the model so that farmers' technology adoption is similar to previously observed adoption patterns. This means that our parameter estimates, and the corresponding results, should only be considered as indicative. We will describe possible approaches to fitting the model parameters, and their data requirements, in chapter 6.

Parameter values for dairy farm profits per hectare per year in New Zealand can be obtained extending the approach in Anastasiadis et al. (2011). We will use results from Smeaton et al. (2011) and Doole \& Pannell (2009) who model farm performance across a range of different technology choices and management practices. Their results link farm profits $(\pi)$, nutrient emissions $(n)$ and technology $(m)$.

Smeaton et al. (2011) use the Farmax (Bryant et al. 2010) and OVERSEER (AgResearch 2009) models to demonstrate the performance of a representative dairy farm in the Bay of Plenty region, New Zealand. In their analysis, farmers are assumed to always use the optimal level of technology, so $m_{i t}=m_{i t}^{*}$. It follows that $m_{i t} \approx e_{i}-n_{i t}+q_{i} / 2 d_{i}$ so, the results by Smeaton et al. (2011) capture the following sub-part of farms' profit function (2.12):

$$
\pi_{i}\left(m_{i t}, n_{i t}\right)=a_{i} n_{i t}^{2}+b_{i} n_{i t}+c_{i}-q_{i} m_{i t}
$$

However, as they do not explicitly report the level or cost of technology we are unable to estimate $q_{i}$ from their results. Instead, we will assume $q_{i}=0$ and allow for the cost of technology to be captured implicitly by our estimates for the $a_{i}, b_{i}$ 
and $c_{i}$ parameters. We estimate these parameters by fitting a quadratic curve to the relationship between profit $\left(\pi_{i}\left(m_{i t}, n_{i t}\right)\right)$ and emissions $\left(n_{i t}\right)$ given by Smeaton et al. (2011). ${ }^{1}$

Doole \& Pannell (2009) use a non-linear programing approach to model reductions in nitrogen emissions on heterogeneous farms in the Waikato region, New Zealand. ${ }^{2}$ In their analysis, farmers do not adopt any new technologies, but only consider changes in fertilizer application, stocking rates, and the use of maize silage. It follows that $m_{i t}=0$ for all observations. Given the parameter estimates $\left(\hat{a}_{i}, \hat{b}_{i}\right.$ and $\hat{c}_{i}$ ) that we construct from Smeaton et al. (2011), we can control for the variation in profit due to changes in farm emissions. Any remaining variation in farm profit can be attributed to the cost of using non-optimal technology $\left(d_{i}\right)$. We estimate $d_{i}$ from the following equation:

$$
\pi_{i}\left(m_{i t}, n_{i t}\right)-\left(\hat{a}_{i} n_{i t}^{2}+\hat{b}_{i} n_{i t}+\hat{c}_{i}\right)=d_{i}\left(\hat{e}_{i}-n_{i t}\right)^{2}+u_{i} .
$$

We include $u_{i}$ as an additive constant to account for level differences in farm profitability between the Waikato and Bay of Plenty regions. The parameter $\hat{e}$ can be obtained from Rutherford et al. (2011) who estimate nitrogen emissions for different land uses in the Lake Rotorua catchment, New Zealand.

Table 6 gives the parameter estimates for the farm profit functions as estimated from Smeaton et al. (2011), Doole \& Pannell (2009), and Rutherford et al. (2011). All these parameters have been estimated on a per hectare basis (e.g.: $\pi_{i}(\cdot)$ and $n_{i t}$ are measured in dollars, and $\mathrm{kg}$ of nitrogen, per hectare respectively). As Rutherford et al. (2011) suggest that there is a non-zero, unavoidable level of nitrogen emissions (some nutrients will be lost even from undeveloped land) we have estimated these parameters with respect to only those emissions that a farmer can manage.

\begin{tabular}{|l|c|c|c|c|c|c|}
\hline Parameter & $\hat{a}$ & $\hat{b}$ & $\hat{c}$ & $\hat{d}$ & $\hat{e}$ & $\hat{q}$ \\
\hline Value & -0.3347 & 41.46 & 92.08 & -0.3757 & 52 & 0 \\
\hline
\end{tabular}

Table 6. Parameters for dairy farms' profit functions

Estimates of farmers' $\alpha_{i}, \beta_{i}, \gamma_{i}$ and $\delta_{i}$ parameters are harder to construct. We will provide parameter values that are consistent with existing farm data and adoption curves. To account for heterogeneity in farmers' inertia we will estimate a range for each parameter that is likely to encompass farmers' individual parameter values.

\footnotetext{
${ }^{1}$ It can be shown that this assumption and the following parameter estimation results in estimates for $b_{i}$ and $c_{i}$ that incorporate $q_{i}$ as follows: $\hat{b}_{i} \approx b_{i}+q_{i}$ and $\hat{c}_{i} \approx c_{i}-q_{i} e_{i}-q_{i}^{2} / 2 d_{i}$.

${ }^{2}$ Doole \& Pannell (2009) report the minimum and maximum profit and nutrient emissions for their heterogeneous farms. We conduct our analysis on a hypothetical median farm with emissions and profit halfway between the maximum and minimum reported values.
} 
We assume that farmers plan investments with ten to fifteen year time horizons. If farmers consider updating at most one-fifth of their existing farm technologies across any given time horizon then this could be reflected in the model with $\alpha_{i}$ values between 0.02 and 0.0133 (updating 20 percent of the farm over ten years is equivalent to updated 0.02 of the farm each year) assuming a constant rate of updating. These numbers are broadly consistent with farmers' assets and depreciation as reported by the Agricultural Resource Management Survey (ARMS) conducted by the United States Department of Agriculture (USDA) for 2010. Therefore, we will consider $\alpha_{i} \in[0.0133,0.02]$.

Using USDA data for 31 states and 132 crop reporting districts, Griliches (1957) investigates the adoption of hybrid corn in the US. Suppose that farmers' adoption of hybrid corn (a new technology) is typical of farmer behavior in two regards: the length of time it takes farmers to fully or partly adopt new technology, and the maximum proportion of adoption that takes place. The percentage of total corn acreage planted using hybrid seeds over time for five different states is given by Griliches (1957). From this, we observe the time from when a state began to adopt hybrid corn to the times when forty and ninety percent of the state had adopted. These values are given in table 7 . We also observe that long run adoption is 95 to 100 percent of full adoption for the states of Iowa, Wisconsin and Kentucky.

\begin{tabular}{|l|c|c|c|c|c|}
\hline State & Iowa & Wisconsin & Kentucky & Texas & Alabama \\
\hline Years to $40 \%$ adoption & 4 & 5 & 6 & 6 & 8 \\
\hline Years to 90\% adoption & 7 & 11 & 14 & $\mathrm{x}$ & $\mathrm{x}$ \\
\hline
\end{tabular}

Table 7. Adoption rates of hybrid corn. Source: Griliches (1957)

We wish to determine the broadest range of $\beta_{i}$ values that are consistent with farmers adopting 90 percent of their long run technologies in seven to eleven years (as we observe for Iowa and Wisconsin). Given the profit function parameters in table 6, we solve the inertia model with a range of $\beta_{i}$ values when $\alpha_{i}=0.0133$ and when $\alpha_{i}=0.02$. By allowing for $\alpha_{i}$ to take its most extreme values we observe the greatest range of possible $\beta_{i}$ values. Our results suggest that $\beta_{i}$ values between 0.042 and 0.112 are consistent with farmers adopting 90 percent of their long run technologies in seven to eleven years. Therefore we will consider $\beta_{i} \in[0.042,0.112]$.

We wish to determine the broadest range of $\gamma_{i}$ values that are consistent with farmers adopting 40 percent of their long run technologies in six to eight years (as we observe for Kentucky, Texas and Alabama). We divide the farmers into two groups. For the first group of farmers $\beta_{i}>0$ and $\gamma_{i}=0$, this group can be thought of as consisting of innovative, profit driven farmers. For the second group of farmers 
$\beta_{i}=0$ and $\gamma_{i}>0$, this group can be thought of as consisting of socially receptive farmers (these farmers can learn from any farmer in the first group). Given the profit function parameters in table 6, we solve the inertia model with a range of $\gamma_{i}$ values for the second group, for all combinations of the most extreme $\alpha_{i}$ and $\beta_{i}$ values (so $\beta_{i}$ equals 0.042 or 0.112 for the first group, and $\alpha_{i}$ equals 0.0133 or 0.02 for either or both of the groups). By allowing $\alpha_{i}$ and $\beta_{i}$ to take their most extreme values we observe the greatest range of possible $\gamma_{i}$ values. Our results suggest that $\gamma_{i}$ values between 0.025 and 0.50 are consistent with farmers adopting 40 percent of their long run technologies in six to eight years. Therefore we will consider $\gamma_{i} \in[0.025,0.050]$.

We wish to determine the largest $\delta_{i}$ value that is consistent with at least 95 percent of full technology adoption (as we observe for the states of Iowa, Wisconsin and Kentucky). As before we divide farmers into two groups: innovative, profit driven farmers and socially receptive farmers. Given the profit function parameters in table 6 , we solve the inertia model with a range of $\delta_{i}$ values, for all combinations of the most extreme $\beta_{i}$ and $\gamma_{i}$ values (so $\beta_{i}$ equals 0.042 or 0.112 for the first group and $\gamma_{i}$ equals 0.025 or 0.50 for the second group). As the $\alpha_{i}$ and $\delta_{i}$ parameters interact we require $\alpha_{i}=0$ for all farmers and interpret our results as estimating the appropriate difference between $\delta_{i}$ and $\alpha_{i} e$. Our results suggest the $\delta_{i}$ values of at most 1.2 larger that $\alpha_{i} e_{i}$ are consistent with at least 95 percent of full technology adoption in the long run (40 years). Therefore we will consider $\delta_{i}-\alpha_{i} e \in[0,1.2]$.

\begin{tabular}{|l|c|c|c|c|}
\hline Parameter & $\hat{\alpha}_{i}$ & $\hat{\beta}_{i}$ & $\hat{\gamma}_{i}$ & $\hat{\delta}_{i}-\hat{\alpha}_{i} \hat{e}_{i}$ \\
\hline Minimum value & 0.0133 & 0.042 & 0.025 & 0 \\
\hline Maximum value & 0.020 & 0.112 & 0.50 & 1.2 \\
\hline
\end{tabular}

Table 8. Parameters for farmers' inertia functions

Table 8 summarizes our parameter estimates for farmers' inertia functions, (2.17) - (2.18). Our aim in estimating these coefficients is to provide a range of values for which farmers' inertia functions produce behavior similar to that observed in reality as given by Griliches (1957). We make no claims as to the accuracy of these parameter estimates, and use them only to illustrate our model.

\subsection{Demonstrated model performance}

For this demonstration of the model, we will consider 100 farmers each managing a 100 hectare farm. Following the classification given by Ward et al. (2008) (table 2) we assign these farmers into four groups: socially influenced, innovative, lifestyle and capital constrained farmers. The proportion of farmers in each group is consistent with the percentages given in table 4 . We divide the parameter ranges given in 
table 8 into quintiles (high, medium-high, medium, medium-low, and low). Each group of farmers will be assigned parameter values from specific quintiles that are consistent with the suggested values given in table 4 , section 2.6.

Farmers with a ++ value in table 4 will be assigned parameter values from the high quintile. Farmers with a + value in table 4 will be assigned parameter values from the medium-high quintile. Farmers with a blank value in table 4 will be assigned parameters from the medium quintile. Farmers with a - value in table 4 will be assigned parameter values from the medium-low quintile. Farmers with a - value in table 4 will be assigned parameter values from the low quintile.

Individual heterogeneity in farmers' inertias will be introduced by randomizing individual farmer's inertia parameters. We will draw each farmer's $\alpha_{i}, \beta_{i}, \gamma_{i}$ and $\delta_{i}$ parameters from the appropriate quintile according to a uniform distribution. As we are not considering heterogeneity in farm profits, for all farmers we will use the $a, b, c, d, e$ and $q$ values given in table 6 . In the absence of data on farmers' social and professional networks we will assume that any farmer can learn from any other farmer $\left(I_{i}=\{i=1, \ldots, I\}\right)$.

We will consider regulation that requires a 50 percent reduction in total emissions from baseline. As farmers' inertia parameters are randomly assigned we will solve the model multiple times, each time with different parameters. Figures 9, 10, 11 and 12 summarize the model's results for the catchment as a whole. ${ }^{3}$

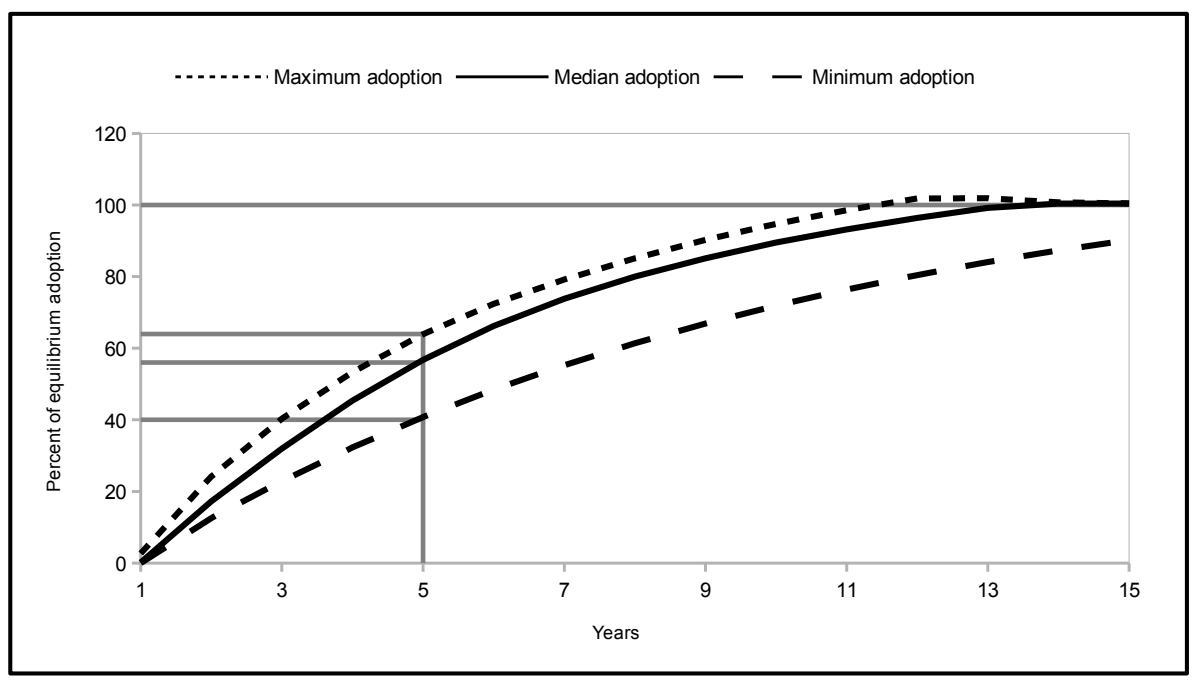

Figure 9. Technology adoption curves

Figure 9 gives the maximum, median and minimum technology adoption by

\footnotetext{
${ }^{3}$ In figures 9, 10 and 11 the results we present are constructed as means from 1001 model solutions with randomized parameters. In figure 12 the result we present is a probability density function constructed from the same 1001 model solutions.
} 
farmers over time. For example, in year 5, all farmers have adopted at least 40 percent, more than half of farmers have adopted at least 55 percent, and no farmer has adopted more that 65 percent of their equilibrium technology. We note that the difference between maximum and median adoption is much smaller than the gap between median and minimum adoption. So, while much of the catchment are less than two years behind the leading innovators (those with the maximum amount of technology), the slowest adopters in the catchment may be more than six years behind. In addition, we observe that around year 12 the maximum adoption curve exceeds 100 percent: some farmers will have adopted more than their equilibrium level of technology (we identified and discussed the possibility of this phenomenon in section 3.4, see in particular figures 6, 7 and 8).

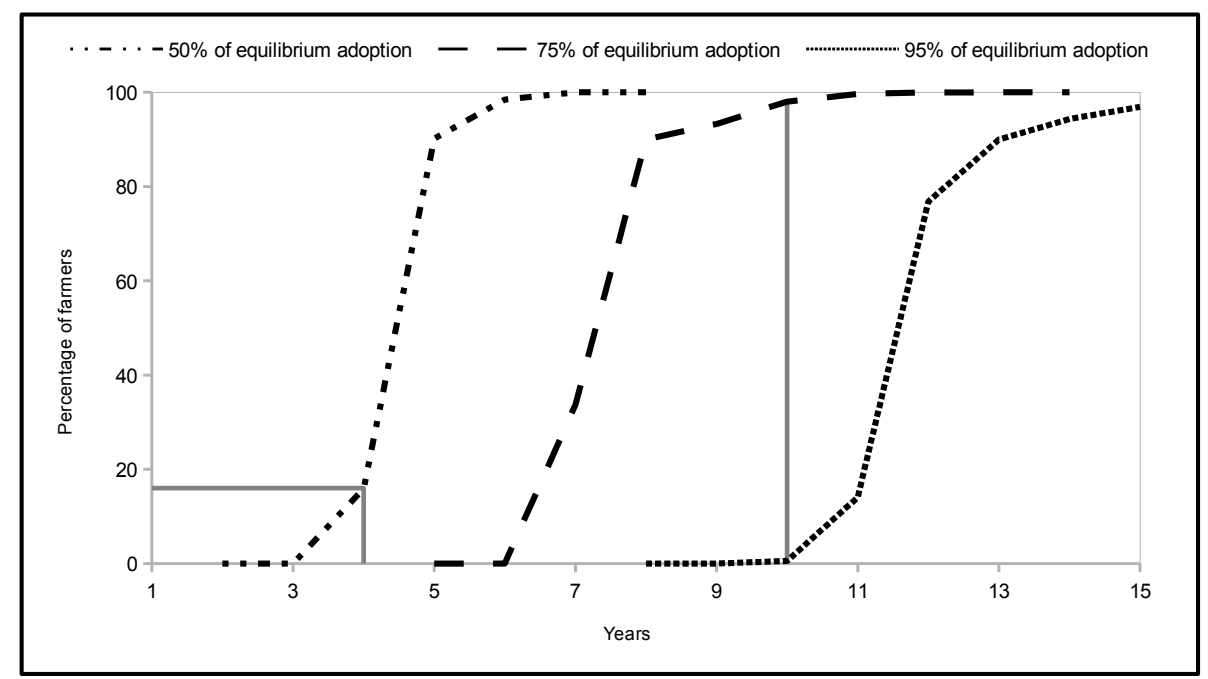

Figure 10. Adoption curves for specific technology thresholds

Figure 10 gives the proportion of farmers, over time, who have adopted at least a specific percentage of their equilibrium technology. For example, in year 4: almost 20 percent of farmers have adopted more than 50 percent of their equilibrium technology; and in year 10: all farmers have adopted at least 50 percent, over 90 percent of farmers have adopted at least 75 percent, and the leading farmers are only just beginning to adopt more than 95 percent of their equilibrium technology. These curves are analogous to the adoption curves developed by Griliches (1957). But rather than considering a specific technology, they consider specific quantities of technology. 4

Figures 9 and 10 provide two ways of viewing farmers' technology adoption

\footnotetext{
${ }^{4}$ We note that some quantities of technology may be equivalent to specific technologies. Suppose that in order for any farmer to reach 75 percent of their equilibrium technology adoption they had to install a feed pad. In this case the 75 percent adoption curve in figure 10 would be equivalent to an adoption curve for feed pads.
} 
over time. They suggests that, given our parameter choices, farmers are quick to make an initial response to nutrient regulation (almost all farmers adopt 50 percent of their equilibrium technology within five years). But full response to regulation can be much slower (note that it takes some farmers a further five years to reach 75 percent of their equilibrium technology). This kind of information is of interest to regulators and social planners as it provides an indication as to how technology adoption varies between farmers.

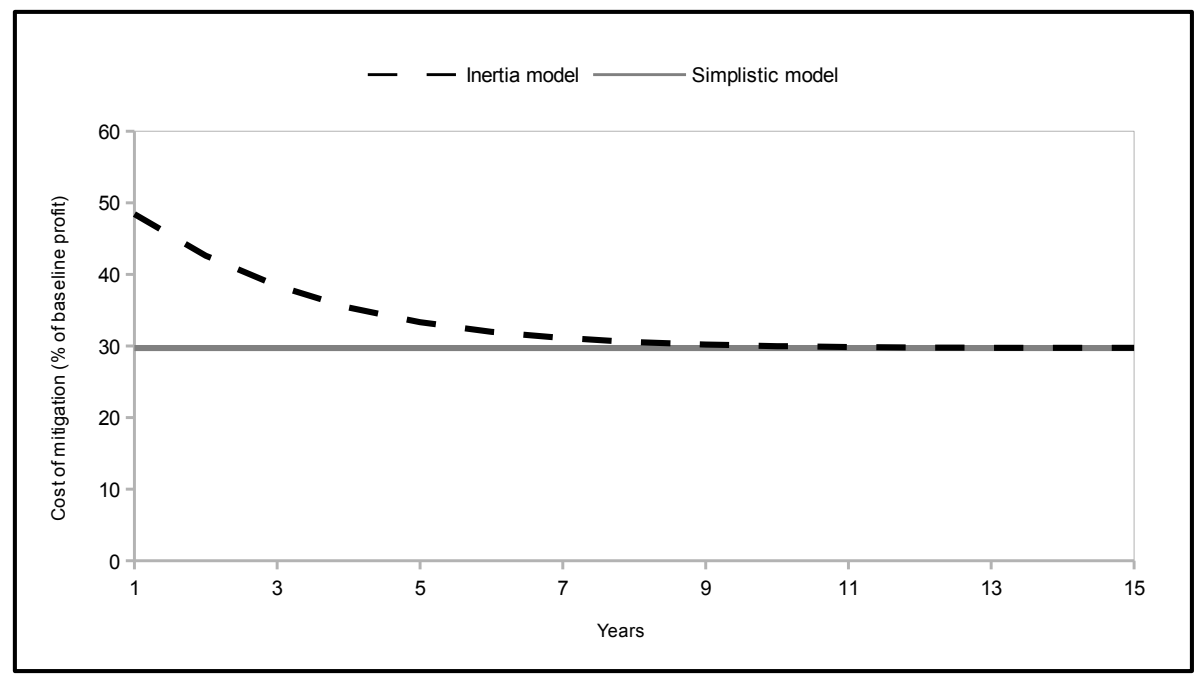

Figure 11. Costs of mitigation over time

Figure 11 gives the cost of mitigation, each period, over the entire catchment for both the static economic and inertia models (equations (2.4) - (2.5) and (2.1) (2.3) respectively). We define the cost of mitigation as the difference between profits before and after regulation (but ignoring the value of allowances) as this captures the value of lost production due to mitigation. ${ }^{5}$ For this figure we have expressed the cost as a percentage of profits before regulation. The static economic model is likely to underestimate the costs of mitigation in the short run as it assumes farmers adjust instantly to new regulation. In contrast, the inertia model provides an estimate of costs that account for farmers being slow to adopt new technology. In our example the cost of mitigation in the first few years is estimated to be up to 18 percentage points higher when inertia is considered. The difference between the two models declines over time as farmers adopt technology and is minimal from year ten onwards.

\footnotetext{
${ }^{5}$ Cost of mitigation over all farmers in period $t=\sum_{i} \pi_{i}\left(0, e_{i}\right)-\pi_{i}\left(m_{i t}, n_{i t}\right)$.
} 


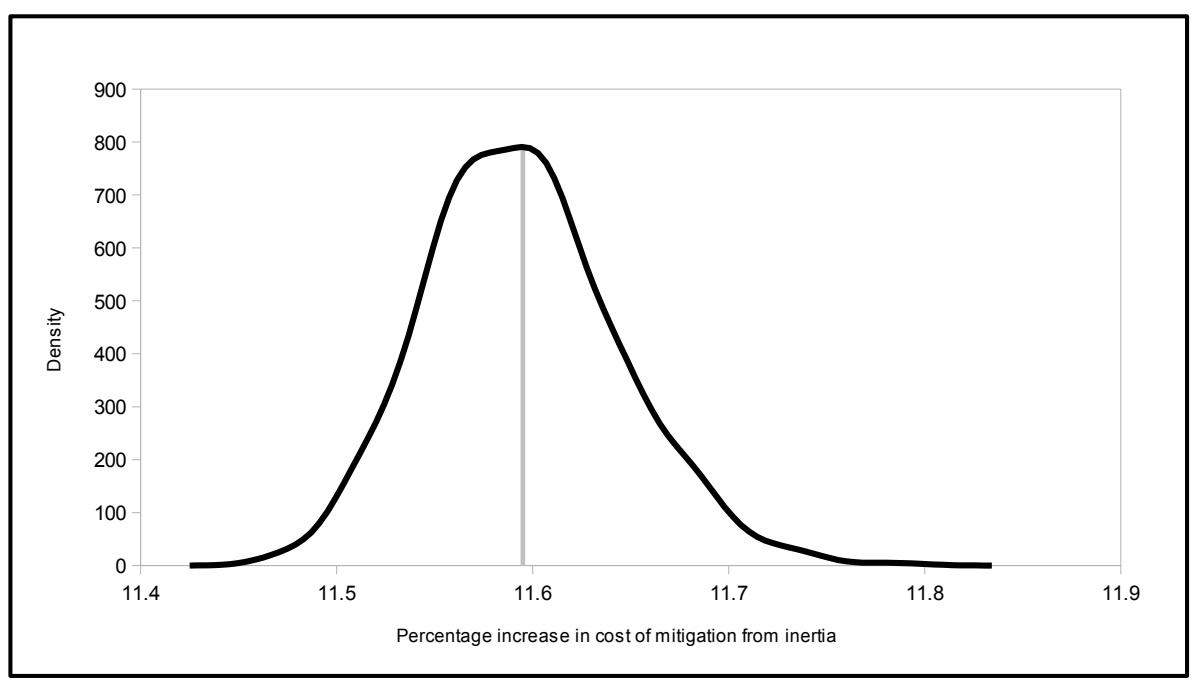

Figure 12. Distribution of the percentage increase in costs due to inertia

Figure 12 gives the distribution of the percentage increase in costs due to inertia. We define the increase in costs due to inertia as the percentage increase in the net present value of the cost of mitigation, across all periods, under the inertia model over the equivalent value under the static economic model. ${ }^{6}$ This is equivalent to considering the (weighted) average difference between the two curves given in figure 11 (where the weights vary across time according to some discounting factor). The distribution in figure 12 has been constructed over the 1001 model solutions with randomly assigned values for farmers' inertia parameters. ${ }^{7}$ We observe that on average, the net present value of the cost of mitigation is estimated to be 11.6 percent higher in the inertia model than in the static economic model, given our choice of parameters (tables 6 and 8).

Figures 11 and 12 provide two ways of viewing similar information. They both show the increases in costs due to farmers' resistance to change. This kind of information will be of interest to researchers who prefer to work with the static economic model (perhaps due to its computational elegance, or because it can be nested inside more complex analysis) and want an indication as to how much they may underestimate the true costs. Local governments will also be interested in this kind of information as it provides an estimate of the potential cost savings from encouraging more rapid adjustment to regulation.

\footnotetext{
${ }^{6}$ Net present value of the cost of mitigation $=\sum_{t}(1+r)^{-t} \sum_{i} \pi_{i}\left(0, e_{i}\right)-\pi_{i}\left(m_{i t}, n_{i t}\right)$. We use a discount rate, $r$, of seven percent as this is the rate preferred by the Bay of Plenty Regional Council (Anastasiadis et al. 2011): the local government body who regulates one of the areas in New Zealand from which we have used data to parameterize our farm profit function.

${ }^{7}$ This density has been constructed using kernel smoothing with a Gaussian kernel. A description of kernel smoothing is provided in appendix D.
} 


\subsection{Farmer performance}

We disaggregate the results from the previous section to consider how adoption decisions differ between the groups of farmers (socially influenced, innovative, lifestyle and capital constrained). This enables us to consider the behavior caused by different parameter choices. Recall that the proportion of farmers in each group is consistent with the percentages given in table 4 . This means that, in the hypothetical catchment we are considering, there are 52 socially influenced, 25 innovative, 10 lifestyle and 13 capital constrained farmers.

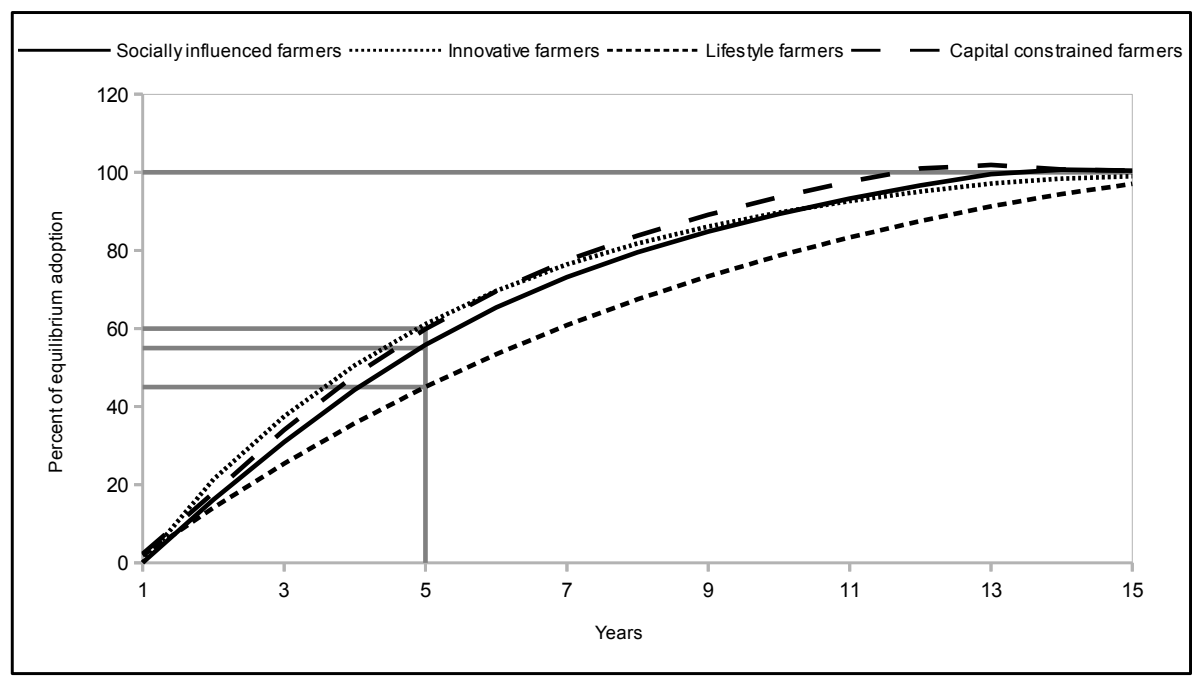

Figure 13. Technology adoption curves by farmer groups

Figure 13 gives the median technology adoption by each group of farmers over time. For example, by year 5 the median lifestyle farmer has adopted 45 percent, the median socially influenced farmer has adopted 55 percent and, the median innovative and the capital constrained farmers have adopted 60 percent of their equilibrium technology. We do not report or compare the maximum and minimum adoption for any group over time as this would be misleading because there are a different number of farmers in each group. We observe that, on average, during the first five years the innovative farmers adopt the most technology, but they are overtaken by the capital constrained farmers in year 6 and the socially influenced farmers in year 10. The lifestyle farmers are consistently the slowest to adopt new technology. 


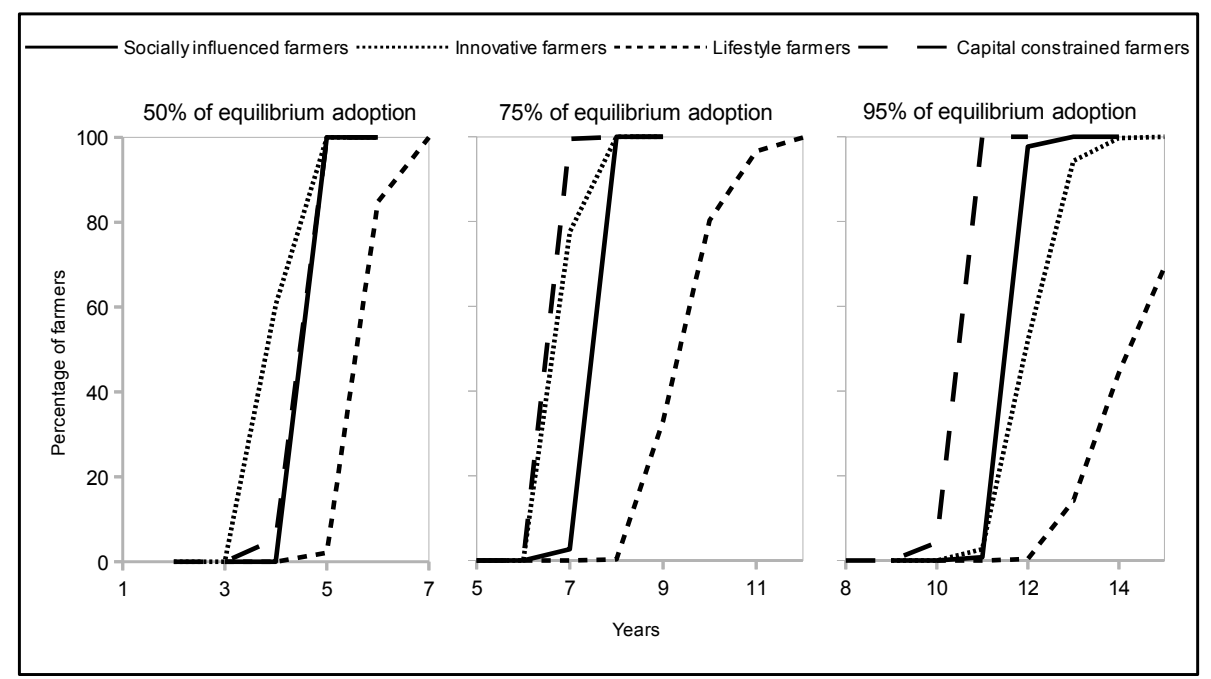

Figure 14. Adoption curves for specific technology thresholds by farmer groups

Figure 14 gives the proportion of farmers, over time, who have adopted at least a specific percentage of their equilibrium technology. For example, 80 percent of lifestyle farmers have adopted at least 50 percent of their equilibrium technology by year 6 and at least 75 percent by year 10. For clarity we have given the adoption curves for 50, 75 and 95 percent of equilibrium technology in separate panels. Note that while all three panels share the same vertical axis, the horizontal axis differs between panels.

The slope of the technology adoption curves given in figure 14, provides an indication of the heterogeneity within each group of farmers. The adoption curves in the left most panel of figure 14 are very steep. This suggests that there is very little variation between farmers within each group for the first five years. While figures 9 and 10 show variation between all farmers in the catchment during the first five years, this variation must be due to differences between the groups of farmers rather than differences within each group of farmers. We observe relatively flatter adoption curves for the innovative and lifestyle farmers in the second and third panels of figure 14. This suggests that the between farmer variation within these groups becomes more pronounced over time.

From figures 13 and 14, we observe that farmers' adoption in the first few years is ordered according to the value of their $\beta$ parameter (The innovative farmers have the highest $\beta$ values and adopt the most technology in the first five years, while the lifestyle farmers have the lowest $\beta$ values and adopt the least technology). We also note that in the long term the socially influenced and the capital constrained farmers may adopt more technology than the innovative farmers. This suggests that the $\beta$ parameter has a strong effect on adoption only in the short term.

Technology adoption for the socially influenced farmers is largely driven by 
their $\gamma$ value. As their $\gamma$ values may be very large (between 0.405 and 0.5 ), the steepness of the adoption curves in figure 14 is to be expected: As soon as one farmer (the leading technology adopter) has adopted a given level of technology, all the socially influenced farmers will adopt very similar levels of technology within two years.

The fact that the capital constrained farmers have the most technology from year six to year thirteen is most likely driven by their very low $\delta$ values. This is the key difference between the socially influenced farmers and the capital constrained farmers. Both groups of farmers have low $\beta$ and very high $\gamma$ values, but the socially influenced farmers have higher $\alpha$ values. If the socially influenced and the capital constrained farmers had the same $\delta$ values we would expect the socially influenced farmers to adopt more technology. However as the capital constrained farmers adopt more technology than the socially influenced farmers, it follows that the key determinant of their technology adoption must be their low $\delta$ value.

Farmers' $\delta$ values act to suppress farmers' technology adoption decisions each year. We would expect that the technology adoption of farmers with higher $\delta$ values slows sooner than the adoption of farmers with lower values. This may help explain why there is little difference between the lifestyle and the innovative farmers in year fifteen, despite the innovative farmers having higher $\beta$ and $\gamma$ values than the lifestyle farmers: The lifestyle farmers have lower $\delta$ values and are hence adopting technology faster in the long term.

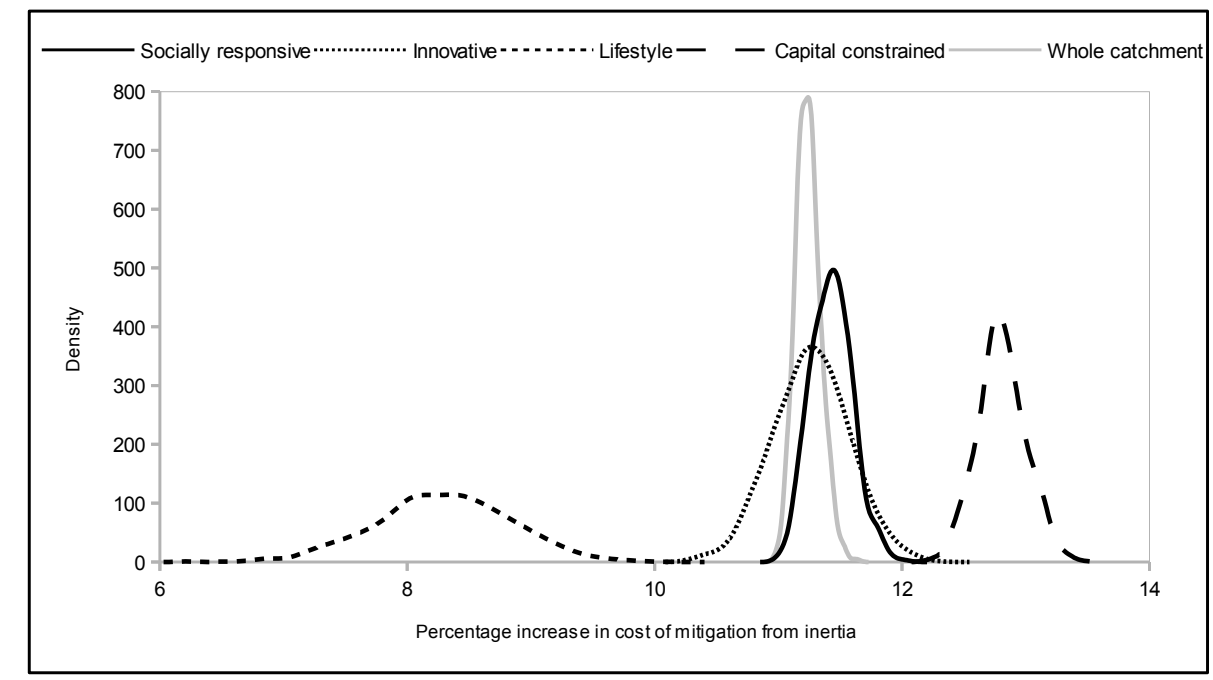

Figure 15. Distribution of the increase in costs due to inertia by farmer groups

Figure 15 gives the distribution of the percentage increase in costs due to inertia for each group of farmers (as per figure 12). These distributions have been calculated over the 1001 model solutions with randomly assigned values for farm- 
ers' inertia parameters. So, the costs estimated for the innovative and socially responsive farmers (as well as for the catchment as a whole) are between 11 and 12 percent higher under the inertia model than under the static economic model. While the costs for the lifestyle and capital constrained farmers are on average 8.5 and 13 percent higher, respectively, under the inertia model than under the static economic model. This might seem to run counter to proposition 4 as the farmers who adopt more technology have higher costs due to inertia. However, proposition 4 considers profit net of the value of allowances, while in this case we have excluded the value of allowances.

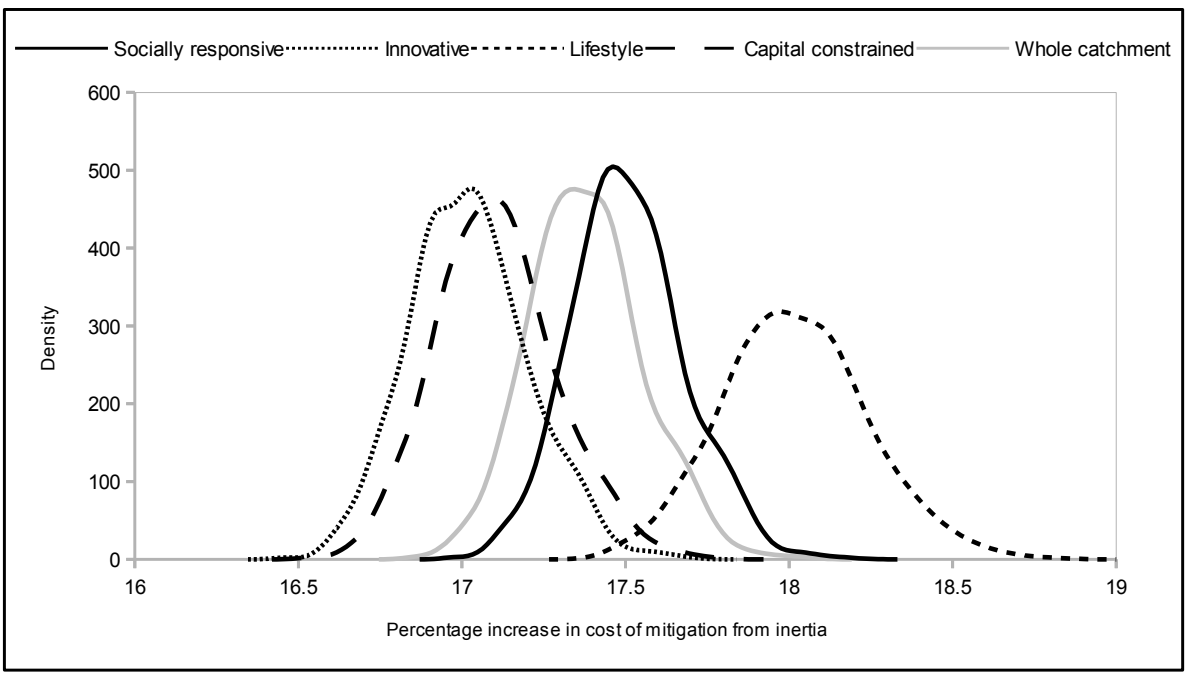

Figure 16. Distribution of the costs due to inertia including the value of allowance

Figure 16 gives the distribution of the percentage increase in costs due to inertia as in figure 15. But while the costs reported in figure 15 have been calculated excluding the value of allowances (as they have been for figures 11 and 12), the costs reported in figure 16 are net of the value of allowances (as they have been for propositions 4 and 5). ${ }^{8}$ These results are consistent with proposition 4 : the innovative and the capital constrained farmers (who adopt technology rapidly) have lower costs under the inertia model than the lifestyle farmers (who adopt technology slowly).

The differences between figures 15 and 16 are driven by different definitions of costs. While the costs considered in figure 15 include only those arising from investing in new technology and from reducing production, the costs considered in figure 16 also include the value of nutrient allowances. Recall from proposition 3 that farmers with more technology will hold fewer allowances. It follows that the farmers who adopt the least technology will hold the most nutrient allowances, and that the farmers who hold the most nutrient allowances will have the highest production. Hence those farmers who have adopted the least technology will appear to

\footnotetext{
${ }^{8}$ Cost of mitigation in period $t$ net of the value of allowances $=\sum_{i} \pi_{i}\left(0, e_{i}\right)-\left(\pi_{i}\left(m_{i t}, n_{i t}\right)-p_{t} n_{i t}\right)$.
} 
face lower costs when the value of nutrient allowances is ignored.

These two figures highlight the potential for confusion to arise over the value of technology adoption. Where farmers are provided with an initial allocation of allowances free of charge they may fail to account for the value of their allowances when estimating farm profitability. This may give rise to the perspective that farmers who adopt less technology are better off.

Furthermore regulation where farmers' initial (and free) allocation of allowances each year is determined by their emissions in the previous year (or in recent years) will be counter productive. Because nutrient allowances are valuable, this approach to allocating allowances punishes farmers who adopt technology and reduce nutrient emissions, but rewards farmers who resist lowering their nutrient emissions. Those farmers who adopt technology, and hence reduce emissions, would have lower profits from their farming activity and would also receive fewer nutrient allocations in future years. In comparison, those farmers who do not adopt technology would have higher profits from their farming activity and would also be rewarded for their non-adoption by higher nutrient allocations in future years. Regulation with this kind of allocation scheme would provide a disincentive for farmers to adopt new technology, further slowing the adoption of new technology and increasing the cost to the catchment due to inertia. 


\section{Chapter 5}

\section{Random Inertia}

While the inertia function (2.17) - (2.18) specified in section 2.5 may be a good indicator for farmers' intention to adopt new technology, there may be factors outside farmers' control that result in actual technology adoption differing from intended adoption. These factors result in random variations in the environment in which the farm and farmer operate. We distinguish between two types of random variations that may arise: global and individual errors.

Global, or catchment wide, errors are those that affect all farmers in a similar way. They include variations in weather, changes in market conditions and prices, and the development (and validation or failure) of new technologies.

Individual, or farmer specific, errors are those that affect a single farmer independently of all other farmers. They include changes in personal circumstances, the availability of farm staff and expertise, and the adjustment of adopted technologies to the specific context of the farm. They may also capture the impacts of global errors that are distributed unevenly across farmers (for example, exposure to weather patterns as determined by farm location in the catchment).

Note that within the Economics literature (see for example Ireland 2004), these errors might be referred to as shocks. However, as we do not consider the arrival of the events that cause these errors or their individual magnitudes, but instead focus on their aggregate impact on farmers' decisions, we will use the term errors to avoid confusion with the notion of shocks in the Statistics and Operations Research literature (see for example Boland \& Proschan 1983). 


\subsection{Modeling random inertia}

Recall from equations (2.17) - (2.18), that $g_{i t}$ provides a measure of the motivation of (or pressure on) farmer $i$ to adopt new technology, and that $\Delta \bar{m}_{i t}$ gives the maximum amount of new technology that farmer $i$ is willing to adopt in period $t$. We allow the random errors on farmers' inertia to affect farmers' adoption of new technology by changing the motivation of farmer $i$ to adopt as follows:

$$
g_{i t}=\alpha_{i} e_{i} \tau_{i}+\beta_{i}\left(m_{i, t-1}^{*}-m_{i, t-\tau_{i}}\right)+\gamma_{i}\left(\max _{j}\left\{m_{j \in I_{i}, t-1}\right\}-m_{i, t-\tau_{i}}\right)+\varepsilon_{t}+\varepsilon_{i t}
$$

where $\varepsilon_{t}$ and $\left\{\varepsilon_{i t}\right\}$ are independent random variables: $\varepsilon_{t} \sim N\left(0, \sigma^{2}\right)$ denotes the global error at time $t$, and $\varepsilon_{i t} \sim N\left(0, \sigma_{i}^{2}\right)$ denotes the individual error for farmer $i$ at time $t$.

We have chosen to introduce random errors on $g_{i t}$. This means that positive errors must also overcome farmers' overall resistance to change $\left(\delta_{i}\right)$. For example, consider a farmer with $\Delta \bar{m}_{i t}=0$ as $g_{i t}<\delta_{i}$ before random errors are introduced. Suppose this farmer is subjected to a positive error, say $\varepsilon$. In order for the error to result in technology adoption it must be large enough such that $g_{i t}+\varepsilon>\delta_{i}$.

The choice of distribution for the random variables $\varepsilon$ and $\left\{\varepsilon_{i}\right\}$ determines the relative likelihood that errors will be positive or negative, and the possible magnitudes of any errors. In the absence of strong preferences for any other shape, we have assumed that errors follow a normal distribution. Hence positive and negative errors are equally likely and small to moderate errors are more common than large errors.

The magnitudes of $\sigma$ and $\left\{\sigma_{i}\right\}$ must be interpreted with respect to farmers' intentions to adopt technology. Consider the inertia model without randomness (as demonstrated in chapters 3 and 4): from this we can calculate farmers' average intention to adopt technology (the mean of $g_{i t}$ when $\forall i, t: \varepsilon_{t}, \varepsilon_{i t}=0$ ). The ratio of farmers' average adoption intentions to $\sigma$ and $\sigma_{i}$ gives an indication of the relative significance of errors on farmers' actual technology adoption.

The introduction of global and individual errors will increase the volatility of farmers' technology adoption. Global errors will affect the technology adoption of the entire catchment in the same way: so their primary effect will be to change the adoption of technology across all farmers. Individual errors will affect the technology adoption of different farmers in different ways: so their primary effect will be to change the differences in technology adoption between farmers. 


\subsection{Model performances with random inertia}

We demonstrate the inertia model with random inertia using the approach given in section 4.2. The results in this section differ from those in chapter 4 by the inclusion of global, $\varepsilon_{t}$, and individual errors, $\left\{\varepsilon_{i t}\right\}$.

As farmers are adopting 26 units of technology (to support a 50 percent reduction in baseline emissions $e_{i}=52$ ) within about 15 years, their average rate of technology adoption is approximately 1.73 units per hectare per year. We choose $\sigma=0.5$ and $\sigma_{i}=0.5$, for all $i$. This ensures that random variations in farmers' inertia $\left(\varepsilon_{t}\right.$ or $\left.\varepsilon_{i t}\right)$ are likely to be less than half of farmers' average technology adoption $\left(\varepsilon_{t}, \varepsilon_{i t}<1.73 / 2\right)$.

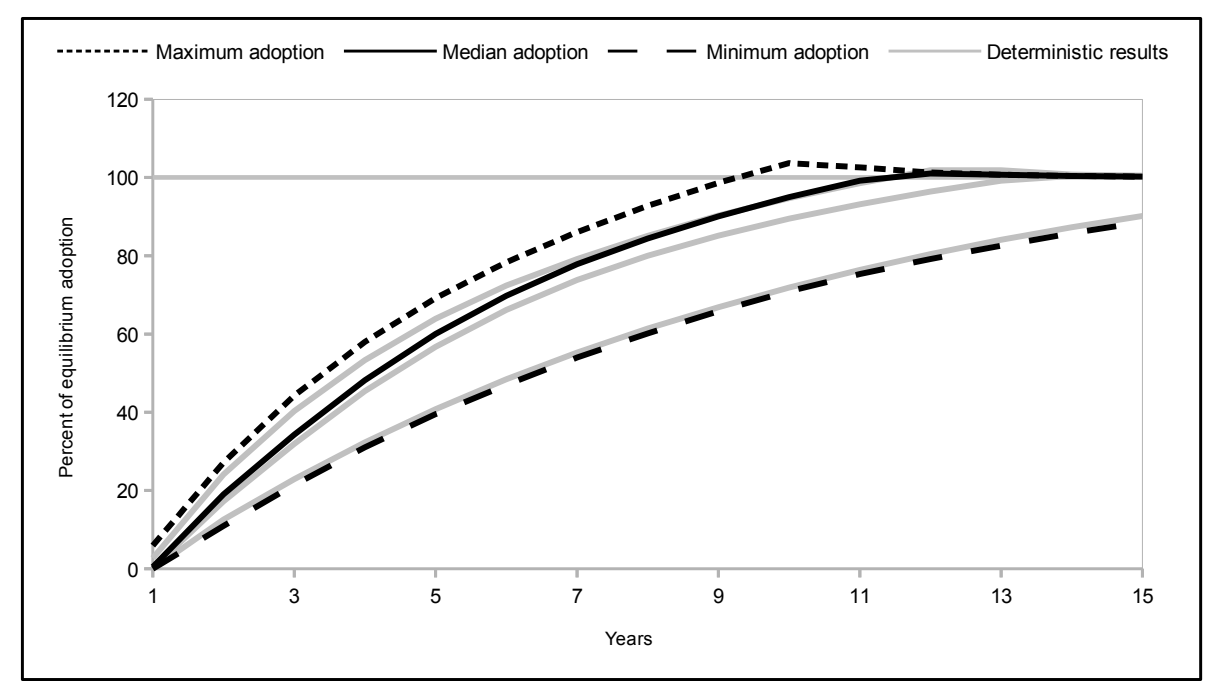

Figure 17. Technology adoption curves with individual errors

Figure 17 gives the maximum, median and minimum technology adoption by farmers over time when subject to individual errors. The results from the deterministic case (as per figure 9) are given in gray. As the expected value of the errors is zero, we might expect that on average random errors would have no effect. However, we observe that individual errors result in faster maximum and median technology adoption. This suggests that there are spillover effects from positive errors that are not completely countered by negative errors. We discuss the effect of each of these errors next.

Suppose there are several farmers who have adopted very similar levels of technology to the farmer with the most amount of technology. If any one of these farmers experiences a positive individual error, their technology adoption will increase ( $m_{i t}$ will be higher than it would have been without the error), and the maximum level of technology adopted by any farmer will also increase $\left(\max _{j}\left\{m_{j t}\right\}\right.$ will 
be higher than it would have been without the error). Recall from (2.18) that farmers learn by comparing their level of technology with the maximum level of technology in use. Hence, as positive errors increase the maximum level of technology adoption, they result in increased technology adoption due to learning.

Alternatively, if the farmer with the most technology experiences a negative individual error, their technology adoption will slow $\left(m_{i t}\right.$ will be lower than it would have been without the error), but there will be minimal decrease in the maximum level of technology adopted by any farmer $\max _{j}\left\{m_{j t}\right\}$ will change very little despite the error) because there exist farmers with very similar levels of technology, at least one of which is likely not to have experienced a negative error. Rather than learning from the farmer who had the most technology, but suffered a negative error, other farmers will instead learn from a farmer who had very similar levels of technology and did not suffer a negative error. Hence, as negative errors have minimal impact on the maximum level of technology adoption, they result in little decrease in technology adoption due to learning.

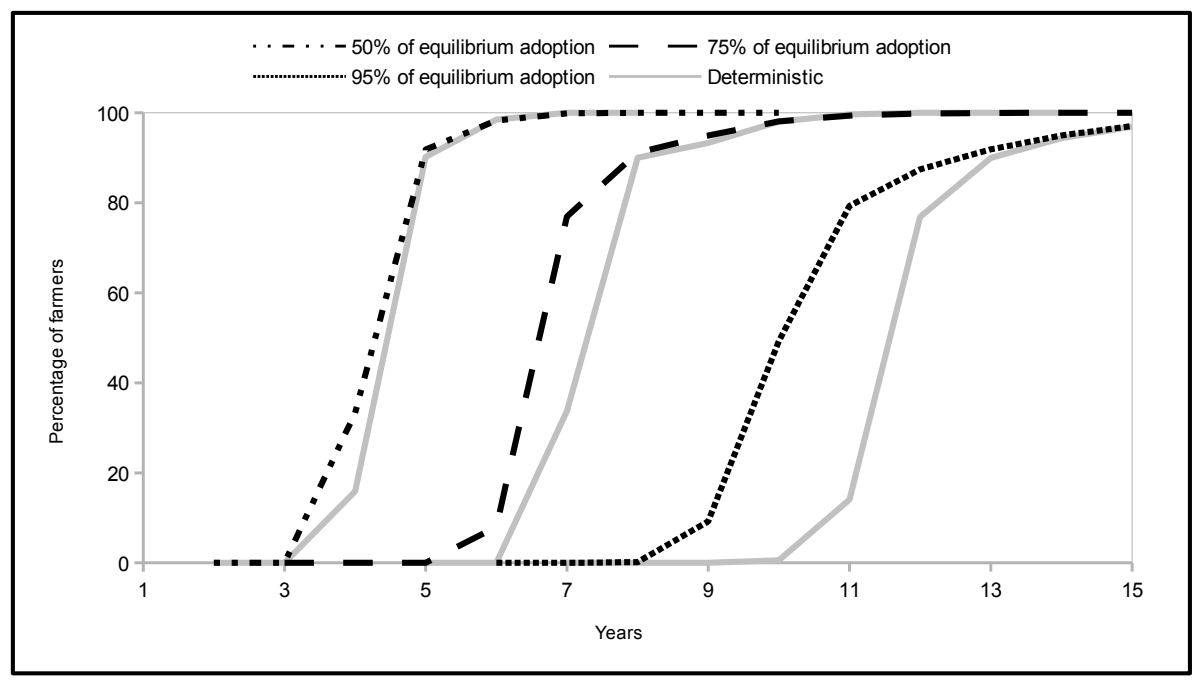

Figure 18. Adoption curves for specific technology thresholds with individual errors

Figure 18 gives the proportion of farmers, over time, who have adopted at least a specific percentage of their equilibrium technology, when subject to individual errors. The results from the deterministic case (as per figure 10) are given in gray. We observe that individual errors result in faster technology adoption than the deterministic results as farmers approach equilibrium. While much of this effect will be due to learning spillovers, part of this effect will be due to how the effect of errors changes over time.

Consider that as farmers approach their equilibrium technology, the rate at which they adopt new technology decreases. As the magnitude of errors is inde- 
pendent of the rate at which farmers are adopting new technology, the magnitude of individual errors relative to a farmer's new technology adoption will be increasing with time. Furthermore, as a farmer approaches equilibrium the impact of negative errors decreases as farmers can not adopt less than zero units of new technology. It follows that while the expected value of individual errors is zero, their average effect over time is positive as farmers approach equilibrium.

This is consistent with our intuition as to how farmers behave in reality: In the short term, after the introduction of regulation farmers will be most active adopting new technologies. While errors may help or hinder their adoption of new technology, they are likely to make some changes each year. However, once farmers have adopted most of the technology they need, further technology adoption is unlikely to be a priority and will be delayed until the circumstances are right (as represented by a positive error).

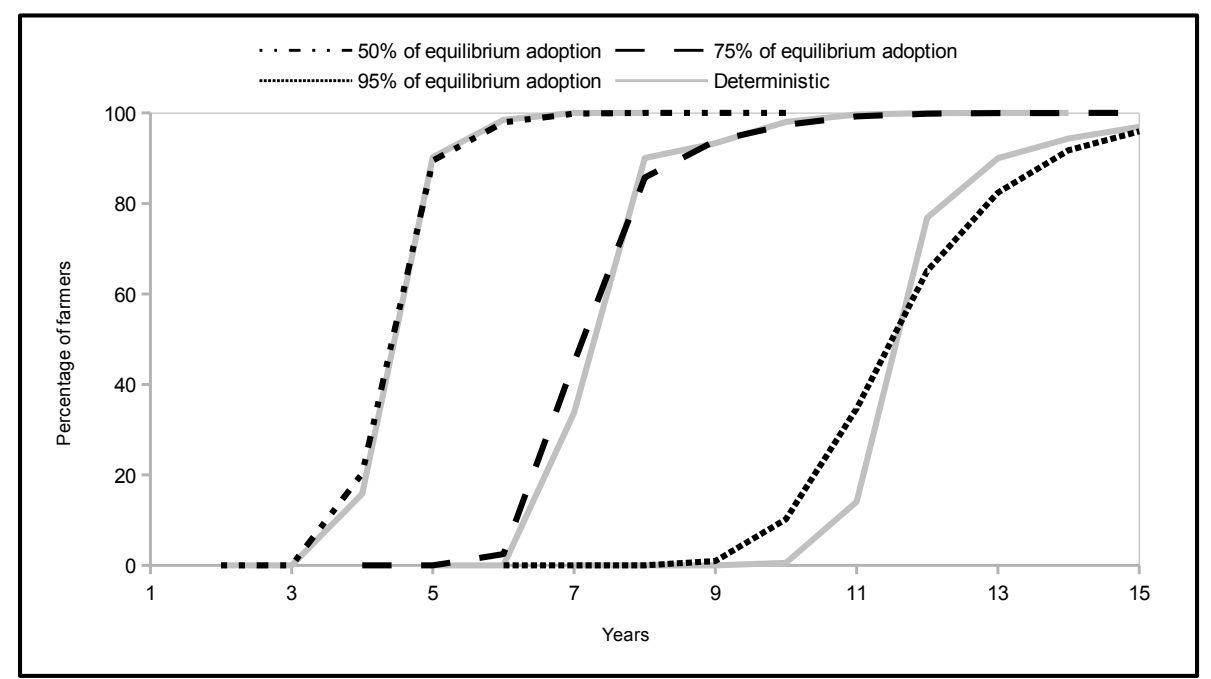

Figure 19. Adoption curves for specific technology thresholds with global errors

Figure 19 gives the proportion of farmers, over time, who have adopted at least a specific percentage of their equilibrium technology, when subject to global errors. The results from the deterministic case (as per figure 10) are given in gray. We observe that global errors result in adoption curves that suggest faster adoption in early years and slower adoption in later years (this is easiest to observe for the 95 percent curve).

This is almost entirely due to the construction of these curves as averages. ${ }^{1}$ Consider that a positive (negative) global error means that all farmers reach any given technology adoption threshold earlier (later). This is effectively a translation

\footnotetext{
${ }^{1}$ As in chapter 4, figures 17, 18 and 19 are constructed as averages over 1001 model solutions. For our results in this section we used the same random seeds for parameterizing the model as in chapter 4 to ensure that our results are directly comparable.
} 
of the deterministic adoption curve to the left (right). When we consider the average of many adoption curves translated by global errors we get the curves given in figure 19. It follows, that what we are observing in figure 19 is an increase in the volatility of farmers' technology adoption.

We constructed an alternative to figure 17 for the case where there are only global errors, and alternatives to figures 17 and 18 for the case where there are both kinds of errors. However, we do not provide these figures as the effect of global errors is difficult to distinguish in the alternative figure 17 , and (because there is no interaction between the different sources of error) the effect of both global and individual errors together is just the combination of the effect of having each source of error separately.

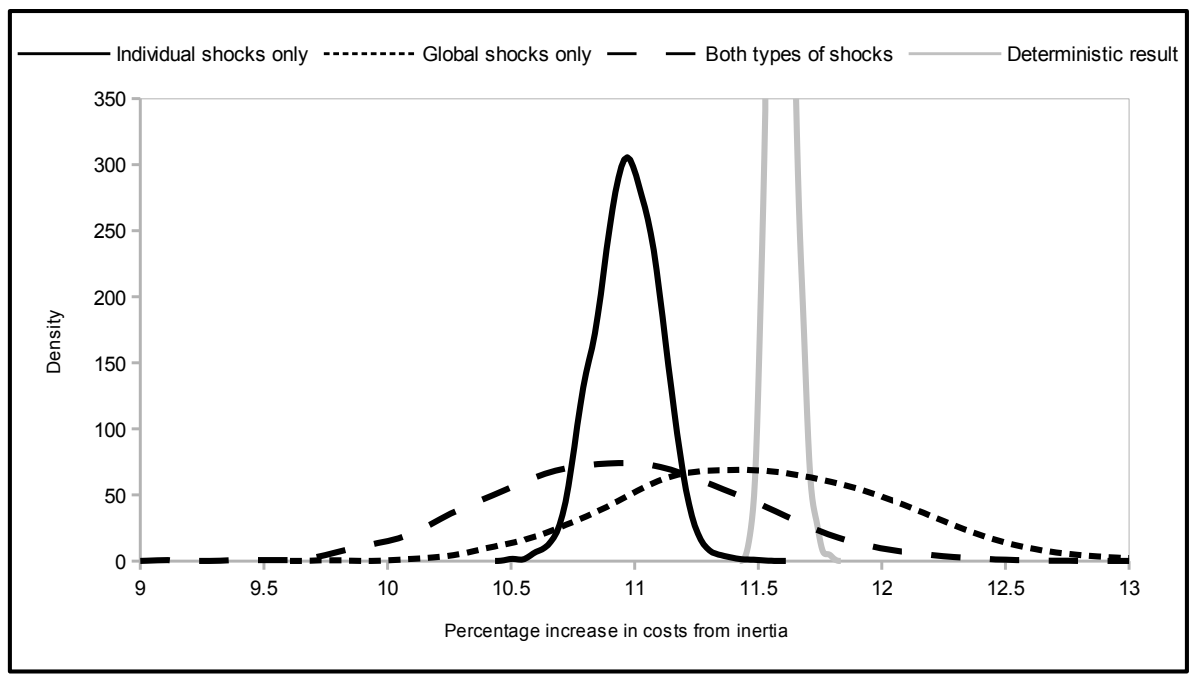

Figure 20. Distribution of the increase in costs due to inertia with random inertia

Figure 20 gives the distribution of the percentage increase in costs due to inertia over 1001 model solutions with randomly assigned values for farmers' inertia parameters. We give the distributions for the cases where there are only individual errors, only global errors, and when there are both individual and global errors. The result from the deterministic case (as per figure 12) is given in gray. We observe that individual errors result in a small decrease in the expected value of costs, while global errors significantly increase the volatility of costs.

We expect that the impact of global errors on the cost of mitigation occurs mostly as a result of errors in the short term. Suppose that in the first few periods there were several positive (negative) errors, and no negative (positive) errors: the joint impact of there errors is that farmers will adopt more (less) technology than they would in the deterministic case. This will increase (decrease) their profits for 
all future time periods, decreasing (increasing) the cost of mitigation. ${ }^{2}$ That individual errors decrease the expected cost of mitigation is consistent with farmers' technology adoption as described by figures 17 and 18 .

Figures 17 to 20 demonstrate the performance of the inertia model when farmers' adopt decisions are subject to random errors. Individual errors result in learning spillovers that increase the overall rate of technology adoption. This is because individual errors change the differences in technology adoption between farmers. Global errors increase the volatility of all farmers' adoption of new technology. This is because global errors change the average adoption across all farmers.

This information is of interest to stakeholders as it provides an indication as to how actual outcomes might differ from those anticipated by the deterministic model. Where regulators or local government are considering intervening in the catchment to encourage adoption, this could be considered as a positive error. Our results suggest that intervention that encourages technology adoption on those farms that other farmers learn from will be the most effective.

\footnotetext{
${ }^{2}$ This effect will be compounded by considering the net present value of the cost of mitigation (as we do when calculating the increase in costs due to inertia). As we use a positive discount rate when calculating the net present value, the cost in the first few periods will have a larger relative impact on our reported measure than the costs in the later periods.
} 


\section{Chapter 6}

\section{Estimation and Validation}

The parameters provided for the demonstration of the model, in chapters 4 and 5 , were chosen to give results that are consistent with our expectations. However, any practical application of the inertia model developed in this study requires the successful completion of two steps: the estimation of the model parameters, and evidence as to the validity of the model results.

This chapter has a two-fold purpose: First, we consider the data that would be necessary to empirically estimate the model parameters and describe how these estimates could be obtained. Second, we discuss some approaches to assessing the validity of the model in comparison to the performance of previously implemented environmental trading schemes.

\subsection{Parameter estimation for farm profit functions}

Recall that the behavior of any given farmer is determined by ten parameters (six for farm profit and four for farmer inertia, see table 5). Just as the choice of functional forms for farms' profit and farmers' inertia functions are independent of each other, so also we can estimate the parameters for each of these functions independently. The six parameters that define a farm's profit function are $a_{i}, b_{i}, c_{i}, d_{i}, e_{i}$ and $q_{i}$.

Farm profit functions define the relationship between technology $m_{i t}$, nutrient emissions $n_{i t}$, and profit $\pi_{i}\left(m_{i t}, n_{i t}\right)$. Any estimation of this relationship will require observations that include farms' technology, emissions and profit across a variety of values. Note that to be consistent with our definitions, technology $m_{i t}$ must be measured as the amount of nutrients the adopted technology (or combination of technologies) can cost effectively mitigate.

Consider a dataset containing observations of farm technology, emissions 
and profit. Each data point must represent a feasible farm system: either a system currently in use on some collection of farms, or a system that expert opinion suggests farmers may adopt. Models of farm production (such as Farmax, Bryant et al. 2010) and emissions (such as OVERSEER, AgResearch 2009) may help experts to construct appropriate farm systems. Observations of current farm systems represent farming approaches that must be feasible. This type of data will be most useful where there exists heterogeneity between existing farm systems and nutrient regulation will encourage all farmers to move towards using the same type of existing farm system. Observations of farm systems that farmers could theoretically adopt (based on expert opinion) are able to capture the full potential of new technologies. This type of data will be most useful when very few farmers are currently using the key technologies.

To supplement this data we require information on each farm's baseline nutrient emissions $e_{i}$, and the cost of technology $q_{i}$. Estimates for farms' baseline emissions must be known prior to any analysis taking place. These will depend on farm inputs, land characteristics (including soil and topography) and the local climate (including temperature and rainfall). The estimation of baseline nutrient emissions is well established in practice, as this information is critical in order to justify the introduction of any nutrient regulation on farmers (see for example Rutherford et al. 2011)

The cost of technology $q_{i}$ can be obtained in two different ways: either calculated by an expert such as a farm consultant or technology supplier, or estimated from observed farm profits at the same time as $a_{i}, b_{i}, c_{i}$ and $d_{i}$, below. If the cost of technology is obtained from a farm consultant then farm profits should be adjusted to exclude the cost of technology when estimating the parameters $a_{i}, b_{i}, c_{i}$ and $d_{i}{ }^{1}$

Given $n_{i t}, m_{i t}$ and an estimate for farm's baseline emissions $\hat{e}_{i}$ we may estimate the parameters $a_{i}, b_{i}, c_{i}, d_{i}$ and $q_{i}$ according to farms' profit function (2.12):

$$
\pi_{i}=a_{i} n_{i t}^{2}+b_{i} n_{i t}+c_{i}+d_{i}\left(\hat{e}_{i}-n_{i t}-m_{i t}\right)^{2}-q_{i} m_{i t}
$$

Note that the profit function is linear with respect to the model parameters. As $n_{i t}{ }^{2}$, $n_{i t},\left(\hat{e}_{i}-n_{i t}-m_{i t}\right)^{2}$ and $m_{i t}$ can be constructed as our explanatory variables we may estimate the parameters using linear regression.

Alternatively, if the cost of technology $q_{i}$ is know from a farm consultant or technology supplier, then we need only estimate $a_{i}, b_{i}, c_{i}$ and $d_{i}$ and may adapt (2.12)

\footnotetext{
${ }^{1}$ This differs from the approach we take in chapter 4 . Where we were unable to identify the cost of technology, we instead estimated the $a, b, c$ and $d$ parameters using profit values that included the cost of technology. Hence the value of $q$ was implicitly captured in our $\hat{a}, \hat{b}, \hat{c}$ and $\hat{d}$ values.
} 
as follows:

$$
\pi_{i}+\hat{q}_{i} m_{i t}=a_{i} n_{i t}^{2}+b_{i} n_{i t}+c_{i}+d_{i}\left(\hat{e}_{i}-n_{i t}-m_{i t}\right)^{2}
$$

Recall from section 2.3 that we require that profit is initially increasing with nutrient emissions; marginal profit is deceasing with nutrient emissions; and the change in profit with respect to nutrient emissions is initially decreasing with the adoption of technology. These requirements imply that our parameters should take specific signs.

We will consider each of the requirements from section 2.3, and the signs they imply for our parameter, in turn. If these sign conditions are not satisfied, following the estimation of the $a_{i}, b_{i}, c_{i}, d_{i}, e_{i}$ and $q_{i}$ parameters, then either the functional form of farms' profit function or the use of the inertia model may not be appropriate.

- Consider the requirement that the change in profit with respect to nutrient emissions is initially decreasing with the adoption of technology (up to some level $\left.m_{i t}^{u}\left(n_{i t}\right)\right)$ :

$$
m_{i t} \in\left[0, m_{i t}^{u}\left(n_{i t}\right)\right] \rightarrow \frac{\partial^{2} \pi_{i}}{\partial m_{i t} \partial n_{i t}}<0 .
$$

Let $m_{i t}^{u}\left(n_{i t}\right)=m_{i t}^{*}$, then we are concerned with farms' profit function when $m_{i t}<m_{i t}^{*}$. From (2.12), if $m_{i t}<m_{i t}^{*}$, we have $\frac{\partial^{2} \pi_{i}}{\partial m_{i t} \partial n_{i t}}=2 d_{i}$. This implies $d_{i}<0$.

- Consider the requirement that marginal profit is decreasing with nutrient emissions:

$$
\frac{\partial^{2} \pi_{i}}{\partial n_{i t}^{2}}<0 .
$$

This must hold regardless of whether or not farmers' use of technology is optimal. From (2.12), if $m_{i t}<m_{i t}^{*}$, we have $\frac{\partial^{2} \pi_{i}}{\partial n_{i t}^{2}}=2 a_{i}+2 d_{i}$; and from (2.12) and (2.13), if $m_{i t}=m_{i t}^{*}$, we have $\frac{\partial^{2} \pi_{i}}{\partial n_{i t}^{2}}=2 a_{i}$. This implies $a_{i}<0$.

- Consider the requirement that profit is initially increasing with nutrient emissions (up to some level $n_{i}^{u}$ ):

$$
n_{i t} \in\left[0, n_{i}^{u}\right] \rightarrow \frac{\partial \pi_{i}}{\partial n_{i t}} \geq 0 .
$$

This must hold regardless of whether or not farmers' use of technology is optimal. From (2.12), if $m_{i t}<m_{i t}^{*}$, we have $\frac{\partial \pi_{i}}{\partial n_{i t}}=2 a_{i} n_{i t}+b_{i}-2 d_{i}\left(e_{i}-n_{i t}-m_{i t}\right)$; and from (2.12) and (2.13), if $m_{i t}=m_{i t}^{*}$, we have $\frac{\partial \pi_{i}}{\partial n_{i t}}=2 a_{i} n_{i t}+b_{i}$. This implies $b_{i}>0 .^{2}$

In addition, we require that the cost of technology is positive: $q_{i}>0$.

\footnotetext{
${ }^{2}$ We might expect that $n_{i}^{u}=e_{i}$, so that farmers' baseline emissions are profit maximizing; or that $n_{i}^{u}>e_{i}$, so farmers can earn more profit from further increasing emissions beyond baseline. Either of these expectations further refine the constraint on the value of $b_{i}$.
} 


\subsection{Parameter estimation for farmers' inertia functions}

Farmers' inertia functions determine their adoption of new technology as a function their past adoption decisions and the past adoption decisions of other farmers. The four parameters that define a farmer's inertia function are $\alpha_{i}, \beta_{i}, \gamma_{i}$ and $\delta_{i}$. An overview of the parameters can be found in table 5 . Each farmer's inertia function also makes use of their farm's baseline leaching, $e_{i}$. We discuss the measurement of $e_{i}$ in the previous section, and for this analysis we assume that it is known.

The ideal data set for estimating farmers' inertia parameters would consist of farmers' technology, $m_{i t}$, and the technology that would have been optimal for them, $m_{i, t-1}^{*}$, for every farmer and for every time period. In addition we should like to know the social and professional network $I_{i}$ for each farmer $i$. From this data it would be straightforward to construct and solve a regression for each farmer's parameter values according to the following equation.

$$
\begin{aligned}
\Delta m_{i t} & =g_{i t}-\delta_{i} \\
& =\alpha_{i} e_{i} \tau_{i}+\beta_{i}\left(m_{i, t-1}^{*}-m_{i, t-\tau_{i}}\right)+\gamma_{i}\left(\max _{j}\left\{m_{j} i n I_{i}, t-1\right\}-m_{i, \tau_{i}}\right)-\delta_{i}
\end{aligned}
$$

Recall from (2.17) that $\Delta \bar{m}_{i t}=0$ if $g_{i t} \leq \delta_{i}$ and $\Delta \bar{m}_{i t}=g_{i t}-\delta_{i}$ if $g_{i t}>\delta_{i}$. As $0 \leq \Delta m_{i t} \leq \Delta \bar{m}_{i t}$ if a farmer's inertia is binding it follows that $\Delta m_{i t}$ will be left censored $\left(\Delta m_{i t}=0\right.$ if $\left.g_{i t}<\delta_{i}\right)$. Regression analysis to determine farmers' inertia parameters will have to account for this censoring of the data. This can be done using a Tobit model (Wooldridge 2010, provides a good explantion of the Tobit model).

However, while farmers' technology adoption, and social and professional networks can be observed, it is difficult to measure the technology adoption that should be optimal for farmers, $m_{i, t-1}^{*}$. Furthermore, if farmers' individual technology adoption is not observed but only a measure of average technology adoption is available, then it also becomes very difficult to determine the maximum technology that farmer $i$ can learn from $\max _{j}\left\{m_{j \in I_{i}, t-1}\right\}$.

We will consider three approaches to determining farmers' inertia parameters: (1) parameter estimation using proxies in place of $m_{i, t-1}^{*}$ and $\max _{j}\left\{m_{j \in I_{i}, t-1}\right\}$; (2) parameter estimation using farmer survey data; and (3) model calibration to match existing technology adoption curves.

Prior to considering any of these approaches we first discuss the estimation of farmers' $\alpha_{i}$ parameter. This parameter represents how often the farmer replaces or updates their existing farm technologies. Unlike the other parameters in the inertia function, $\alpha_{i}$ can be observed in the year-to-year management of the farm business 
(irrespective of nutrient regulation, or the availability of new technology). Consider the financial statements produced by a farmer each year. Where adopted technologies represent assets to the farm their value will appear in the financial statements. We can infer the frequency with which these assets are replaced from their annual depreciation, which should also be reported in the financial statements. This frequency will be an estimation for $\alpha_{i}$.

Proxies may be useful for estimating farmers' inertia parameters (especially $\beta_{i}$ and $\gamma_{i}$ ) where $m_{i, t-1}^{*}$ and $\max _{j}\left\{m_{j \in I_{i}, t-1}\right\}$ can not be observed. A potential proxy for $m_{i, t-1}^{*}$ is a farmer's expected equilibrium technology adoption. A potential proxy for $\max _{j}\left\{m_{j \in I_{i}, t-1}\right\}$ is technology that is being used or demonstrated on farms regardless of whether or not they are part of farmers' social and professional networks. Note that in our demonstration of the model in chapter $4, m_{i, t-1}^{*}$ and $\max _{j}\left\{m_{j \in I_{i}, t-1}\right\}$ for each farmer $i$ change as other farmers adopt new technology $\left(m_{i, t-1}^{*}\right.$ decreases over time and $\max _{j}\left\{m_{j \in I_{i}, t-1}\right\}$ increases). It follows that care must be taken to ensure that proxies for these values demonstrate similar behavior. ${ }^{3}$

Surveying farmers about when they would adopt technology could create a dataset for estimating farmers' inertia function parameters. Such a survey should capture farmers' intentions conditional on the information they are provided with. This information would include what technology other farmers are adopting (to represent $\max _{j}\left\{m_{j \in I_{i}, t-1}\right\}$ ) and what technology is likely to be optimal for them to adopt (to represent $m_{i, t-1}^{*}$ ). For example, consider the following questions: ${ }^{4}$

1. Here is a list of technologies and practices that could be used to manage your farm's nutrient emissions. Please identify any of these options that you are already using on your property.

2. Suppose you were required to reduce the nutrient emissions from your property by $X$ percent. Please identify which technologies and/or practices you would use to meet this reduction.

3. Here is a time-line. Please mark on it in which years you would use the technologies and/or practices you identified in the previous question.

4. Suppose your neighbor or friend installed technology $Z$ on their farm in year $Y$. Would your response to question 3 change in response to this additional information? If so, what would you do differently?

5. Suppose that in year $Y$ a farm consultant looked at your farm and provided good evidence that technology $Z$ would improve the profitability of your farm. Would your response to question 3 change in response to this additional infor-

\footnotetext{
${ }^{3}$ Or the form of farmers' inertia function must be revised to use the available data.

${ }^{4}$ These questions are only provided as an example to demonstrate the kind of information we would like to collect. Proper survey design and execution are essential for collecting valid data.
} 
mation? If so, what would you do differently?

Analysis of these questions to estimate farmers' $\beta_{i}$ and $\gamma_{i}$ parameters would focus on the difference between farmers' responses to question three and farmers' responses to questions four and five. The intention of question three is to identify farmers' technology adoption decisions when they have no information as to what technology would be optimal and no other farmers to learn from (so $m_{i, t-1}^{*}$ and $\max _{j}\left\{m_{j \in I_{i}, t-1}\right\}$ are implicitly zero). The intention of comparing questions three and four is to identify how farmers' technology adoption decisions change when they have the opportunity to learn from other farmers (so $\max _{j}\left\{m_{j \in I_{i}, t-1}\right\}$ is non-zero). From this information we would estimate the value of farmers' $\gamma_{i}$ parameters. The intention of comparing questions three and five is to identify how farmers' technology adoption decisions change when they have information as to what technology would be optimal for them (so $m_{i, t-1}^{*}$ is non-zero). From this information we would estimate the value of farmers' $\beta_{i}$ parameters.

From farmers' answers to each of questions three, four and five we could infer their intended technology use in the long run. Given estimates for farmers $\alpha_{i}$, $\beta_{i}$ and $\gamma_{i}$ parameters, we could use this information to estimate the value of farmers' $\delta_{i}$ parameters.

Calibrating the model to match existing adoption curves is likely to be a less data intensive approach than using proxies or surveying farmers. This approach assumes that farmers' adoption of technologies in the past will provide a good estimator of their technology adoption in the future. Inspection of figures 3, 6 to 8 , 13 and 14 suggests that the effect of farmers' profit motivations (represented by $\beta_{i}$ ), learning from others (represented by $\gamma_{i}$ ), and resistance to change (represented by $\delta_{i}$ ) on technology adoption vary over time.

In the short term, the years immediately following the introduction of regulation, farmers will have adopted very little technology, and all farmers will have similar levels of technology. This implies that $m_{i, t-1}^{*}-m_{i, t-1}$ will be large and $\max _{j}\left\{m_{j \in I_{i}, t-1}\right\}-m_{i, t-1}$ will be small for most farmers. It follows that farmers' technology adoption in the short term will be largely determined by the magnitude of their $\beta_{i}$ parameters.

In the medium term, after farmers' initial response to regulation, farmers will have adopted some technology, and there will exist difference between individual farmers' technologies. This implies that $m_{i, t-1}^{*}-m_{i, t-1}$ will be small and $\max _{j}\left\{m_{j \in I_{i}, t-1}\right\}-m_{i, t-1}$ will be large for most farmers. It follows that farmers' technology adoption in the medium term will be largely determined by the magnitude 
of their $\gamma_{i}$ parameters.

In the long term, before farmers have completely responded to regulation, many farmers will be close to their equilibrium level of technology. This implies that both $\beta_{i}\left(m_{i, t-1}^{*}-m_{i, t-1}\right)$ and $\gamma_{i}\left(\max _{j}\left\{m_{j \in I_{i}, t-1}\right\}-m_{i, t-1}\right)$ will be small relative to $\delta_{i}$ for most farmers. It follows that farmers' technology adoption in the long term will be largely determined by the magnitude of their $\delta_{i}$ parameter.

We can use the knowledge that the drivers of farmers' technology adoption vary over time to help calibrate the model. Suppose we partition an existing adoption curve into short, medium and long terms. In the short term the effect of farmers' profit motivation is strong, while the effect of farmers' learning from others and resistance to change is weak. This suggests that $\beta_{i}$ values should be calibrated using the short term part of the adoption curve. In the medium term the effect of farmers' learning from others is strong, while the effect of farmers' profit motivation and resistance to change is weak. This suggests that $\gamma_{i}$ values should be calibrated using the medium term part of the adoption curve. In the long term the effect of farmers' resistance to change is strong, while the effect of farmers' profit motivation and learning from others is weak. This suggests that $\delta_{i}$ values should be calibrated using the long term part of the adoption curve.

\subsection{Model validation}

Formal validation of our model, and model results, requires detailed data on how farmers respond to nutrient regulation. As regulation of farms as non-point sources of emissions is still an emerging practice, we suspect that the necessary data is not yet available. However, we are hopeful that this data will be collected in the course of administering nutrient regulation of non-point sources.

We identify three ways to access the validity of the model given appropriate data: (1) comparing the speed with which farmers adopt new technology in reality against the speed suggested by our model; (2) comparing farms' profits before and after regulation against the profits suggested by our model; and (3) comparing the actual cost of obtaining an environmental goal against the cost estimated by our model. We discuss each of these approaches in turn.

Investigation of the speed with which farmers respond to nutrient regulation would enable us to assess the validity of farmers' inertia functions. This would require records of farmers' technology adoption over time. Construction of actual and model technology adoption curves (as per figure 9) or adoption curves for specific technology thresholds (as per figure 10) would provide an excellent way to 
compare the model results to reality.

Investigation of farm level profits before and after regulation would enable us to assess the validity of farms' profit functions. We would compare the profit of farms given their emissions and technology against the profit suggested by the farm profit functions. This would require records for both emissions and technology as well as actual farm profit. Some of this information could be obtained by linking the number of allowances surrendered by each farmer under a nutrient trading scheme with the technology and management practices each farmer reports using on their farm. An analysis of this type might soon be possible in the Lake Taupo catchment, New Zealand, where data on farm management and expected emissions are collected by the regional council as part of approving any trade of nutrient allowances (Duhon et al. 2012).

Investigation of the costs of obtaining an environmental goal would enable us to assess the overall validity of the model, including how the profit and inertia functions interact. This would entail a comparison of actual and model catchment profits over time following the introduction of regulation (similar to the dashed line in figure 11). As farm profits can be estimated from tax data or obtained from farm surveys, ${ }^{5}$ this approach to model validation is likely to be the easiest to obtain data for. However, without a supporting validation of the profit or inertia functions, this analysis alone will not be sufficient to ensure the validity of the model. As apparent consistency between the model and reality may be due to inconsistencies in farmers' inertia and profit functions that happen to offset each other.

In the absence of detailed farmer level data, the validity of the model may be demonstrated more generally using a range of other sources. These include how farmers have responded to other water related regulations and trading schemes.

The Dairying and Clean Streams Accord (Fonterra Co-operative Group et al. 2003) is an agreement between Fonterra (representing dairy farmers collectively) and the New Zealand government (both national and regional). It establishes targets for effluent management and stock exclusion from water ways in order to preserve the quality of New Zealands streams and rivers. Snapshots of progress are published every year, tracking the progress that is being made towards full exclusion of stock and effluent from water ways (see for example, the most recent report: Fonterra Co-operative Group et al. 2011). The accord expired in 2012, after around ten years, with 85 and 70 percent of dairy farms having stock excluded from water

\footnotetext{
${ }^{5}$ See for example the Agricultural Resource Management Survey (ARMS) conducted by the United States Department of Agriculture (USDA), or the farm monitor reports produced by the Ministry of Primary Industries (MPI), New Zealand.
} 
ways and compliant effluent systems respectively. While not directly comparable to nutrient trading regulation, farmers' behaviors in response to the accord are consistent with the behaviors suggested by the inertia model. In particular: farmers are still responding to the accord after ten years, and new response to the accord is faster (slower) where fewer (more) farmers have already responded. Furthermore we observe variations in response across regions of farmers under the accord, just as we would observe variation between farmers (or groups of farmers) under the inertia model.

Around 2009, New Zealand implemented a nutrient trading scheme for nonpoint sources (farms) in the Lake Taupo catchment. Although this scheme is still relatively young, with only 32 trade reported between January 2009 and June 2012 (Duhon et al. 2012), we are able to observe that the number of trades has become more frequent over time. While there may be other contributing factors, this is consistent with the motivation for our model: farmers display initial resistance to change, but this resistance weakens over time.

Many regulatory schemes for water quality (more broadly than nutrients), especially in the United States, focus on point sources (Selman et al. 2009). While in a few cases non-point sources are regulated directly and trades between non-point sources occur, in the majority of cases non-point sources are not included by default but instead have the option to opt-in and trade with point sources. According to Breetz et al. (2004) trades between non-point sources and trades from non-point to point sources occur infrequently, much less than was originally anticipated. While this will be due to a range of factors, the lack of non-point source opt-in and trading is consistent with the ideas developed in our inertia model. That regulators are not focusing on non-point source trading schemes may be due to a recognition that farmers' inertia will make it difficult to obtain support for such regulation and will reduce the effectiveness of any regulation that would be passed.

A note on data from point sources: The fundamental difference between point and non-point sources is that leaching from non-point sources is diffuse. This means that almost any reduction in nutrient emissions must be accompanied by some reduction in farm intensity or inputs. In contrast, point sources can achieve reductions in nutrient emissions by installing technology, such as filters, at their point(s) of discharge. In addition, point sources (such as sewage treatment plants) tend to have greater access to finance and more research staff than non-point sources who, in New Zealand, tend to be operated by an individual for whom their wealth, wellbeing and sense of identity may be tied up in their business. Due to these fundamental differences data from point sources is of little help validating the model described here. 


\section{Chapter 7}

\section{Discussion and Conclusions}

The inertia model developed in this study uses aspects of farmers' behavior to determine their technology adoption decisions over time when faced with nutrient regulation. While many studies have identified factors that contribute to the adoption of new technology by farmers, our study is among the first to develop a model that explicitly captures the dynamics of farmers' technology adoption decisions and how these decisions impact the profitability of their farms.

Our work extends the static economic model for profit maximization given an environmental constraint (equations (2.4) - (2.5)) by introducing an additional constraint that requires farmers' technology use each period to be similar to their technology use in the previous period (our inertia constraint, equation 2.3). We attribute this need for similarity between periods to farmers' resistance to change, which we describe as inertia.

We have specified both the general form of the model as well as specific functional forms for the farm profit and farmer inertia functions. These specific functional forms were chosen to provide an intuitive demonstration of the model. We analytically investigated the individual technology adoption behavior of farmers in several special cases when there are only two farmers. Our model suggests that farmers' profit motivation drives their technology adoption in the short term, and that learning from other farmers drives technology adoption in the medium term. Furthermore, when other farmers are slow to adopt technology, those farmers that are the first to adopt new technology may adopt more technology than is optimal in equilibrium. These results are of interest to policy makers where they want to understand or encourage technology adoption by farmers.

Analysis of the model in the 'many farmer' case (chapter 4) is analytically intractable. Hence we investigate the performance of the model in this case using a nu- 
merical approach. As we lacked the necessary data to formally estimate the model parameters, these were instead chosen to produce behavior consistent with existing profit and adoption measures. Our results detail both how technology adoption varies between farmers and how progressive technology adoption increases the cost of regulation. For our choice of parameters the majority of farmers had similar technology adoption curves over time but a small number of farmers consistently took longer to adopt new technology. Full technology adoption took more than 15 years and the cost of satisfying the environmental target was estimated to be more than 11 percent higher under the inertia model than under the static economic model.

\subsection{Extensions}

The inertia model relaxes the assumptions that

1. farmers are willing to change,

2. farmers' decisions are independent of their past decisions,

3. and farmers' decisions are independent of the decisions of other farmers.

However, in doing this we have introduced two alternative assumptions. First, decision makers are short sighted, and second, technology adoption can occur continuously. We should like to further investigate the significance of these assumptions and to further develop the model to consider alternatives to these assumptions.

In a static world, where prices and technologies are constant, we might expect farmers to adopt technology as rapidly as possible. This kind of behavior arises in our model from our assumption that decision makers are short-sighted. However, as we move away from a static world, assuming short-sighted decision making becomes harder to justify: Farmers will have incentives to delay technology adoption, not due to inertia, but because costs are expected to be more favorable in future time periods. The assumption of short-sightedness could be replaced by incorporating farmers' planning horizons (the length of time over which farmers make investment decisions) into the model and allowing farmers to optimize within their planning horizon.

The inertia model allows for continuous technology adoption. Where $m_{i t}$ captures not just the technology that farmers have adopted but also how the technology is incorporated into the farm system (and any associated management practices) it may be reasonable to consider technology as a continuous decision. However, the adoption of any specific technology (such as the installation of a feeding or wintering pad) is a step increase in a farm's technology. We could relax the assumption that technology adoption is continuous by adapting the inertia model to allow for discrete (or lumpy) technology adoption. This would enable us to construct adop- 
tion curves for specific technologies (instead of technology thresholds as per figures $10,14,18$, and 19).

One of the frequent concerns with environmental markets is the potential for local hot spots (see for example Schary \& Fisher-Vanden 2004, in the case of water quality). These occur where there is (spatial or temporal) clustering of the environmental damages from emissions. So, despite the average environmental damage being within acceptable levels, the damage in specific locations, or at specific times, exceeds acceptable levels. Regulators who are concerned about the potential for hot spots often respond with zonal emission restrictions (so emitters face both an overall limit as well as a local limit on emissions) or trading ratios (so when farmers trade there is not a one-to-one ratio between the decrease in the seller's emissions and the increase in the buyer's emissions). The inertia model could be extended to account for localized hot spots by introducing either of these regulatory responses.

We calibrated farmers' inertia functions using existing technology adoption curves. If the inertia model captures the key determinants of farmers' technology adoption then we might expect it to be able to replicate existing adoption curves. If so, then this suggests that the S-shape of technology adoption curves for farmers may be due to the aggregation of the decisions of many farmers who have different motivations for adopting. ${ }^{1}$ Investigation of this has been left for future research.

Recall from section 2.1 that farm profits are additive in the social planner's objective function (2.1). This implies that profits from different farms are equivalent and the social planner has no preference as to which farm, or farms, generate the profits. This assumption need not hold and the inertia model could be easily adapted by introducing weights into the social planner's objective function (2.1). Alternatively, we anticipate that an equivalent to introducing weights in the social planner's objective function could be accomplished by the use of trading ratios that favor some farmers over other farmers.

The inertia model is a partial equilibrium model as it treats the available technologies, the environmental target, and commodity prices as exogenous. Our work in this study could be nested within a more general economic framework that would allow some of these factors to be endogenous. For example: new technologies may be developed by innovative farmers, giving other farmers an incentive to delay technology adoption until the new technologies are proven; the cost of technologies may decrease over time as more efficient approaches to construction or installation are

\footnotetext{
${ }^{1}$ We have observed the inertia model to produce S-shaped curves for total technology adoption when there are a small number of profit-driven farmers (who's adoption is driven by their $\beta_{i}$ parameter) and large number of learning-driven farmers (who's adoption is driven by their $\gamma_{i}$ parameter).
} 
developed ( $q_{i}$ becomes time dependent); or the stringency of the environmental target may be adjusted by the regulator if the cost to farmers is perceived to be too high. These more general frameworks might provide insight into how farmers' resistance to change affects not just their profitability but also the outcomes for their communities.

In our model each farmer is described by ten parameters $\left(a_{i}, b_{i}, c_{i}, d_{i}, e_{i}, q_{i}\right.$, $\alpha_{i}, \beta_{i}, \gamma_{i}$ and $\left.\delta_{i}\right)$. We have provided an example of the calibration of our model and the results it produces. However, it would be worthwhile to demonstrate the application of this model to actual data. We anticipate that a more formal parameter estimation and model validation will be conducted once the appropriate data becomes available.

\subsection{Contribution}

This study extends the static economic model for profit maximization under an environmental constraint (equations (2.4) - (2.5)) to account for farmers' resistance to change. The inertia model we have developed (sections 2.1 - 2.3) is able to capture the short run dynamics of farmers' technology adoption while being consistent with the static model in equilibrium (section 3.1).

Farmers' willingness and motivation to change is difficult to measure. However, by defining inertia as the maximum amount of technology a farmer will adopt $\left(\bar{m}_{i t}\right)$, we are able to quantify it. While many studies have identified different drivers of technology adoption for farmers (section 1.1), our model enables us to combine the different factors that influence adoption decisions (such as profit, risk, learning, and environmental concern) as part of farmers' inertia function (2.3).

In section 2.4 and 2.5 we have provided functional forms for the farm profit functions (2.12) and farmer inertia functions (2.17) - (2.18), respectively. These functional forms were chosen for their simplicity and mathematical elegance in order to ensure that our demonstration of the model is both intuitive and computationally tractable. Propositions 2 - 5 (sections 3.2 - 3.3) prove that our choice of functional forms are consistent with the outcomes we would expect in reality.

We demonstrate the performance of the inertia model in chapter 4 . This includes outcomes for both the adoption of new technology (figures 9 and 10) and the costs of mitigation (figures 11 and 12). Furthermore, these outcomes can be decomposed for groups of farmers (figures 13 to 16). We anticipate that researchers working with the static economic model will be interested in the type of results we demonstrate as they provide an estimate of how results from the static model may 
differ from reality.

While the inertia function may provide a good indication of farmers' intentions to adopt new technology, there will be other factors that influence farmers' actual adoption. As one way to account for these factors we allow for farmers' technology adoption to be subject to random errors (chapter 5). This highlights the value of learning spillovers in encouraging more rapid technology adoption, and provides further information to users of the static model, as to how their results may differ from reality.

As the regulation of non-point source emissions from farms is still an emerging practice we lack the data necessary to formally estimate the model parameters, or assess the validity of our model. Instead we provide a clear description as to what such data would look like and how it might be obtained (chapter 6).

In developing the inertia model we have taken a novel approach to considering farmers' technology adoption decisions. However, despite being unconventional, our model is capable of reflecting a range of the complex behaviors observed in reality without requiring complex mathematical structures. This helps make our model intuitive, so stakeholders and policy makers can understand its key aspects and implications with ease. 


\section{Bibliography}

AgResearch (2009), 'An introduction to the OVERSEER nutrient budgets model (version 5.4)'. Ministry of Agriculture and Forestry, FertResearch and AgResearch.

Anastasiadis, S., Nauleau, M.-L., Kerr, S., Cox, T. \& Rutherford, K. (2011), Does complex hydrology require complex water quality policy? NManager simulations for Lake Rotorua, Motu Working Paper 11-14, Motu Economic and Public Policy Research.

Bandiera, O. \& Rasul, I. (2006), 'Social networks and technology adoption in northern Mozambique', Economic Journal 116, 869-902.

Barnes, P. \& Breslow, M. (2001), 'Pie in the sky? the battle for atmospheric scarcity rent'. working paper 13. Political Economy Research Institute, University of Massachusetts Amherst.

Baumgart-Getz, A., Stalker Prokopy, L. \& Floress, K. (2012), 'Why farmers adopt best management practice in the United States: A meta-analysis of the adoption literature', Journal of Environmental Management 96, 17-25.

Bellman, R. (1957), 'Dynamic programming'. Princeton University Press, New Jersey.

Berger, T. (2001), 'Agent-based spatial models applied to agriculture: a simulation tool for technology diffusion, resource use changes and policy analysis', Agricultural Economics 25, 245-260.

Besley, T. \& Case, A. (1993), 'Modeling technology adoption in developing countries', American Economic Review 83(2), 396-402.

Bewsell, D. \& Brown, M. (2009), 'Involvement and decision making on-farm: The use of wintering feedpads and nitrogen inhibitors on dairy farms in New Zealand', Extension Farming Systems 5(2).

Boland, P. J. \& Proschan, F. (1983), 'Optimum replacement of a system subject to shocks', Operations Research 31(4), 697-704. 
Breetz, H. L., Fisher-Vanden, K., Garzon, L., Jacobs, H., Kroetz, K. \& Terry, R. (2004), 'Water quality trading and offset initiatives in the U.S.: A comprehensive survey'.

Bryant, J. R., Ogle, G., Marshall, P. R., Glassey, C. B., Lancaster, J. A. S., Garcia, S. C. \& Holmes, C. W. (2010), 'Description and evaluation of the Farmax Dairy Pro decision support model', New Zealand Journal of Agricultural Research 53(1), 13-28.

Carpenter, S. R., Caraco, N. F., Correll, D. L., Howarth, R. W., Sharpley, A. N. \& Smith, V. H. (1998), 'Nonpoint pollution of surface waters with Phosphorus and Nitrogen', Ecological Applications 8(3), 559-568.

Coase, R. (1960), 'The problem of social cost', Journal of Law and Economics 3, 1-44.

Conley, T. G. \& Udry, C. R. (2010), 'Learning about a new technology: Pineapple in Ghana', American Economic Review 100(1), 35-69.

Connor, J. D., Ward, J., Clifton, C., Proctor, W. \& Hatton MacDonald, D. (2008), 'Designing, testing and implementing a trial dryland salinity credit trade scheme', Ecological Economics 67, 574-588.

Dong, D. \& Saha, A. (1998), 'He came, he saw, (and) he waited: An empirical analysis of inertia in technology adoption', Applied Economics 30(7), 893-905.

Doole, G. \& Pannell, D. J. (2009), 'Nonpoint pollution policy evaluation under ambiguity', contributed conference paper Australian Agricultural \& Resource Economics Society.

Duflo, E., Kremer, M. \& Robinson, J. (2004), Understanding technology adoption: Fertilizer is western Kenya, preliminary results from field experiments. Unpublished manuscript.

Duhon, M., McDonald, H. \& Kerr, S. (2012), Nitrogen trading in Lake Taupo: An analysis and evaluation of an innovative water management policy. unpublished working paper, Motu Economic and Public Policy Research.

Dury, J., Garcia, F., Reynaud, A., Therond, O. \& Bergez, J. (2010), Modelling the complexity of the cropping plan decision-making, in D. A. Swayne, W. Yang, A. A. Voinov, A. Rizzoli \& F. T., eds, 'International Congress on Environmental Modelling and Software Modelling for Environments Sake'.

Ellison, G. \& Fudenberg, D. (1993), 'Rules of thumb for social learning', Journal of Political Economy 101(4), 612-643. 
Fenemor, A., Sinner, J., Anastasiadis, S., Cradock-Henry, N., Crengle, H., Harris, S., Bright, J., Greenhalgh, S. \& Kerr, S. (2012), 'Simulating market based instruments (MBIs) for water allocation and quality in New Zealand', Report prepared for Ministry of Primary Industries, Landcare, Cawthron and Motu Economic and Public Policy Research.

Fonterra Co-operative Group, Regional Councils, Ministry for the Environment \& Ministry of Agriculture and Forestry (2003), 'Dairying and clean streams accord'.

Fonterra Co-operative Group, Regional Councils, Ministry for the Environment \& Ministry of Agriculture and Forestry (2011), 'Dairying and clean streams accord: Snapshot of progress 2010/2011'.

Foster, A. D. \& Rosenzweig, M. R. (1995), 'Learning by doing and learning from others: Human capital and technical change in agriculture', Journal of Political Economy 103(6), 1176-1209.

Griliches, Z. (1957), 'Hybrid corn: An exploration in the economics of technological change', Econometrica 25(4), 501-522.

Hanna, R., Mullainathan, S. \& Schwartzstein, J. (2012), 'Learning through noticing: Theory and experimental evidence in farming'. NBER Working Paper 18401.

Horan, R. D. \& Shortle, J. S. (2011), 'Economic and ecological rules for water quality trading', Journal of the American Water Resources Association 47(1), 59-69.

Ireland, P. N. (2004), 'Technology shocks in the New Keynesian model', Review of Economics and Statistics 86(4), 923-936.

Kerr, S., McDonald, H. \& Rutherford, K. (2012), 'Nutrient trading in Lake Rotorua: a policy prototype'. Motu Note 10. Motu Economic and Public Policy Research.

Kerr, S. \& Newell, R. G. (2003), ‘Policy-induced technology adoption: evidence from the U.S. lead phasedown', Industrial Economics 51(3).

Maciejewski, R. (2011), Data Representations, Transformations, and Statistics for Visual Reasoning, Morgan \& Claypool.

Marshall, G. (2008), 'Multi-level governance and on-farm adoption of conservation practices in three Australian regions'. Presented to the 12th Biennial conference of the Internation Association for the Study of the Commons.

Ministry of Agriculture and Forestry (2011), 'Farm monitoring overview'. www.mpi.govt.nz. 
Munshi, K. (2004), 'Social learning in a heterogeneious population: Technology diffusion in the Indian green revolution', Development Economics 73, 185-213.

Pagan, A. \& Ullah, A. (1999), Nonparametric Econometrics, Cambridge University Press.

Pannell, D. J., Marshall, G. R., Barr, N., Curtis, A., Vanclay, F. \& Wilkinson, R. (2006), 'Understanding and promoting adoption of conservation practices by rural landholders', Australian Journal of Experimental Agriculture 46, 1407-1424.

Parliamentary Commissioner for the Environment (2006), 'Restoring the Rotorua lakes: The ultimate endurance challenge'. Parliamentary Commissioner for the Environment, Wellington.

Ram, S. (1987), 'A model of innovation resistance', Advances in Consumer Research 14, 208-212.

Rutherford, K., Palliser, C. \& Wadhwa, S. (2011), 'Prediction of nitrogen loads to Lake Rotorua using the ROTAN model'. NIWA Client report HAM2010-134. National Institute for Water and Atmospheric Research, Hamilton.

Schary, C. \& Fisher-Vanden, K. (2004), 'A new approach to water quality trading: Applying lessons from the acid rain program to the lower Boise River watershed', Environmental Practice 6(4), 281-295.

Selman, M., Greenhalgh, S., Branosky, E., Jones, C. \& Guiling, J. (2009), ‘Water quality trading programs: An international overview'.

Sin, I. (2012), 'The adoption of environmentally friendly technologies in agriculture'. Motu Note 12. Motu Economic and Public Policy Research.

Skinner, J. \& Staiger, D. (2005), Technology adoption from hybrid corn to beta blockers, Technical Report 11251, NBER working paper series.

Smeaton, D. C., Cox, T., Kerr, S. \& Dynes, R. (2011), 'Relationships between farm productivity, profitability, N leaching and GHG emissions: a modeling approach', New Zealand Grassland Association 73, 57-62.

Sutton, M., Oenema, O., Erisman, J. W., Leip, A., van Grinsven, H. \& Winiwarter, W. (2011), 'Too much of a good thing', Nature 472, 159-161.

Tietenberg, T. H. (2006), Emissions Trading: Principles and Practice. 2nd ed., Resources for the Future Press.

Wand, M. P. \& Jones, M. C. (1995), Kernel Smoothing, CRC Monographs on Statistics and Applied Probability Series, Chapman \& Hall. 
Ward, J., Bryan, B., Crossman, N. \& King, D. (2008), Evidence based farmer decision models to assess the potential for multiple benefit carbon trading, in 'International Association for the Study of Commons, conference July 2008'.

Wooldridge, J. M. (2010), Econometric Analysis of Cross Section and Panel Data, second edition edn, MIT Press. 


\section{Appendix A}

\section{Key Terminology}

For readers who are less familiar with environmental regulation and nutrient trading, we provide a brief descriptions of the key terms used in this study.

- Emission Trading Schemes are regulatory tools that provide a fixed number of allowances (forms, tokens) and the rules that govern the trading of allowances. Each allowance entitles the bearer to emit a specified quantity of pollution (nutrients, nitrogen, phosphorus, byproduct, discharge), after the which it must be surrendered. Theory suggests that trading will encourage efficiency: allowances will be used where they earn the greatest return.

- Allocations or Allowance Holdings refer to the number of allowances (forms, tokens) that an entity / farmer owns. These include those allowances provided to the farmer directly by the regulator at the start of the regulation (initial allowances), possibly at zero cost (free allocation), plus or minus any allowances gained or lost via exchanges with other entities / farmers (trading).

- The cap is the total number of allowances in an emissions trading scheme. It is determined by the regulator to ensure that the environmental targets are met.

- NManager is a simulation model of the impacts of different designs of nitrogen management regulation on farms in the Lake Rotorua catchment (Anastasiadis et al. 2011).

- Surface water flow is the flow of nutrients via rainfall runoff, streams and rivers. These nutrients typically reach the lake less than a year after they are lost from pasture.

- Groundwater flow is the flow of nutrients via underground aquifers and into springs. These nutrients typically take many years to reach the lake. In the 
Lake Rotorua catchment, underground aquifers are large and some nitrogen spends more than 100 years underground before reaching the lake.

- Point sources are emitters of pollution where the location of the emission occurs at a point, for example: waste water from the end of a pipe. Factories, power plants, vehicles are all point sources of emissions. The emissions from a point source can typically be measured (mitigated) by attaching a device (filter) to the end of the pipe.

- Non-point sources are emitters of pollution where the location of the emission is diffuse, for example: nutrient runoff into local waterways. Farms and mines are non-point sources of emissions. More complex science is typically required to measure the emissions from a non-point source. Often these emissions have to be estimated. Some mitigation of non-point emissions can be done via controls at the boundary of the source, for example: fencing or riparian planting. While other mitigation can only be done via changing or reducing system inputs.

- The catchment is the land area within which nutrient emissions lead to increased levels of nutrients in the local water body (lake, bay, river or stream). For any water body, the size and shape of a catchment is determined by the local topography and is approximately all the land from which water would flow down hill towards the water body.

- Hot spots arise where there is (spatial or temporal) clustering of the environmental damages from emissions. So despite the average environmental damage being within acceptable levels, the damage in specific locations, or at specific times, exceeds acceptable levels. 


\section{Appendix B}

\section{Non-trading behavior}

New Zealand farmers have expressed, not only a resistance to adopting new mitigation technologies and practices, but also a resistance to dealing with nutrient trading regulation (Fenemor et al. 2012). These farmers have expressed a strong preference to build their livelihood from farming and not from trading activities (we might expect a similar perspective from the traditionist farmers identified by Connor et al. 2008).

We propose an additional constraint for the inertia model, specified above, that would enable it to reflect farmers' preferences to earn their livelihood from agricultural activity rather than the sale of allowances. The constraint anticipates that farmers with this kind of preference are willing to buy allowances, as this enables them to carry out further farming activities; but are unwilling to sell allowances if this would require them to reduce their farming activities (though they may sell unused or excess allowances).

Let farmers' production decision each period be constrained as follows:

$$
n_{i t} \nless n_{i t}^{0} \text { if } \exists n \in\left(n_{i t}, n_{i t}^{0}\right): \frac{\partial}{\partial n_{i t}} \pi\left(m_{i t}, n\right)>\pi_{i}^{0}
$$

where $n_{i t}^{0}$ is the farmer's initial allowance allocation, and $\pi_{i}^{0}$ is the minimum return farmer $i$ expects from their farming activities for each unit of emissions.

This constraint results in a lower bound on nitrogen allowance holdings $n_{i t}^{\ell}$, such that a farmer will always hold at least $n_{i t}^{\ell}$ allowances, unless their initial allocation is less than this lower bound $\left(n_{i t}^{0}<n_{i t}^{\ell}\right)$. If this is the case the farmer will hold at least $n_{i t}^{0}$ allowances.

The introduction of this constraint in the inertia model leads to the following behavior by farmers: 
- Farmers will purchase allowances if, given their technology, the profit from their marginal allowance exceeds the price of allowances (when $\frac{\partial \pi}{\partial n}>p_{t}$ ).

- Farmers will only sell allowances if, given their technology, the profit from their marginal allowance is less than $\pi_{i}^{0}$ (when $\frac{\partial \pi}{\partial n}<\pi_{i}^{0}$ ). This means that farmers may not sell allowances even if the profit from their marginal allowance is less that the value of the allowances (when $\frac{\partial \pi}{\partial n}<p_{t}$ ).

- Farmers will use only their initial allowances (neither buying or selling) if, given their technology, the profit from their marginal allowance is less than the price of allowances, but the profit from their marginal allowance exceeds $\pi_{i}^{0}\left(\right.$ when $\left.\pi_{i}^{0}<\frac{\partial \pi}{\partial n}<p_{t}\right)$.

The impact of this additional constraint in the inertia model will depend on how farmers are allocated their initial allowance holdings. If farmers' initial allocations are close to their equilibrium allowance holdings then this constraint is unlikely to result in significant increases in the cost of reducing nutrient emissions. However, if farmers' initial allocation are far from their equilibrium allowance holdings then this constraint is likely to result in significant increases in costs.

While it is straight forward to introduce this constraint into the farmer level model given in section 2.2, a full examination of this behavior would require us to consider how farmers' refusals to trade would change over time, and has been left for future research. 


\section{Appendix C}

\section{Solving a System of First Order Linear Difference Equations}

In this appendix we demonstrate the solution to a two equation system of first order linear difference equations. Our notation and methodology follows notes prepared by Akila Weerapana (of Wellesley College, 2005). ${ }^{1}$

Consider the system of first order linear difference equations expressed as:

$$
\left[\begin{array}{l}
m_{1 t} \\
m_{2 t}
\end{array}\right]=\left[\begin{array}{ll}
u_{1} & u_{2} \\
u_{3} & u_{4}
\end{array}\right] \times\left[\begin{array}{l}
m_{1, t-1} \\
m_{2, t-1}
\end{array}\right]+\left[\begin{array}{l}
v_{1} \\
v_{2}
\end{array}\right]
$$

Or alternatively, using matrix notation, as:

$$
M_{t}=U \times M_{t-1}+V
$$

where

$$
M_{t}=\left[\begin{array}{l}
m_{1 t} \\
m_{2 t}
\end{array}\right], \quad U=\left[\begin{array}{ll}
u_{1} & u_{2} \\
u_{3} & u_{4}
\end{array}\right], \quad V=\left[\begin{array}{l}
v_{1} \\
v_{2}
\end{array}\right] .
$$

We first find a matrix $C$ that will diagonalize $U$. This will enable us to reduce the problem to two subproblems, each regarding a univariate difference equation. We require that $U$ is diagonalizable.

In the two equation system, the eigenvalues of $U$ are:

$$
\begin{aligned}
& \lambda_{a}=\frac{\left(u_{1}+u_{4}\right)+\sqrt{4 u_{2} u_{3}+\left(u_{1}+u_{4}\right)^{2}}}{2}, \\
& \lambda_{b}=\frac{\left(u_{1}+u_{4}\right)-\sqrt{4 u_{2} u_{3}+\left(u_{1}+u_{4}\right)^{2}}}{2} .
\end{aligned}
$$

\footnotetext{
${ }^{1}$ These are available online at www.wellesley.edu/Economics/weerapana/econ300/ econ300pdf/lectureะ20300-18.pdf. Accessed October, 2012.
} 
If we assume $u_{1}$ is non-zero, the corresponding eigenvectors can be expressed as:

$$
\left[\begin{array}{c}
\lambda_{a}-u_{4} \\
u_{3}
\end{array}\right] \text { and }\left[\begin{array}{c}
\lambda_{b}-u_{4} \\
u_{3}
\end{array}\right]
$$

Let $C$ be the $2 \times 2$ matrix with columns equal to the eigenvectors of $U$, and let $\Lambda$ be the diagonal matrix with diagonal entries equal to the eigenvalues of $U$.

$$
C=\left[\begin{array}{cc}
\lambda_{a}-u_{4} & \lambda_{b}-u_{4} \\
u_{3} & u_{3}
\end{array}\right], \quad C^{-1}=\frac{1}{u_{3}\left(\lambda_{a}-\lambda_{b}\right)}\left[\begin{array}{cc}
u_{3} & -\lambda_{b}+u_{4} \\
-u_{3} & \lambda_{a}-u_{4}
\end{array}\right], \quad \Lambda=\left[\begin{array}{cc}
\lambda_{a} & 0 \\
0 & \lambda_{b}
\end{array}\right] .
$$

It follows that we can diagonalize $U$ as $C \Lambda C^{-1}$.

Consider the following:

$$
\begin{aligned}
M_{t} & =U M_{t-1}+V \\
M_{t} & =C \Lambda C^{-1} M_{t-1}+V \\
C^{-1} M_{t} & =\Lambda C^{-1} M_{t-1}+C^{-1} V
\end{aligned}
$$

If we define $Z_{t}=C^{-1} M_{t}$ then we can express the system in terms of $Z$ as follows:

$$
Z_{t}=\Lambda Z_{t-1}+C^{-1} V
$$

Since $\Lambda$ is diagonal, this is now a collection of univariate difference equations:

$$
\begin{aligned}
& z_{1 t}=\lambda_{a} z_{1, t-1}+\frac{v_{1} u_{3}-v_{2}\left(\lambda_{b}-v_{4}\right)}{u_{3}\left(\lambda_{a}-\lambda_{b}\right)}, \\
& z_{2 t}=\lambda_{a} z_{1, t-1}+\frac{-v_{1} u_{3}+v_{2}\left(\lambda_{a}-v_{4}\right)}{u_{3}\left(\lambda_{a}-\lambda_{b}\right)} .
\end{aligned}
$$

Univariate difference equations are straightforward to solve. The solutions for $z_{1 t}$ and $z_{2 t}$ are given as follows:

$$
\begin{aligned}
& \dot{z}_{1 t}=\frac{v_{1} u_{3}-v_{2}\left(\lambda_{b}-v_{4}\right)}{u_{3}\left(\lambda_{a}-\lambda_{b}\right)} \frac{1-\lambda_{a}{ }^{t}}{1-\lambda_{a}}, \\
& \dot{z}_{2 t}=\frac{-v_{1} u_{3}+v_{2}\left(\lambda_{a}-v_{4}\right)}{u_{3}\left(\lambda_{a}-\lambda_{b}\right)} \frac{1-\lambda_{a}{ }^{t}}{1-\lambda_{b}} .
\end{aligned}
$$

Given this result we can construct the solution to the original system of difference equations according to the relationship $M_{t}=C Z_{t}$. This gives the following results:

$$
\begin{aligned}
& m_{1 t}=\left(\lambda_{a}-u_{4}\right) \dot{z}_{1 t}+\left(\lambda_{b}-u_{4}\right) \dot{z}_{2 t}, \\
& m_{2 t}=u_{3} \dot{z}_{1 t}+u_{3} \dot{z}_{2 t}
\end{aligned}
$$

where $\dot{z}_{1 t}$ and $\dot{z}_{2 t}$ are the solutions to the univariate difference equations given immediately above, and $\lambda_{a}$ and $\lambda_{b}$ are the eigenvalues of $U$. 


\section{Appendix D}

\section{Kernel Density Smoothing}

In this appendix we provide a brief introduction to kernel density estimation. Our notation and explanations draw on material by Pagan \& Ullah (1999) and Maciejewski (2011). Wand \& Jones (1995) provide a dedicated introduction to kernel smoothing.

Kernel density estimation can be thought of as a continuous equivalent to histograms. Both histograms and kernel density estimation provide a non-parametric means of visualizing the distribution of sample observations. But while histograms group observations into discrete bins, kernel density estimation uses a weighting of all nearby observations.

In its simplest form, kernel density smoothing can be expressed as:

$$
\hat{f}(x)=\frac{1}{N h} \sum_{i=1}^{N} K\left(\frac{x-x_{i}}{h}\right),
$$

where $\hat{f}(x)$ is our estimate for the density at $x, N$ is the number of observations, $h$ is the kernel smoothing parameter, $x_{i}$ are the sample data, and $K(\cdot)$ is the kernel estimator.

The kernel estimator is the equivalent of the bin width when constructing a histogram. The kernel estimator determines how close sample observations $x_{i}$ have to be to $x$ to affect the density at $x$, and how large an effect they have on the density. The most common kernel is the Gaussian (or normal) kernel.

Consider for example the following simple kernel density estimator. At each point $x$ the density at the point will be estimated by the number of sample observations within an interval of length $h$ centered on $x$.

$$
\hat{f}(x)=\frac{1}{N h} \sum_{i=1}^{N} I\left(x-\frac{h}{2} \leq x_{i} \leq x+\frac{h}{2}\right),
$$


where $I(\phi)=1$ if $\phi$ is true and zero otherwise. It is obvious that this provides a continuous estimate for the density function as any value of $x$ can be chosen. However, as we are still considering observations within some interval we have not differed significantly from the construction of a histogram.

Kernel density estimations used in practice are significantly more sophisticated. In particular, the width of the interval may vary as a function of the data and observations within an interval may not all carry equal weight. We provide only a brief discussion of each of these aspects.

Just as an appropriate choice of bin widths in a histogram is crucial, so also is the interval width in kernel density smoothing. Narrow intervals may not provide sufficient smoothing, and wide intervals may result in excess smoothing (for example consider the two extremes for a histograms: when no observations share the same bin - not enough smoothing, and when all observations share the same bin - too much smoothing). Adaptive measures of kernel density estimation attempt to adjust the interval width based on the local density of the data. This means that where observations are more clustered (near the mode or modes) smaller interval widths are used and where observations are less clustered (near the tails) larger interval widths are used. Adaptive measures of kernel density estimation are frequently based on the distance to the $k$-th nearest neighbor.

Consider the simplistic example we give above: an observation counts towards the density at $x$ if it falls within the interval $x \pm h / 2$. In this case, our kernel density estimator ignores where in the interval an observation falls. We would expect that an interval with observations clustered near the middle would suggest a higher density than an interval with observations spread uniformly across it. More sophisticated kernel density estimation uses the distance $\left|x-x_{i}\right|$ to determine the significance of observations within any given interval. In our analysis in this paper, the Gaussian distribution has been used for this purpose. 